\title{
FEM Analysis of In-flight Ice Break-up
}

\author{
Shiping Zhang \\ Master of Engineering \\ Department of Mechanical Engineering \\ McGill University \\ Montreal, Quebec, Canada \\ June 01, 2012
}

Copyright $\odot$ by Shiping Zhang 2012. 


\section{DEDICATION}

I dedicate this thesis to my family because of all the wonderful things they do for me, and for supporting me all the way. 


\section{ACKNOWLEDGMENTS}

I would like to thank my supervisor Professor Wagdi G. Habashi for his great guidance and steady support during the entire course of my study at McGill. Studying under the supervision of a prolific world-renowned scholar is a great honour for me.

I am very grateful to Dr. Rooh-UI-Amin Khurram, Post-Doctoral Fellow at the CFD Lab and now at KAUST, for his incredible support and endless help. I truly enjoyed working with him. His understanding, encouragement and personal guidance have provided a good basis for the present thesis. 


\section{TABLE OF CONTENTS}

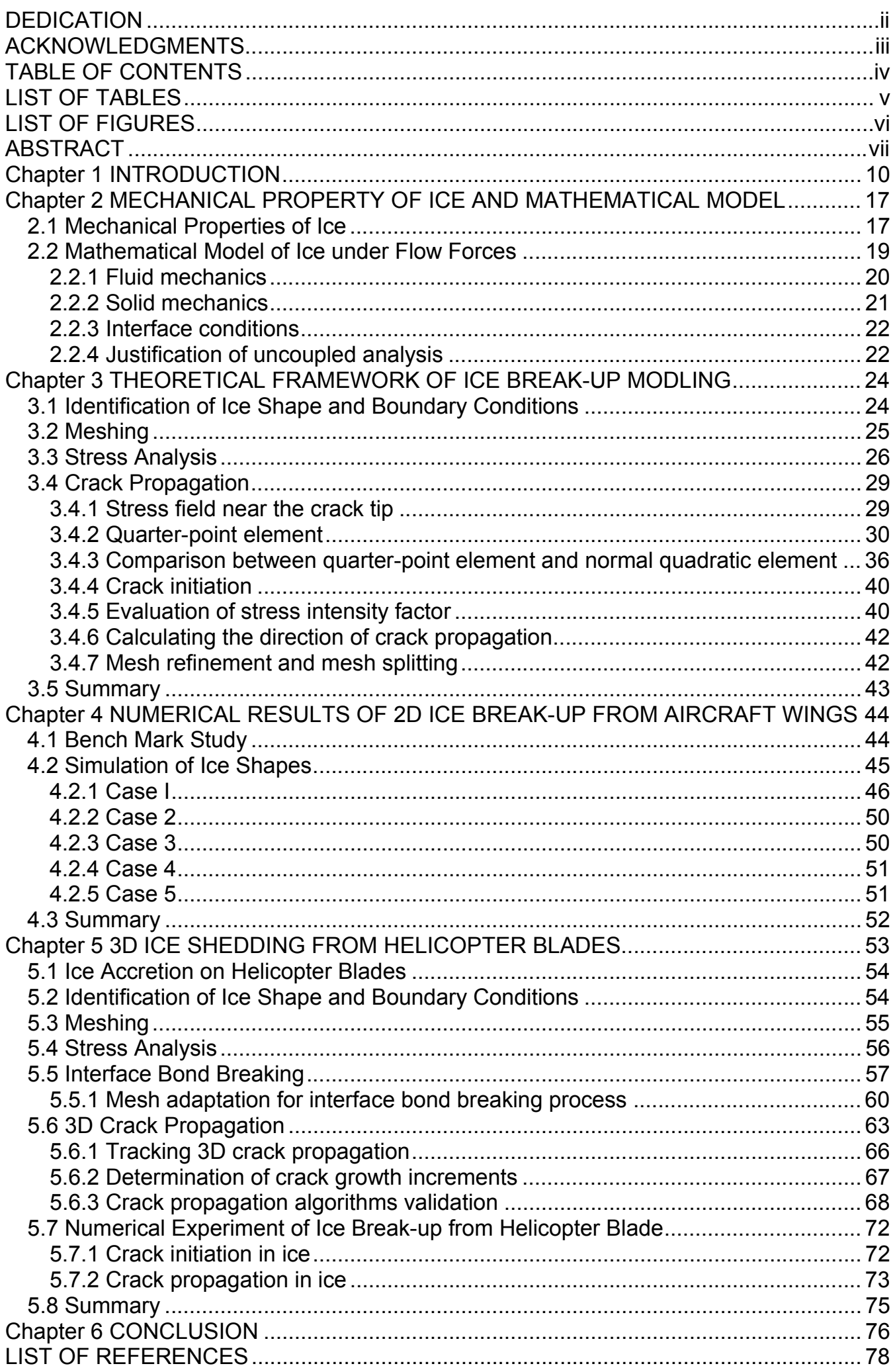




\section{LIST OF TABLES}

Table 1: Elastic properties of homogeneous polycrystalline isotropic ice at $-16^{\circ} \mathrm{C}$ 17 


\section{LIST OF FIGURES}

Figure 1. In-flight icing: Phenomenology and typical ice shapes. .............................. 10

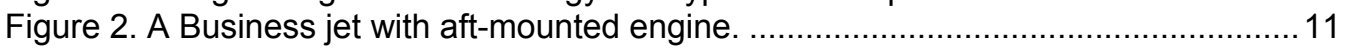

Figure 3. Air crash due to ice ingestion.............................................................. 11

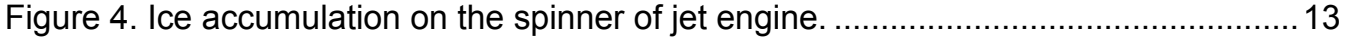

Figure 5. Ice accretion on S-76D engine air inlet................................................ 13

Figure 6. Schematic stress-strain curves are shown for various strain-rates.................. 18

Figure 7. Fluid pressure and the induced stress in ice. ......................................... 19

Figure 8. Ice break-up analysis in the in-flight icing framework of FENSAP-ICE. ...........23

Figure 9. Block diagram of ice break-up analysis. ................................................. 24

Figure 10. Input information from the flow solution required for ice break-up analysis. ... 25

Figure 11. Closed polygon of nodes describing the shape of ice. ................................25

Figure 12. The solid's (ice) computational mesh. ................................................... 26

Figure 13. Pictorial representation of un-coupled stress analysis in ice........................27

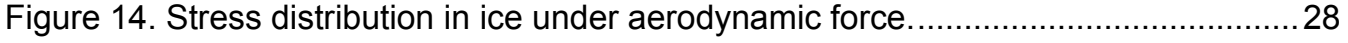

Figure 15. Displacement field for small deformation and finite deformation analysis.......29

Figure 16. Quadrilateral (left) and triangle (right) quarter-point elements. .....................3 32

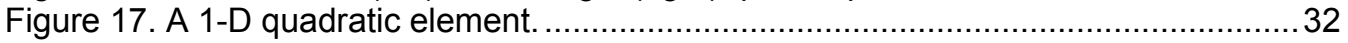

Figure 18. Stress sig-xx distribution within one quarter-point element. ........................... 35

Figure 19. Rosette around crack tip ..................................................................... 36

Figure 20. Quart-point element (left) and normal quadratic element (right). .................37

Figure 21. Principal stress I distribution in 3D of quart-point element. ..........................38

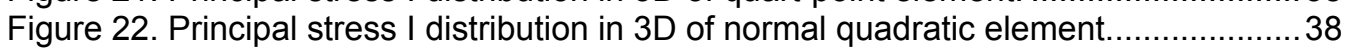

Figure 23. P1 distribution at the vicinity of crack tip of quart-point element. ....................39

Figure 24. P1 distribution at the vicinity of crack tip of normal quadratic element............39

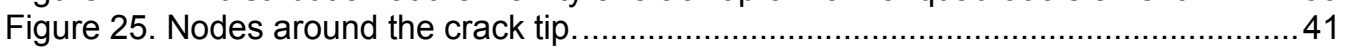

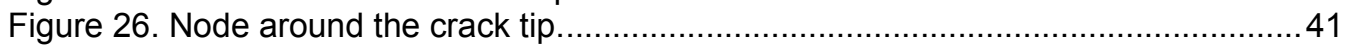

Figure 27. The crack tip vectors and cross product............................................... 43

Figure 28. Problem description of the single edge cracked plate.............................. 45

Figure 29. Crack shape for reference result (left) and in-house code (right).................45

Figure 30. Stress Intensity factor I for reference result and in-house code...................45

Figure 31. Fluid domain: mesh (left) and pressure field (right)................................46

Figure 32. Solid (ice) domain: principal stress 1 (left) and cracked ice (right)...............47

Figure 33. Evolution of crack (top to right) and principal stress 1 distribution................47

Figure 34. Mesh refinement during the evolution of crack (top to right). .....................48

Figure 35. FRANC2D mesh (left) and in-house code mesh (right).............................49

Figure 36. Principal stress 1 distribution for FRANC2D (left) and in-house code (right). . 49

Figure 37. Comparison of crack shape in ice. ...................................................... 49

Figure 38. Stress Intensity factor I for reference result and in-house code...................49 49

Figure 39. Principal stress 1 distribution for FRANC2D and in-house code...................50

Figure 40. Principal stress 1 distribution obtained by the in-house code (Case 3).........51

Figure 41. Principal stress 1 distribution obtained by the in-house code (Case 4). ........51

Figure 42. Principal stress 1 distribution obtained by the in-house code (Case 5).........52

Figure 43. Ice accretion on helicopter blades. .................................................... 54

Figure 44. Grid on the clean airfoil (left) grid on the iced airfoil (right).........................55

Figure 45. 3D ice shape obtained from blade (left) surface mesh of the ice (right)..........55

Figure 46. Tetrahedral volume mesh of ice generated by TetGen. ..............................56

Figure 47. Stress distribution at the ice-airfoil interface ........................................ 57

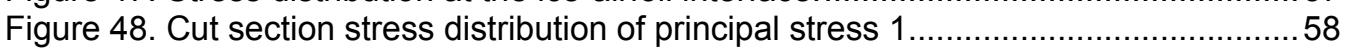

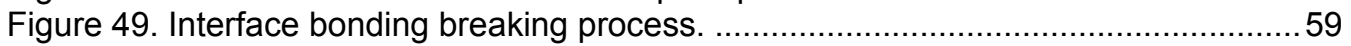

Figure 50. Principal stress during interface bonding breaking process. ........................6 60

Figure 51. Mesh adaptation in the process of interface bond breaking........................6 62

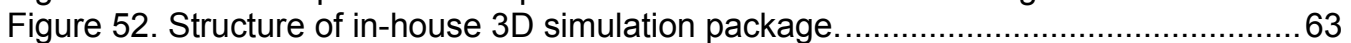

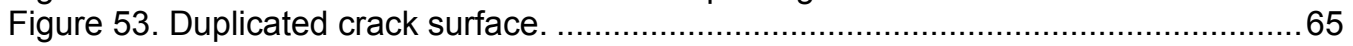

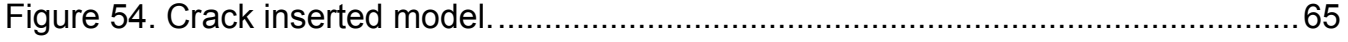


Figure 55. Local coordinate system along the crack front. .......................................67

Figure 56. Three point bending test with the initial crack of an inclined plane. ...............69

Figure 57. The model of three point bending test. ..................................................69

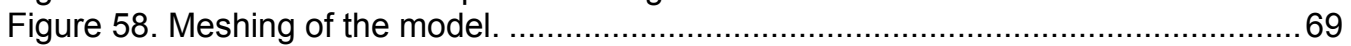

Figure 59. Crack fronts obtained for each propagation step........................................ 70

Figure 60. Crack fronts of the solution reported in reference. .................................... 70

Figure 61. Crack propagation inside the specimen. ……....................................... 71

Figure 62. 3D geometry of crack inside the specimen............................................ 71

Figure 63. Crack path on the surface and its principal stress distribution. ......................71

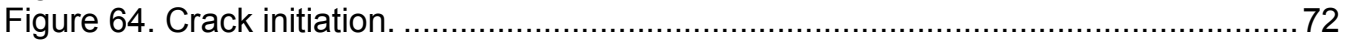

Figure 65. Crack propagation process ............................................................... 74

Figure 66. Principal stress 1 during the crack propagation process............................... 75

Figure $67.3 \mathrm{D}$ crack shape growth during the crack propagation process. ....................75 


\begin{abstract}
Using a fracture mechanics framework, we present a finite element method to simulate the break-up of $2 \mathrm{D}$ ice accreted on the wings of aircraft and the shedding of 3D ice accreted on blades of helicopter. The fully automated ice break-up module is integrated in FENSAP-ICE [1-2], which is an in-flight ice accretion simulation code that solves flow, droplet impingement and ice accretion, in sequence. The 2D and 3D crack propagation packages are developed and validated by comparing with published results for a single edge cracked plate test case and a single edge-notched specimen with three points bending load, respectively. Numerous complicated ice-shapes are analyzed and comparisons are performed with a contemporary fracture mechanics code. Under typical icing and flow conditions, linear elasticity is found to be adequate for ice break-up analysis. For ice accreted on wings, an important finding of this study is that the breaking of ice has a strong dependence on its shape, i.e. under similar aerodynamic loading, some ice shapes fail while others do not. For ice accreted on helicopters, the finding is that the rotational speed of the blade and interface strength between ice and blade material are the major factors governing the ice break-up. The main objective of this work is to analyze complex multi-physics phenomenon and provide a simplified ice break-up model for the industrial users and aerodynamic designers. The potential use of this tool, however, is not limited to aerodynamics; it can be applied in areas of environmental science, material science, glaciology, earthquake and rupture analysis.
\end{abstract}

KEY WORDS: Ice break-up, ice shedding, in-flight icing, finite element methods, fracture mechanics, multi-physics phenomenon 


\section{RÉSUMÉ}

Dans le cadre de la mécanique des fractures, nous présentons une méthode d'éléments finis qui simule le bris de la glace accumulée sur les ailes d'avions, en deux dimensions, ainsi que le délestage du givre accumulé sur les pales de I'hélicoptère, en trois dimensions. Le module de bris de glace, entièrement automatisé, est intégré en FENSAP-ICE [1-2], un logiciel de simulation qui résout séquenciellement le flux, l'impact des gouttelettes et le cumul de glace. Les modules bidimensionnels et tridimensionnels de propagation de fissures sont développés et validés par comparaison avec des résultats expérimentaux sur une plaque fissurée d'un seul côté, ainsi que pour un spécimen entaillé d'un seul côté avec une charge de flexion en trois points. Plusieurs formes de glace sont analysées et des comparaisons faites avec un autre code traitant la mécanique des fractures. Dans des conditions typiques de givrage et d'écoulement, l'élasticité linéaire s'est avérée adéquate pour une analyse du bris de glace. Pour la glace accumulée sur les ailes, une conclusion importante de cette étude est que le bris de glace dépend fortement de sa forme, c'est-à-dire que pour des charges aérodynamiques similaires, certaines formes de glace briseront, tandis que d'autres ne le feront pas. En ce qui concerne la glace accumulée sur les hélicoptères, il a été conclu que les facteurs les plus importants pour le bris de glace sont la vitesse rotationnelle de la pale et la force d'adhésion entre la glace et la pale. L'objectif principal de cet ouvrage est d'analyser des phénomènes multi-physiques complexes et de fournir un modèle simplifié du bris de la glace pour les utilisateurs industriels et les concepteurs en aéronautique. L'utilisation de cet outil n'est toutefois pas limitée à l'aérodynamique, puisqu'il peut être employé dans des domaines tels que les sciences environnementales, les sciences des matériaux, la glaciologie et l'analyse des tremblements de terre et de rupture.

MOTS CLÉS : Givrage en vol, bris de glace, délestage de glace, éléments finis, mécanique des fractures, phénomènes multi-physiques 


\section{Chapter 1 \\ INTRODUCTION}

When an aircraft traverses a cloud containing supercooled water droplets, ice may accrete on its surface and depending on flight conditions, ice can accumulate at different locations and form a wide variety of shapes. Figure 1 shows in-flight ice phenomenology and typical ice shapes for long-term in-flight ice accretion.
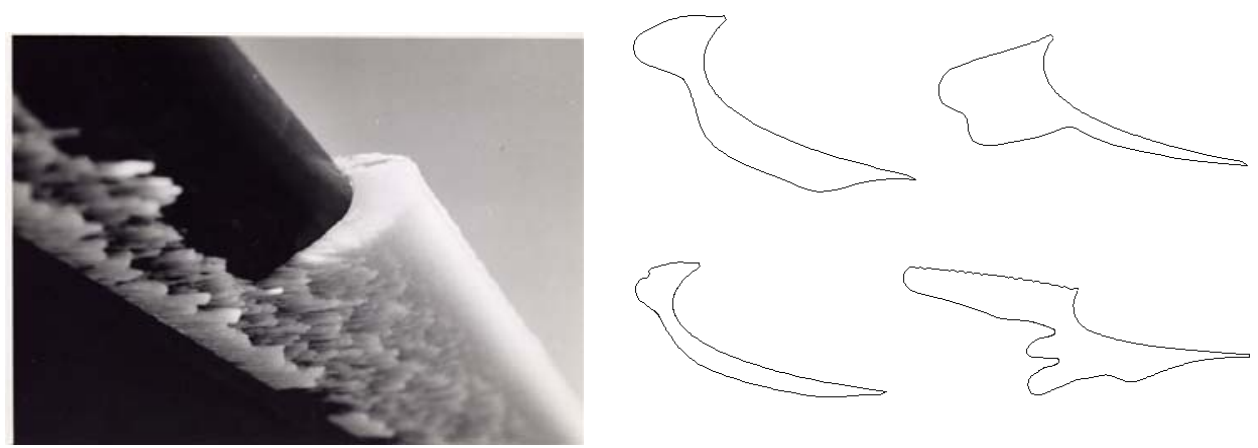

Figure 1. In-flight icing: Phenomenology (left) and typical ice shapes (right)

Commercial airplane and helicopter manufacturers have to demonstrate, through a rigorous and lengthy certification process, that their airplanes can fly safely into known-icing conditions. The accurate simulation of ice accretion over wings and other surfaces of an aircraft is a key issue in the growing acceptance of computational fluid dynamics (CFD) as an aid to in-flight icing certification. In recent years, several aircraft accidents have been caused by ice accretion on aircraft structural components. One of many examples is the American Eagle Flight 4184 crash on 31 October 1994 near Roselawn, Indiana, as a consequence of ice buildup on its wings. The formation of ice over the wings and other part of aircraft deteriorates aerodynamic performance and can result in shedding chunks of ice that could strike the aircraft or, worse, find their way into the engine, particularly for aircraft with aft-mounted engines. Figure 2 shows a business jet with aft-mounted engines, it can be seen that chances could be very 
high that ice shed from the nose of fuselage or root of wings flies into the aftmounted engine of the aircraft.

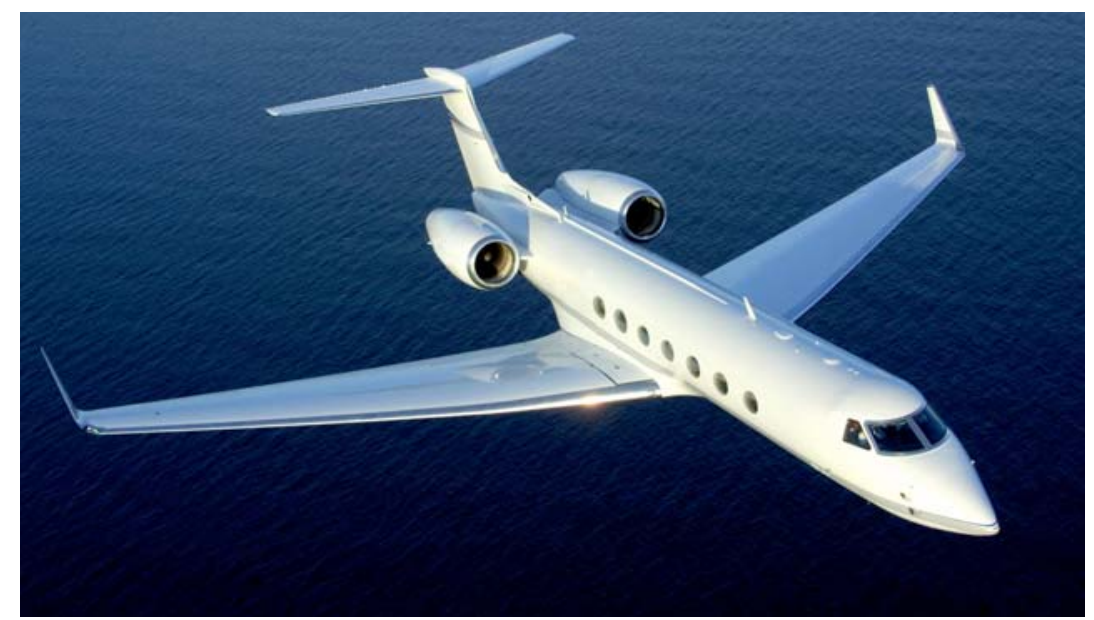

Figure 2. A business jet with aft-mounted engines

A famous example of ice break-up and ingestion is the air crash of Scandinavian Airlines Flight 751 in 1991. The McDonnell Douglas MD-81, with an aft-mounted engine, crashed in a field near Gottrora, Sweden, and is shown in figure 3.

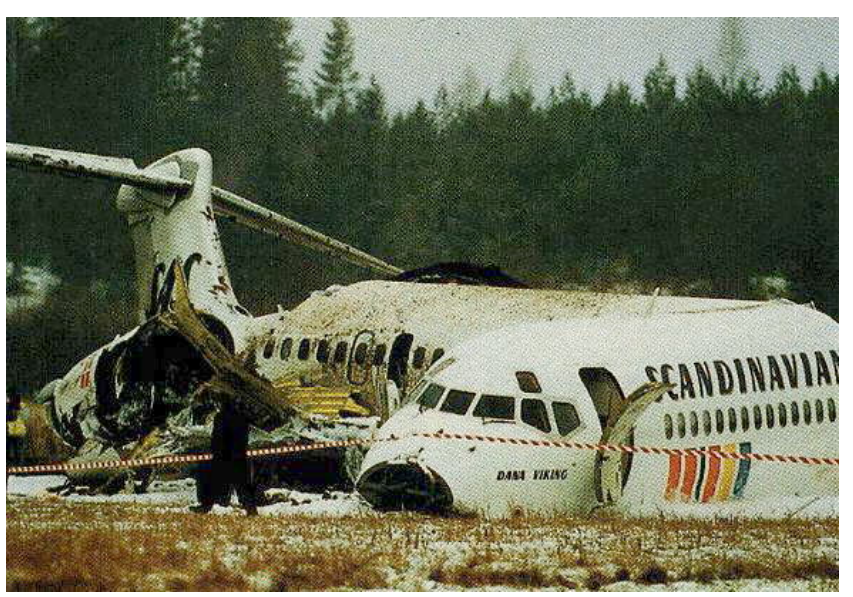

Figure 3. Air crash due to ice ingestion

Some modern aircraft designs have engine inlets in close proximity to the fuselage or wings with a purpose to reduce boundary layer separation and hence increase efficiency, however, these designs are potentially prone to ice ingestion into the engines. 
Interest for ice break-up and shedding could date back to 1983 by DeWolfe since the concern was first seriously investigated for the Space Shuttle program. Shed ice, being a relatively low-density material, decelerates rapidly in the atmosphere thus introducing high relative velocity between itself and the impact point on the aircraft [3].

Ice shedding is also a concern for rotorcraft. For helicopters, in-flight icing has become a more important issue with a greatly expanded concept of operations and an ever-increasing range of tasks [4]. There are many scenarios that the pilot cannot fly until ice is removed from the blades, for example emergency rescue. The shedding ice from helicopter blades due to centrifugal forces not only poses a ballistics danger to the fuselage, but also creates extremely severe vibrations due to imbalanced rotors. The severity of these vibrations has been documented [4] by test pilots engaged in conducting natural icing studies with helicopters. Their reports identify numerous occasions where in-flight icing tests have been aborted because of main rotor blade icing and the subsequent asymmetrical shedding which caused vibrations so severe that it became impossible to read the instrument panel [4].

In addition, for both aircraft and rotorcraft, a great potential threat from shed ice originates at engine intake. Fig 4 shows ice accretion at the spinner of a jet engine. Fig 5 shows ice accretion on an S-76 engine air inlet. When the engines are running, a strong suction force develops at the intake and ice accreted there can be sucked in. As a result, the fan blades and interior parts of the engine can be damaged. Even a small amount of ice can cause very serious damage. 


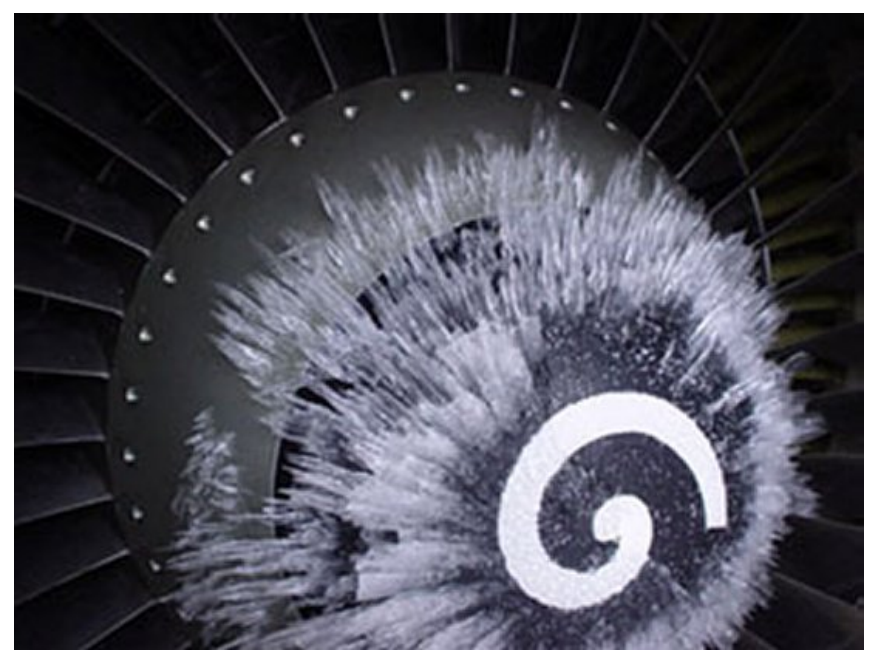

Figure 4. Ice accumulation on the spinner of a jet engine

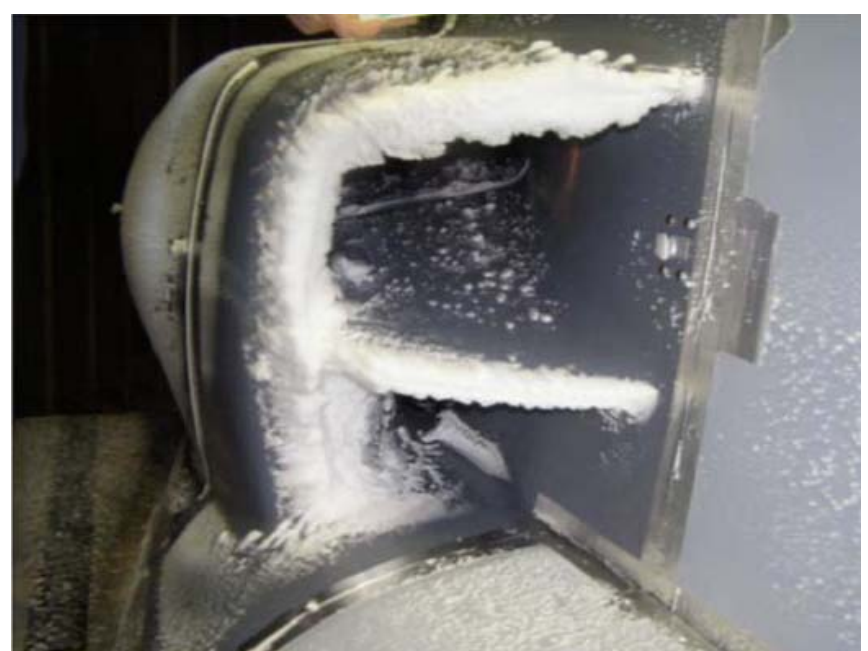

Figure 5. Ice accretion on S-76D engine air inlet

Interest in ice shedding involves its three phases: ice detachment from the surface, tracking of the piece of ice as it is carried through the flow field and the subsequent impact forces if it hits a solid surface [5]. The first phase actually provides initial conditions for the tracking phase. The impact phase obviously results from the terminal conditions of the tracking phase [6]. However, each phase can be treated separately. This study is aimed at modeling ice break-up and metal-ice bond separation under the influence of various kinds of forces, using a fracture mechanics approach. 
Stresses that develop in the accreted ice and at the metal-ice bond during normal operation are caused by the following sources: 1) direct loading of aerodynamic forces acting on the ice; 2 ) inertia forces in the case of rotating propellers or blades; 3 ) thermal stresses developed due to expansion and shrinkage of ice due to temperature variation in the accreted ice; 4) flexing of the aerodynamic surface caused by structural vibration and aerodynamic forces [7]. In the present ice break-up study, only the direct loading of aerodynamic pressure and inertia forces are considered. In future studies, the thermal stresses and flexing of the aerodynamic surface could also be included.

Advances of finite element methods (FEM) and computational fracture mechanics now allow analyzing crack generation and growth. While the fundamental rules for crack propagation come from the fracture mechanics approach $[8,9]$, FEM makes it possible to apply these rules to complicated geometries. In this study, a 2D and 3D crack propagation package is developed based on linear elastic fracture mechanics (LEFM).

The research and development of linear elastic fracture mechanics (LEFM) date back to World War I [10]. With advances in computers and computational methods, a lot of efforts have been made in LEFM, with currently the two most important algorithmic approaches being boundary element (BEM) and finite element (FEM) methods. Due to its wider use in industrial applications, the FEM , has been adopted in this study for the calculation of stresses and for crack propagation.

Early efforts made in FEM of fracture mechanics date back to 1970 [11], and with over 4 decades of development, LEFM based on FEM has achieved considerable maturity for crack propagation in both 2-D and 3-D [12]. For crack propagation based on FEM, there are currently two approaches, one approach is using the quarter-point element method, like Franc2d [12] developed by the Cornell Fracture Research group; another direction is using the extended finite 
element method first developed by Owen and Hinton in the 1980's. Due to its easy implementation and high accuracy, quarter-point element method is used in this study.

Most research on ice and its mechanical properties are in civil engineering or naval engineering departments. Recent research on ice has focused on the effect of sea ice on floating structures, like well-drilling platforms. The brittle behavior of ice was studied by Schulson, and the tensile strength of ice and its relationship with the environment was investigated [14]. In ductile behaviour, the strain rate hardening in ice is studied by Sinha [15], and the ice failure envelope is presented by Schulson et al [16]. For the mechanical properties of ice accreted on aircraft, there are few research studies. The only research that could be found on the mechanical properties of impact ice is by Scavuzzo [17], the ice is obtained in the NASA Lewis Icing Research Tunnel. However, in his research there is no detailed information about the aluminum used, as the surface properties, like roughness and aluminum composition could significantly affect the metal-ice interface strength. Nowadays, more and more new carbon fiber composite materials are used on wings of aircraft and blades of helicopters, and there seems to be no open literature information about the interface strength of impact ice with these materials. However, for ice frozen on to a substrate, the interface strengths of ice with different materials have been investigated by Raraty [18].

In the realm of ice break-up and shedding, most research activities focus on electrical transmission lines [19]. Recently, there have been few experimental investigations on ice shedding from aircraft. Mazzawy worked on ice accretion and shedding in Turbofan Engines [20], while Brouwers and coworkers [21] performed experiments to study ice-shedding from the rotor of a helicopter. An experimental investigation on aerodynamically-induced fracture of ice from the space shuttle was carried out by Hardy and coworkers [22]. In addition, the influence of aerodynamic forces in ice-shedding was studied by Scavuzzo and 
coworkers [7]. A parametric investigation of ice shedding from aircraft is carried out by Michael and coworkers [23]. In recent years, quite a few numerical studies have been performed on ice-shedding from wings of aircraft and helicopter blades for long-term in-flight ice accretion. Brouwers with coworkers [21] and Scavuzzo [24] have developed an ice shedding model for helicopter blades. However, their shedding models are based on simplified 2D or 3D-extended ice shapes, and the boundary conditions are also greatly simplified. To the best of the author's knowledge, no one has developed a truly $2 \mathrm{D}$ and $3 \mathrm{D}$ ice shedding model and published it in the open literature. Thus, the main objective of this study is to develop a fully-automatic simulation model based on fracture mechanics to predict the mechanical shedding of impact ice adhering to airfoil surfaces or to propellers and helicopter blades, and integrate the model in an inflight icing simulation framework.

An outline of the thesis is as follows: Chapter 2 presents the mechanical properties of ice and mathematical model of ice under fluid forces. The theoretical framework of the ice break study is detailed in chapter 3 , and numerical results are presented in Chapter 4 . Chapter 5 covers the 3D ice breakup and shedding from helicopter blades. Finally, conclusions are drawn in Chapter 6. 


\section{Chapter 2 MECHANICAL PROPERTIES OF ICE AND}

\section{MATHEMATICAL MODEL}

This chapter discusses the basic knowledge and background for ice break-up analysis. The mechanical properties of ice are reviewed in details, and the mathematical description of ice under flow forces is introduced. The mathematical model of fluid mechanics and solid mechanics are briefly reviewed. The description of fluid structure interaction and the framework of ice break-up are also introduced in this chapter.

\subsection{Mechanical Properties of Ice}

Ice is a complex anisotropic material and its mechanical behavior strongly depends on two factors: temperature and strain rate. Temperature determines the mechanical properties of ice, such as the elastic modulus and Poisson's ratio, while strain rate determines whether the ice will exhibit ductile or brittle behavior. Generally, the strength of ice increases with decreasing temperature in both tension and compression. However, this effect is more prominent in compression than in tension [25]. Elastic properties of homogeneous polycrystalline isotropic ice at $-16^{\circ} \mathrm{C}$ are shown in Table 1.

\begin{tabular}{|lll|}
\hline \hline Property & Units & Value \\
\hline Young's modulus, $E$ & $\mathrm{~N} \mathrm{~m}^{-2}$ & $9.33 \times 10^{9}$ \\
Compressibility, $K$ & $\mathrm{~N}^{-1} \mathrm{~m}^{-2}$ & $112.4 \times 10^{-12}$ \\
Bulk modulus, $B$ & $\mathrm{~N} \mathrm{~m}^{-2}$ & $8.90 \times 10^{9}$ \\
Shear Modulus, $G$ & $\mathrm{~N} \mathrm{~m}^{-2}$ & $3.52 \times 10^{9}$ \\
Poisson's ratio, $u$ & $\mathrm{n} / \mathrm{a}$ & 0.325 \\
\hline \hline
\end{tabular}

Table 1. Elastic properties of homogeneous polycrystalline isotropic ice at $-16^{\circ} \mathrm{C}[26]$

For a different temperature these values will change since ice properties are highly dependent on temperature. The most accurate values to date have been obtained by Gammon [26] and Gold [27]. For randomly oriented polycrystals, 
typical values of the modulus of elasticity and Poisson's ratio are 9.0 GPa and 0.33 at $-5^{\circ} \mathrm{C}$. Hobbs [28] gives a more complete account and lists both the elastic stiffness and the elastic compliance tensors versus temperature. Depending on the measurement method of the elastic properties, one may obtain an underestimate of the stiffness [29]. Values of modulus of elasticity obtained from experiments may be two to seven times lower than the true elastic modulus. At temperatures of $-10^{\circ} \mathrm{C}$ the Young's modulus of ice was reported in the range of 9.7-11.2 GPa, and Poisson's ratio ranged from 0.29-0.32 [30]. These are the ranges that will be used later in the analysis. The density of ice is $917 \mathrm{~kg} \mathrm{~m}^{-3}$ between 0 and $-10^{\circ} \mathrm{C}$ [31]. The tensile strength of ice varies from 0.7-3.1 MPa, and its compressive strength varies from 5-25 MPa over the temperature range $10^{\circ} \mathrm{C}$ to $-20^{\circ} \mathrm{C}$ [26]. The ice compressive strength increases with decreasing temperature, but ice tensile strength is relatively insensitive to temperature. Schematic stress-strain curves are shown in figure 6, where I, II and III denote low-, intermediate- and high-strain rates. The arrows indicate either ductile (horizontal) or brittle (vertical) behavior [31]. Under compressive loading, ice exhibits either ductile or brittle behavior, depending on the loading conditions. At low strain rates, ice is ductile, with brittle behavior setting in at higher strain rates. The strain rate that marks the transition is around $10^{-4}$ to $10^{-3} \mathrm{~s}^{-1}$ at temperatures from -5 to $-40^{\circ} \mathrm{C}$ [32]. In the present study, we assume low strain rate and linear stress-strain relationship. The linear elasticity assumption is justified in Chapter 3.

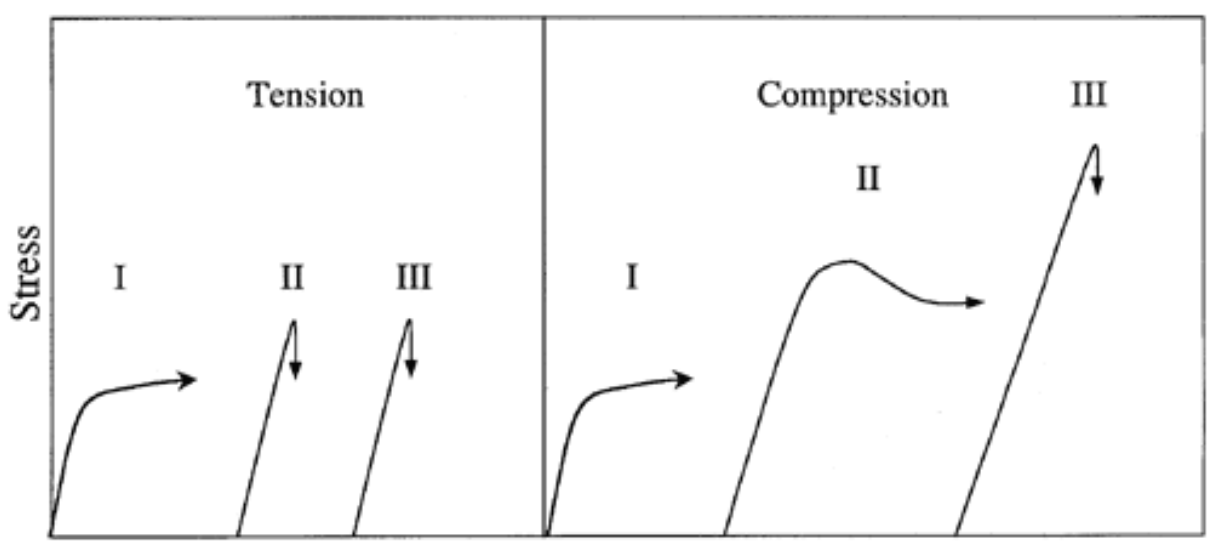

Axial Strain

Figure 6. Schematic stress-strain curves are shown for various strain-rates [33] 
Except for cohesive strength within the ice itself, another property of concern for ice shedding is the interface bonding strength between ice and airfoil. Traditionally, most airfoils have been made of aluminum, but more and more airfoils are now made from carbon fiber composite material. For aluminum-ice interface, the adhesive strength at $-11^{\circ}$ varies from 0.3 to $1.6 \mathrm{MPa}$ [17]. For polymeric materials or carbon fiber composite material, according to reference [18], their adhesive strength with ice is much lower than Aluminum.

\subsection{Mathematical Model of Ice under Flow Forces}

The multi-physics process of ice break-up is governed by multiple simultaneous balance laws that are represented via sets of independent state variables. Fluidstructure interaction $(\mathrm{FSI})$ is a classical example of this class of problems. A comprehensive FSI capability requires fluid analysis [34,35], solid analysis [36], modeling of coupling effects at the common interfaces [37], and a method of dealing with the changing and evolving fluid boundaries [37] that are dictated by the motion of the adjoining structures. However, for the problem at hand, we assume that deformation in the solid (ice) domain is small and hence arbitrary Lagrangian-Eulerian formulation and mesh motion schemes are not required. The small deformation assumption is justified in Chapter 3 . Figure 7 shows the fluid and solid domains that are represented as $\Omega_{f}$ and $\Omega_{s}$, respectively, and the interface that is represented as $\Gamma_{i}$. Flow pressure and the induced stress in ice are also shown in figure 7. 


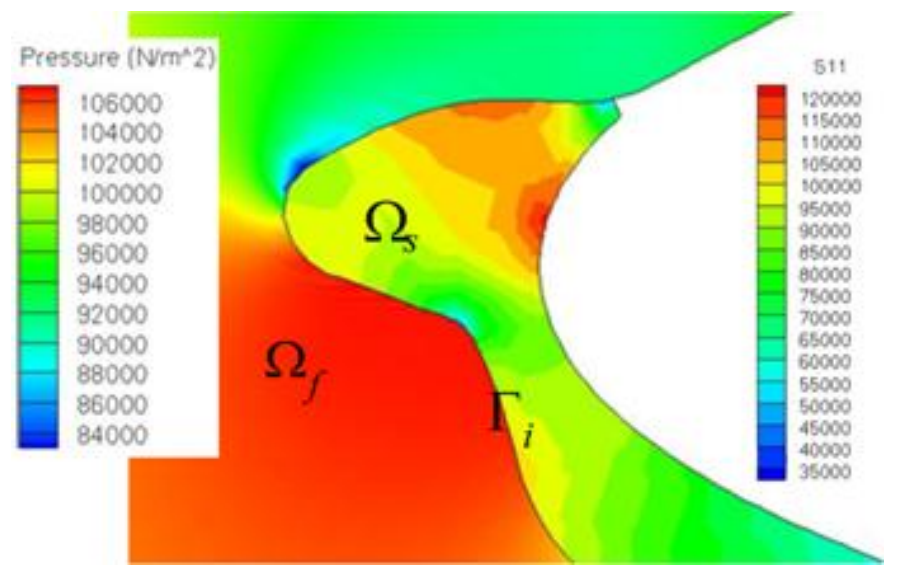

Figure 7. Fluid pressure and the resulting induced stress in ice

The mathematical model for the analysis of ice under the influence of aerodynamic forces, with the small deformation assumption, is described below.

\subsubsection{Fluid mechanics}

Let $\Omega_{f} \subset R^{n_{s d}}$ and $(0, T)$ be the spatial and temporal domains, respectively, where $n_{s d}$ is the number of space dimensions, and let $\Gamma_{f}$ denote the boundary of $\Omega_{f}$. The spatial and temporal conditions are denoted by $\boldsymbol{x}$ and $t$. The Navier-Stokes equations governing the fluid flow, in conservation form, are:

$$
\begin{aligned}
& \frac{\partial \rho^{f}}{\partial t}+\nabla \cdot(\rho \mathbf{u})=0 \text { on } \Omega_{f} \text { for }(0, \mathrm{~T}) \\
& \frac{\partial\left(\rho^{f} \boldsymbol{u}\right)}{\partial t}+\nabla \cdot\left(\rho^{f} \boldsymbol{u u}\right)+\nabla p-\nabla \cdot \boldsymbol{T}=\mathbf{0} \text { on } \Omega_{f} \text { for }(0, \mathrm{~T}) \\
& \frac{\partial\left(\rho^{f} e\right)}{\partial t}+\nabla \cdot\left(\rho^{f} e \boldsymbol{u}\right)+\nabla \cdot(p \boldsymbol{u})-\nabla \cdot(\mathbf{T u})+\nabla \cdot \boldsymbol{q}=0 \text { on } \Omega_{f} \text { for }(0, \mathrm{~T})
\end{aligned}
$$

Here $\rho^{f}, \boldsymbol{u}, p, \boldsymbol{T}, e$ and $\boldsymbol{q}$ are the fluid density, velocity, pressure, viscous stress tensor, total energy per unit mass, and heat flux vector, respectively. The viscous stress tensor is defined as:

$$
\boldsymbol{T}=\mu\left((\nabla \boldsymbol{u})+(\nabla \boldsymbol{u})^{T}\right)+\lambda(\nabla \cdot \boldsymbol{u}) \boldsymbol{I}
$$

where $\mu$ and $\lambda$ are the viscosity coefficients. It is assumed that $\mu$ and $\lambda$ are related by 


$$
\lambda=-\frac{2}{3} \mu
$$

Pressure is related to the other variables via the equation of state. For ideal gases, the equation of state assumes the special form:

$$
p=(\gamma-1) \rho i
$$

where $\gamma$ is the ratio of specific heats, and $i$ is the internal energy per unit mass which is related to the total energy per unit mass and kinetic energy as

$$
i=e-\frac{1}{2}\|\boldsymbol{u}\|^{2}
$$

The heat flux vector is defined as

$$
\boldsymbol{q}=-\kappa \nabla \theta
$$

where $\kappa$ is the heat conductivity and $\theta$ is the temperature, the temperature is related to the internal energy by the following relation:

$$
\theta=\frac{i}{C_{v}}
$$

where $C_{v}$ is the specific heat of the fluid at constant volume. For an ideal gas

$$
C_{v}=\frac{R}{\gamma-1}
$$

where $R$ is the ideal gas constant. Prandtl number $\left(P_{r}\right)$, assumed to be specific, relates the heat conductivity of the fluid to its viscosity according to the following relation:

$$
\kappa=\frac{\mu C_{p}}{P_{r}}
$$

where $C_{p}$ is the specific heat of the fluid at constant pressure. For an ideal gas

$$
C_{p}=\frac{\gamma R}{\gamma-1}
$$

\subsubsection{Solid mechanics}


Let $\Omega_{s} \subset R^{n_{s d}}$ be the spatial solid mechanics domain with boundary $\Gamma_{s} \cdot\left(\Gamma_{s}\right)_{g}$ and $\left(\Gamma_{s}\right)_{h}$ are the parts of $\Gamma_{s}$ corresponding to the Dirichlet and Neumann boundary conditions, respectively. The equations of motion for the structure are written as:

$$
\rho^{s}\left(\frac{d^{2} \boldsymbol{y}}{d t^{2}}-f^{s}\right)-\nabla \cdot \boldsymbol{\sigma}^{s}=0 \text { on } \Omega_{s} \text { for }(0, \mathrm{~T})
$$

where $\rho^{s}, \boldsymbol{y}, f^{s}$ and $\boldsymbol{\sigma}^{s}$ are the material density, structural displacement, external force and the Cauchy stress tensor, respectively.

\subsubsection{Interface conditions}

We consider a coupled FSI model, which consists of a fluid domain $\Omega_{f}$, a solid domain $\Omega_{s}$, and a common interface boundary $\Gamma_{i}$. At each FSI cycle, two interface boundary conditions corresponding to the continuity of tractions and velocities must be satisfied along $\Gamma_{i}$. Let $\boldsymbol{t}_{f}$ and $\boldsymbol{u}_{f}$ denote the fluid traction vector and displacement fields along the fluid interface $\Gamma_{f}$, while $\boldsymbol{t}_{s}$ and $\boldsymbol{u}_{s}$ denote the solid traction vector and displacement fields along the solid interface $\Gamma_{s}$, respectively. The equilibrium of tractions and compatibility of velocity field can be expressed as:

$$
\boldsymbol{t}_{s}=\boldsymbol{t}_{f}, \frac{\partial \boldsymbol{u}_{s}}{\partial t}=\frac{\partial \boldsymbol{u}_{f}}{\partial t} \text { on } \Gamma_{i},
$$

where $\boldsymbol{t}_{f}=p_{f} \boldsymbol{n}_{f}-\boldsymbol{\sigma}_{f} \boldsymbol{n}_{f}$ and $\boldsymbol{t}_{s}=\boldsymbol{\sigma}_{s} \boldsymbol{n}_{s}$. Here, $p_{f}$ is the fluid pressure along the interface; $\sigma_{f}$ and $\sigma_{s}$ are the fluid viscous tensor and solid stress tensor, respectively; $\boldsymbol{n}_{f}$ and $\boldsymbol{n}_{s}$ are the unit outward normals along the fluid interface $\Gamma_{f}$ and solid interface $\Gamma_{s}$, respectively.

\subsubsection{Justification of uncoupled analysis}

Due to prohibitive computational costs, even in 2D, a quasi-steady approach is adopted in FENSAP-ICE for simulating ice accretion. Figure 8 describes the overall solution procedure that requires solving the Navier-Stokes equations for 
flow around the desired shape. Then, employing this flow solution, FENSAP-ICE determines water collection efficiency over the surface exposed to the flow. Based on the flow and water solutions, the equations for ice accretion are solved providing the mass and shape of ice that accretes on the surface. The fluid mesh is deformed next, using a mesh motion algorithm, and then ice break-up analysis is performed. Since the flow and droplet analyses employ steady-state simulations and only ice accretion analysis is time accurate, the stress analysis of ice can be uncoupled from the flow/droplet analyses. This approach is adopted in the present study and the fluid forces are applied to the ice shapes that are formed in each step of the ice accretion analysis. The simplified mathematical model is shown in Chapter 3.

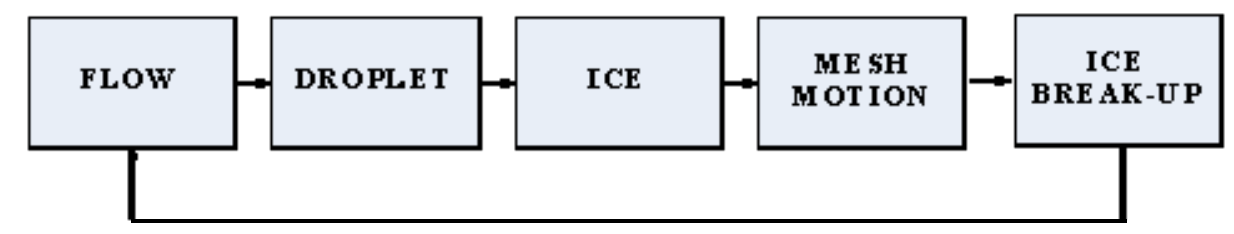

Figure 8. Ice break-up analysis in the in-flight icing framework of FENSAP-ICE 


\section{Chapter 3 THEORETICAL FRAMEWORK OF ICE BREAK-UP MODELING}

2D ice break-up analysis is integrated as a module in FENSAP-ICE framework and the fully automatic module takes in two grids, one on the clean airfoil and the other on the iced airfoil, and the flow solution on the iced airfoil. The output of this module is the broken ice shape, provided the induced stress in ice and ice geometry satisfy the conditions for ice break-up. This analysis involves identification of the ice boundaries, generating a mesh inside the ice, performing stress analysis and crack propagation simulation. The entire cycle has to be repeated for each step of crack propagation. Figure 9 shows the block diagram of this process and each step is described in detail thereafter.

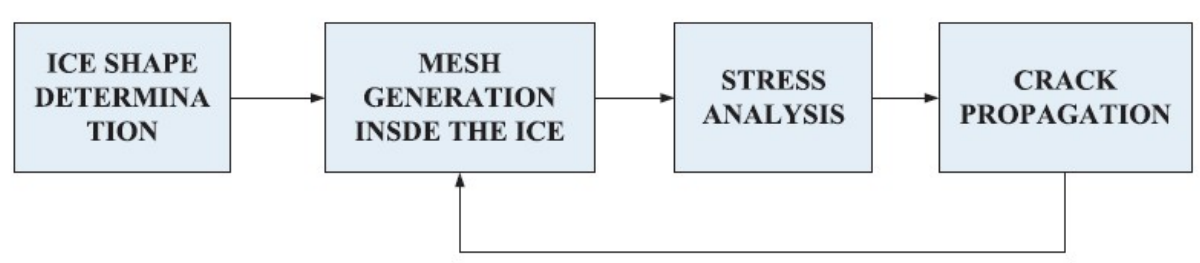

Figure 9. Block diagram of ice break-up analysis

\subsection{Identification of Ice Shape and Boundary Conditions}

This step requires input from the flow solution, namely: grid on the clean airfoil (figure 10a), grid on the iced airfoil (figure 10b), and the flow solution on the iced airfoil (figure 10c). The shape of ice is determined by comparing the distances of each node on the wall of the clean airfoil, to each node on the wall of the iced airfoil. In this process, a closed polygon of the nodes, as shown in figure 11, is obtained that describes the shape of ice. These nodes are the boundary nodes of the computational domain of solid (ice) mesh and are separated into Dirichlet and Neumann nodes. Pressure is extracted from the flow solution and associated with the Neumann boundary nodes. Note that only pressure is applied as a force 
and the much smaller contribution of the shear stress of the fluid will be considered in future work.

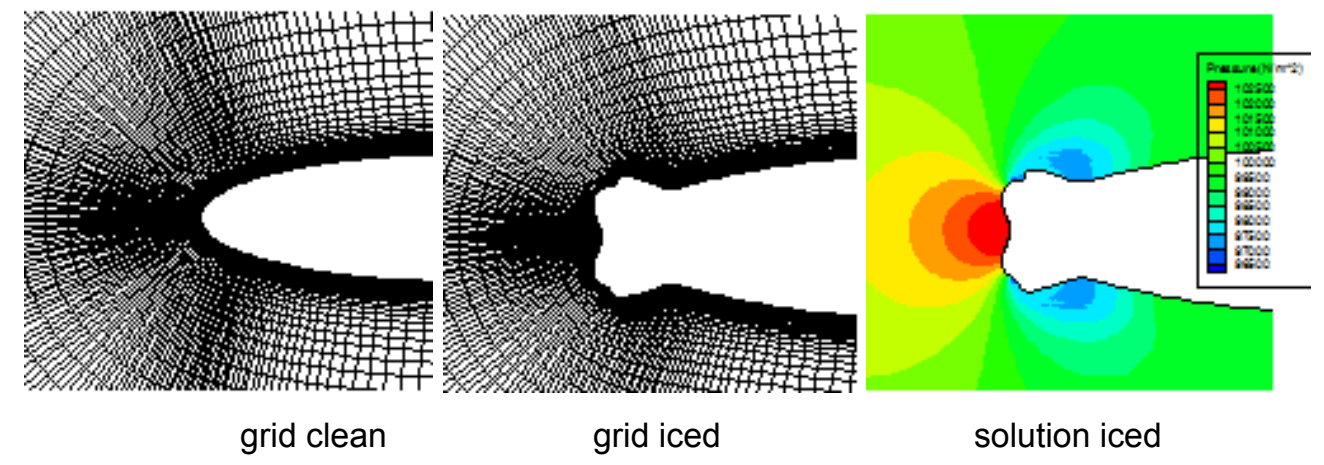

Figure 10. Input information from the flow solution required for ice break-up analysis

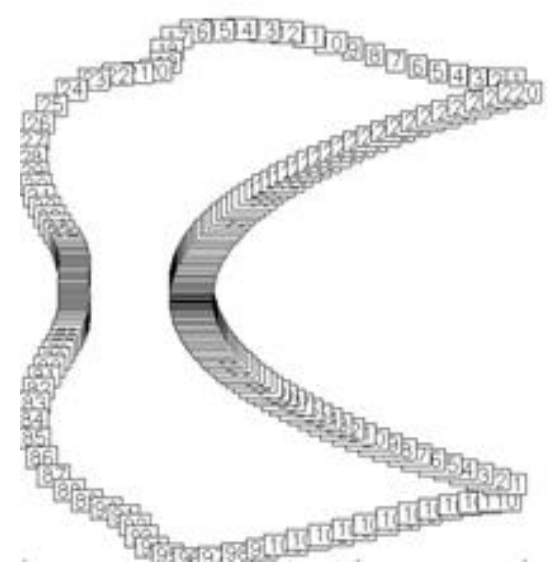

Figure 11. Closed polygon of nodes describing the shape of ice

\subsection{Meshing}

The meshing in the ice is done by using an open source code named Triangle [38]. The closed polygon consisting of the boundary nodes are input to the code and a mesh of unstructured linear triangular elements is produced based on Delaunay triangulation. The constraint mesh is generated such that the boundary nodes and their numbering are not altered. Figure 12 shows the computational mesh generated by Triangle. 


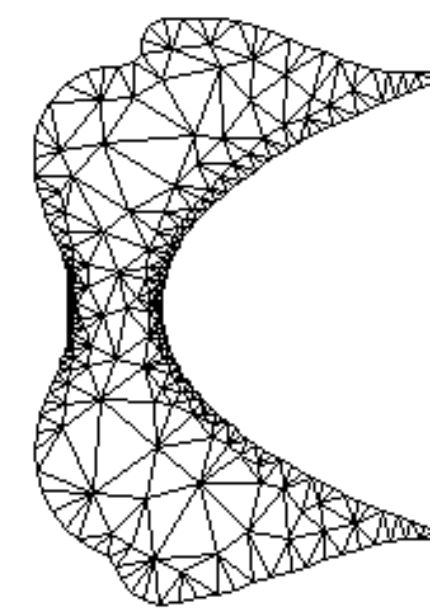

Figure 12. The solid's (ice) computational mesh

\subsection{Stress Analysis}

Stress analysis is performed via linear elasticity equations, along with the appropriate boundary conditions. A formal statement of the strong form of the boundary-value problem goes as follows:

Given $\boldsymbol{f}: \Omega_{s} \rightarrow R^{n_{s t}}, \boldsymbol{g}:\left(\Gamma_{s}\right)_{g} \rightarrow R^{n_{s t}}$, and $\boldsymbol{h}:\left(\Gamma_{s}\right)_{h} \rightarrow R^{n_{s t}}$ such that

$$
\begin{aligned}
& \nabla \cdot \boldsymbol{\sigma}+\boldsymbol{f}=\mathbf{0} \text { in } \Omega_{s} \\
& \boldsymbol{u}=\mathbf{0} \text { on }\left(\Gamma_{s}\right)_{g} \\
& p_{f} \boldsymbol{n}_{f}=\boldsymbol{h} \text { on }\left(\Gamma_{s}\right)_{h}
\end{aligned}
$$

where $\boldsymbol{u}$ is the displacement field and $\boldsymbol{f}$ is the body force. $\boldsymbol{h}$ is the Neumann boundary conditions on $\left(\Gamma_{s}\right)_{h}$, which comes from the fluid solution. Zerodisplacement Dirichlet boundary condition is imposed on $\left(\Gamma_{s}\right)_{g}$ i.e. the nodes on airfoil. $p_{f}$ is the fluid pressure along the fluid-solid interface, which is same as $\left(\Gamma_{s}\right)_{h}$. Figure 13 is a pictorial representation of this mathematical model. $\sigma$ is the Cauchy stress tensor which, for isotropic case, is related to displacement by the relation:

$$
\sigma_{i j}=\lambda u_{k, k} \delta_{i j}+\mu\left(u_{i, j}+u_{j, i}\right)
$$


where $\delta_{i j}$ is the Kronecker delta and Lame's constants $\mu$ and $\lambda$ are related to material properties by the relation:

$$
\begin{aligned}
& \mu=\frac{E}{2(1+v)} \\
& \lambda=\frac{2 v \mu}{1-2 v}
\end{aligned}
$$

where $\mathrm{E}$ is the Young's modulus and $v$ is the Poisson's ratio.

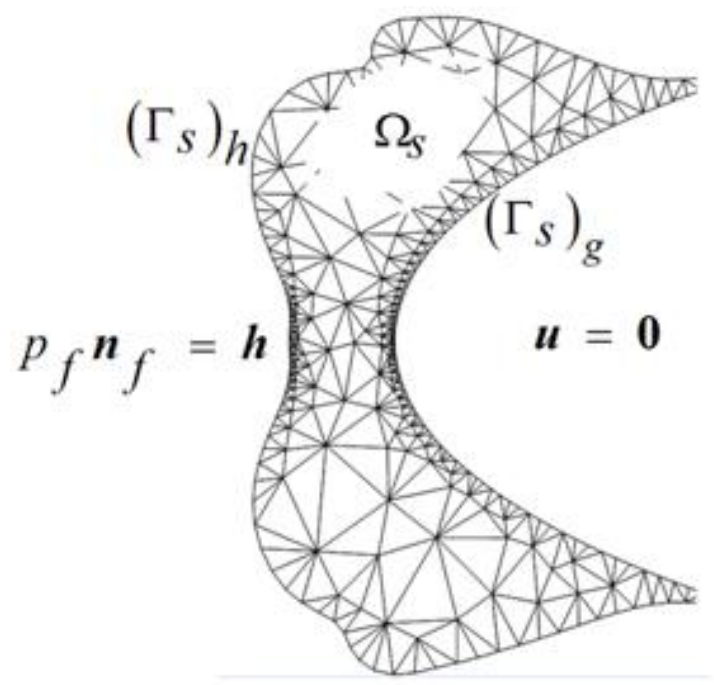

Figure 13. Pictorial representation of uncoupled stress analysis in ice

The Neumann boundary condition comes from the fluid solution, and a zerodisplacement Dirichlet boundary condition is imposed on the nodes on the airfoil. We used standard Galerkin formulation with isoparametric Lagrange interpolation. Linear triangular elements and three quadrature points for numerical integration are used for the numerical experiments shown in chapter 4 . Figure 14 shows the stress distribution in ice under aerodynamic force. 


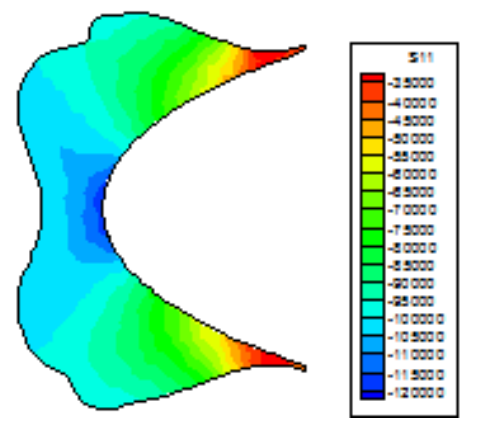

(a) $\sigma_{11}$

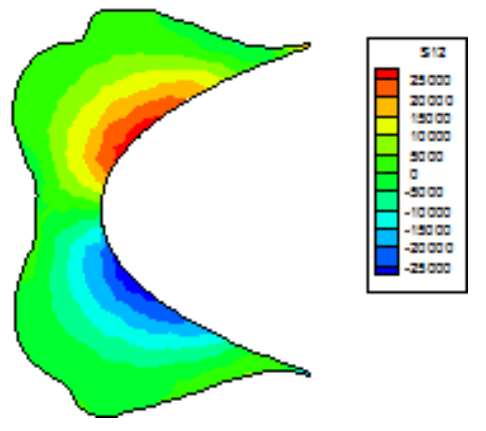

(b) $\sigma_{11}$

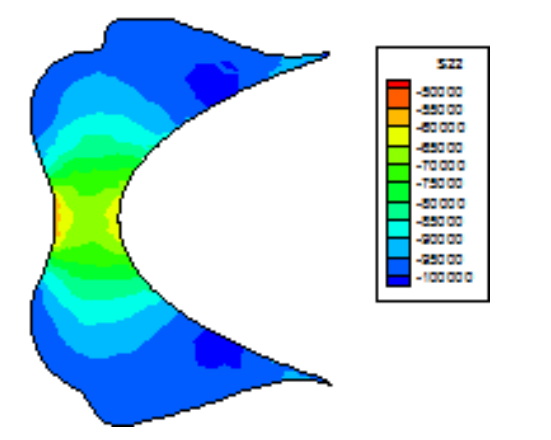

(c) $\sigma_{11}$

Figure 14. Stress distribution in ice under aerodynamic force

\section{Justification of linear constitutive relation}

Literature review [32] reveals that, for low strain rate, ice deforms linearly up to stress values of 0.8MPa. The stresses obtained in ice under typical aerodynamic loads and with typical material properties do not exceed $0.8 \mathrm{MPa}$. The maximum stress shown is figure 14 is $0.12 \mathrm{Mpa}$. Hence, a linear stress-strain relationship is used throughout the study.

\section{Justification of small deformation approximation}

The simulation shown in figure 14 is repeated with a finite deformation formulation, and Newton-Raphson iterations are performed for convergence of the non-linear system of equations, arising from geometric nonlinearity. Figure 15 shows the comparison of displacement fields obtained by the small and finite deformation formulations. The displacement fields are identical, hence from hereon, small deformation analysis is performed. It is interesting to note that the 
solution converged to machine zero in two iterations for the finite deformation analysis.
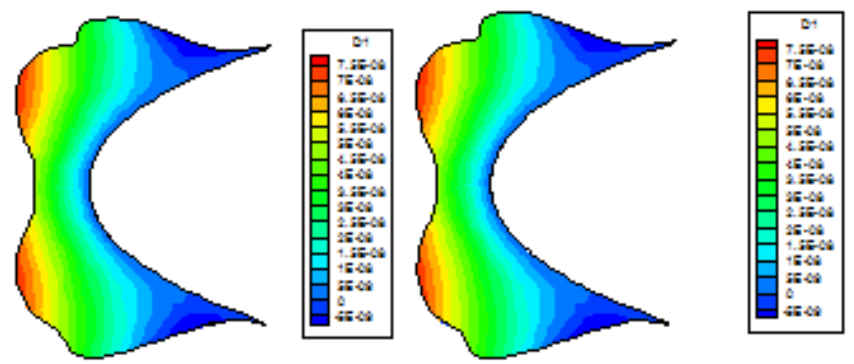

(a) X-displacement (linear) (b) X-displacement (non-linear)
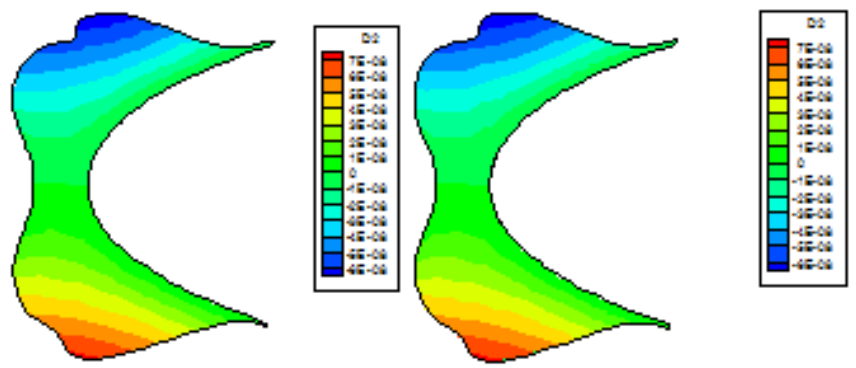

(c) Y-displacement (linear) (d) Y-displacement (non-linear)

Figure 15. Comparison of the displacement field for small deformation (left) and finite deformation (right) analysis

\subsection{Crack Propagation}

Earlier efforts in applying FEM to linear elastic fracture mechanics date back to 1970's. Over 40 years of development, the FEM has achieved great success in fracture analysis. Employing linear elastic fracture mechanics, a 2D crack propagation package described below was developed based on FEM.

\subsubsection{Stress field near the crack tip}

The stress field near the crack tip is described by a series, called Williams expansion as shown below [39]:

For mode I: 


$$
\begin{aligned}
& \sigma_{x}=\sum_{n=1}^{\infty} \frac{n}{2} r^{\frac{n}{2}-1} a_{n}^{1}\left[\left(2+\frac{n}{2}+(-1)^{n}\right) \cos \left(\frac{n}{2}-1\right) \theta-\left(\frac{n}{2}-1\right) \cos \left(\frac{n}{2}-3\right) \theta\right] \\
& \sigma_{y}=\sum_{n=1}^{\infty} \frac{n}{2} r^{\frac{n}{2}-1} a_{n}^{1}\left[\left(2-\frac{n}{2}-(-1)^{n}\right) \cos \left(\frac{n}{2}-1\right) \theta+\left(\frac{n}{2}-1\right) \cos \left(\frac{n}{2}-3\right) \theta\right] \\
& \tau_{y}=\sum_{n=1}^{\infty} \frac{n}{2} r^{\frac{n}{2}-1} a_{n}^{1}\left[\left(\frac{n}{2}-1\right) \sin \left(\frac{n}{2}-3\right) \theta-\left(\frac{n}{2}+(-1)^{n}\right) \sin \left(\frac{n}{2}-1\right) \theta\right]
\end{aligned}
$$

For mode II:

$$
\begin{aligned}
& \sigma_{x}=-\sum_{n=1}^{\infty} \frac{n}{2} r^{\frac{n}{2}-1} a_{n}^{2}\left[\left(2+\frac{n}{2}-(-1)^{n}\right) \sin \left(\frac{n}{2}-1\right) \theta-\left(\frac{n}{2}-1\right) \sin \left(\frac{n}{2}-3\right) \theta\right] \\
& \sigma_{y}=-\sum_{n=1}^{\infty} \frac{n}{2} r^{\frac{n}{2}-1} a_{n}^{2}\left[\left(2-\frac{n}{2}+(-1)^{n}\right) \sin \left(\frac{n}{2}-1\right) \theta+\left(\frac{n}{2}-1\right) \sin \left(\frac{n}{2}-3\right) \theta\right] \\
& \tau_{y}=\sum_{n=1}^{\infty} \frac{n}{2} r^{\frac{n}{2}-1} a_{n}^{2}\left[\left(\frac{n}{2}-1\right) \cos \left(\frac{n}{2}-3\right) \theta-\left(\frac{n}{2}-(-1)^{n}\right) \cos \left(\frac{n}{2}-1\right) \theta\right]
\end{aligned}
$$

Where $\sigma$ and $\tau$ are normal stress and shear stress respectively. $r$ is the radius to the crack tip.

Example of expansion along the crack line

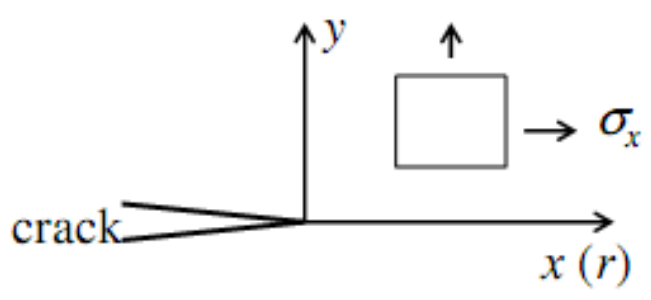

$\sigma_{x}=\frac{a_{1}}{\sqrt{r}}+4 a_{2}+3 a_{3} \sqrt{r}+8 a_{4} r+5 a_{5} r^{3 / 2}+\cdots$

$\sigma_{y}=\frac{a_{1}}{\sqrt{r}}+3 a_{3} \sqrt{r}+5 a_{5} r^{3 / 2}+\cdots$

In the above expansions, the first term is the singular term, with the square root of $r$, and $\mathrm{a}_{1}$ is the stress intensity factor. The second term $\mathrm{a}_{2}$ represents T-stress, and the third term $a_{3}$ is the leading higher order term. 


\subsubsection{Quarter-point element}

In the early times of modeling fracture problems using FEM, the fundamental difficulty had been that the polynomial basis functions used for most conventional elements cannot represent the singular crack tip stress and strain fields predicted by the theory as discussed in the previous part. This means that as the mesh is refined the finite element solutions will initially begin to converge to the theoretical solution, but will eventually diverge. This difficulty was recognized and demonstrated relatively early in the development of the finite element method [40]. A number of researchers investigated special finite element formulations that incorporate singular basis functions or stress intensity factors as nodal variables. While successful, these special purpose elements are not available in most general-purpose finite element programs and thus are used very infrequently [40].

A significant advancement in the use of the finite element method for linear elastic fracture mechanics problems was the simultaneous, and independent, development of "quarter-point" elements by Henshell and Shaw (1975) and Barsoum (1976) [40]. These researchers showed that the proper crack-tip displacement, stress, and strain fields are modeled by standard quadratic order isoparametric finite elements if one simply moves the element's mid-side node to the position one quarter of the way from the crack tip to the far end of the element. This procedure introduces a singularity into the mapping between the element's parametric coordinate space and Cartesian space.

Figure 16 shows a quadrilateral quarter-point element and a triangle quarterpoint element. The discovery of quarter-point element was a significant milestone in the development of finite element procedures for linear elastic fracture mechanics. With these elements standard and widely available, finite element programs can be used to model crack tip fields accurately with only minimal preprocessing required. 

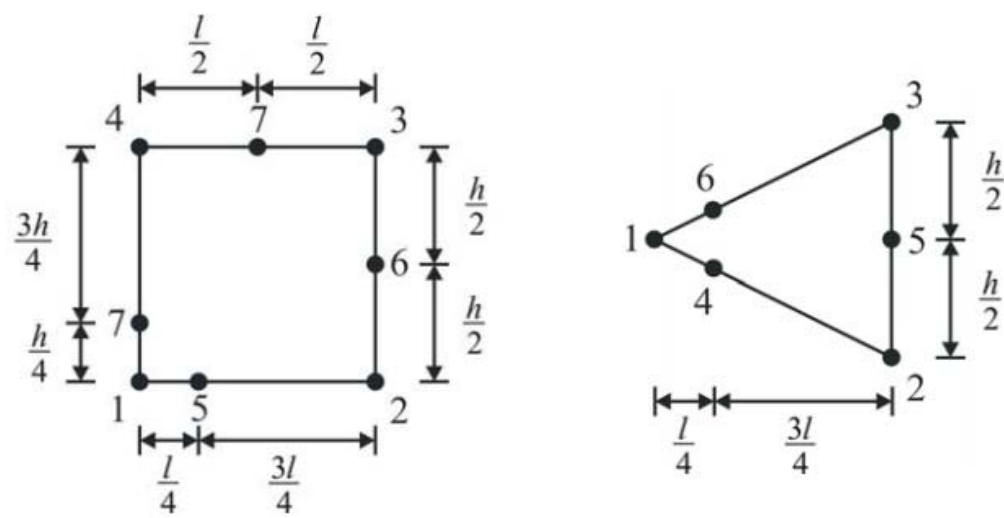

Figure 16 Quadrilateral (left) and triangle (right) quarter-point elements

The effect of moving the side node of a quadratic element to the quarter-point position can be best illustrated with a one-dimensional element. Though onedimensional element is not practically useful, the algebra is much simpler than with two- and three dimensional elements, and is same in principle for the higher dimensionality elements. A 1-D quadratic order element is illustrated in Fig. 17. Figure $17 \mathrm{a}$ shows the parametric space of the element. Fig. 17b shows the element in Cartesian space with the location of the center node controlled by the value of the parameter $\alpha$. The crack tip is located at $r=0$. The displacement $u$ at any point within the element is determined by interpolating the nodal displacements using the standard Lagrange second order shape functions.

(a)

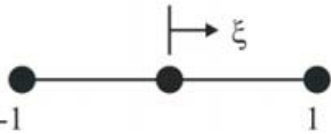

(b)

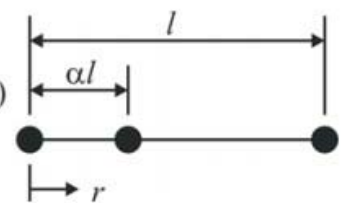

Figure 17. A 1-D quadratic element, (a) the parametric space of the element, (b) the Cartesian space of the element [40].

The standard Lagrange second order shape functions of 1D quadratic element are as follows:

$$
\begin{aligned}
& N_{1}=\frac{1}{2} \xi(\xi-1) \\
& N_{2}=\left(1-\xi^{2}\right)
\end{aligned}
$$




$$
N_{3}=\frac{1}{2} \xi(\xi+1)
$$

Hence, the displacement $u$ could be written as:

$$
u=u_{1} N_{1}+u_{2} N_{2}+u_{3} N_{3}
$$

Substituting those shape functions, we can get:

$$
u=u_{1} \cdot \frac{1}{2} \xi(\xi-1)+u_{2} \cdot\left(1-\xi^{2}\right)+u_{3} \cdot \frac{1}{2} \xi(\xi+1)
$$

Regrouping in powers of $\xi$,

$$
u=u_{2}+\frac{1}{2} \xi\left(u_{3}-u_{1}\right)+\xi^{2}\left[\frac{1}{2}\left(u_{1}+u_{3}\right)-u_{2}\right]
$$

Using the same shape functions to interpolate the geometry of the element,

$$
r=\sum_{i=1}^{n} N_{i} \cdot r_{i}=r_{2}+\frac{1}{2} \xi\left(r_{3}-r_{1}\right)+\xi^{2}\left[\frac{1}{2}\left(r_{1}+r_{3}\right)-r_{2}\right]
$$

As $r_{1}=0, r_{2}=\alpha l, r_{3}=l$, the above equation can be written as:

$$
r=\alpha l+\frac{1}{2} \xi l+l \xi^{2}\left[\frac{1}{2}-\alpha\right]
$$

First consider the center node is located at the middle of the element. That is $\alpha=\frac{1}{2}$, from equation (3.22), we can get,

$$
r=\frac{1}{2} l+\frac{1}{2} \xi l
$$

Using $r$ to denote $\xi$, we can write

$$
\xi=\frac{2 r-l}{l}=\frac{2 r}{l}-1
$$

Equation (3.24) links the Cartesian space and parametric coordinate system.

Substituting equation (3.24) into (3.20), we can get

$$
u=u_{1}+\left(-3 u_{1}+4 u_{2}-u_{3}\right) \cdot \frac{r}{l}+2\left(u_{1}-2 u_{2}+u_{3}\right) \frac{r^{2}}{l^{2}}
$$

Differentiating the displacement field in (3.25), strain in the element could be obtained,

$$
\varepsilon=\frac{d u}{d r}=\left(-3 u_{1}+4 u_{2}-u_{3}\right) \cdot \frac{1}{l}+2\left(u_{1}-2 u_{2}+u_{3}\right) \frac{2 r}{l^{2}}
$$


Under linear elastic conditions, the stresses are linearly related to the strains, so from equation (3.26), the stress distribution in the element will be linear with $r$.

Now consider the case where the middle node is moved to the quarter-point position. For this case, $\alpha=\frac{1}{4}$, and from equation (3.22), we can get,

$$
r=\frac{1}{4} l+\frac{1}{2} \xi l+\frac{1}{4} \xi^{2} l
$$

From (3.27), denote $\xi$ in $r$, we get,

$$
\xi=2 \sqrt{\frac{r}{l}}-1
$$

Substituting (3.28) into (3.20), we get

$$
u=u_{1}+2\left(u_{1}-2 u_{2}+u_{3}\right) \cdot \frac{r}{l}+\left(-3 u_{1}+4 u_{2}+u_{3}\right) \cdot \frac{\sqrt{r l}}{l}
$$

In the same way, differentiating (3.29) by $r$ will give us the strain in the element,

$$
\varepsilon=\frac{d u}{d r}=2\left(u_{1}-2 u_{2}+u_{3}\right) \cdot \frac{1}{l}+\frac{1}{2}\left(-3 u_{1}+4 u_{2}+u_{3}\right) \cdot \frac{1}{\sqrt{r l}}
$$

we can see clearly from (3.29) that the three terms in the displacement expression model a constant value, a linear variation in $r$, and the square root variation in $r$. This corresponds to the leading terms in the LEFM expressions for the near crack-tip displacement. From (3.30), the expression for the strains contains a constant term and a singular term that varies as $r^{-1 / 2}$, which is the form of lead term in the LEFM stress and strain expansions. The theoretical displacement and stress field, the normal displacement field (middle point displacement field) and quarter-point displacement field are listed as:

Theoretical displacement field,

$$
u=\sum_{n=1}^{\infty} \frac{r^{\frac{n}{2}}}{2 \mu} a_{n}^{1}\left[\left(\kappa+\frac{n}{2}+(-1)^{n}\right) \cos \frac{n}{2} \theta-\frac{n}{2} \cos \left(\frac{n}{2}-2\right) \theta\right]
$$

Middle node displacement field,

$$
u=u_{1}+\left(-3 u_{1}+4 u_{2}-u_{3}\right) \cdot \frac{r}{l}+2\left(u_{1}-2 u_{2}+u_{3}\right) \frac{r^{2}}{l^{2}}
$$


Quarter-point displacement field,

$$
u=u_{1}+2\left(u_{1}-2 u_{2}+u_{3}\right) \cdot \frac{r}{l}+\left(-3 u_{1}+4 u_{2}+u_{3}\right) \cdot \frac{\sqrt{r l}}{l}
$$

Theoretical field,

$$
\sigma_{x}=\sum_{n=1}^{\infty} \frac{n}{2} r^{\frac{n}{2}-1} a_{n}^{1}\left[\left(2+\frac{n}{2}+(-1)^{n}\right) \cos \left(\frac{n}{2}-1\right) \theta-\left(\frac{n}{2}-1\right) \cos \left(\frac{n}{2}-3\right) \theta\right]
$$

Middle node strain field,

$$
\varepsilon=\frac{d u}{d r}=\left(-3 u_{1}+4 u_{2}-u_{3}\right) \cdot \frac{1}{l}+2\left(u_{1}-2 u_{2}+u_{3}\right) \frac{2 r}{l^{2}}
$$

Quarter-point strain field,

$$
\varepsilon=\frac{d u}{d r}=2\left(u_{1}-2 u_{2}+u_{3}\right) \cdot \frac{1}{l}+\frac{1}{2}\left(-3 u_{1}+4 u_{2}+u_{3}\right) \cdot \frac{1}{\sqrt{r l}}
$$

From the above listing, one can observe easily that the quarter-point quadratic element produces the correct leading displacement and strain terms. Figure 18 shows distribution of stress $\sigma_{x}$ in a crack tip quarter-point element. It can be observed that the stress grows to singular towards one side of the element.

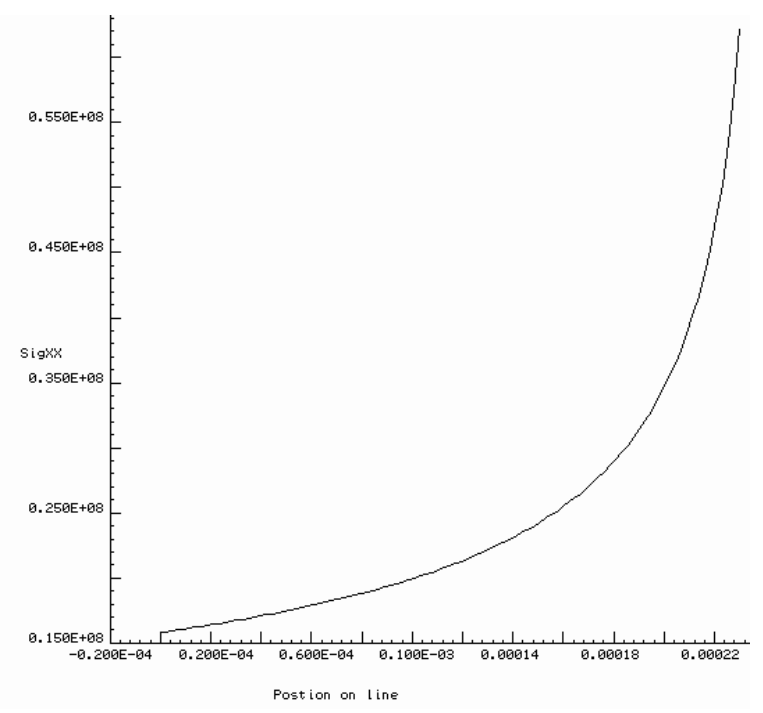

Figure 18. Stress sig-xx distribution within a quarter-point element

Except for producing the correct solution, another big advantage of the quarterpoint element is that no special software coding is needed, only perturbed nodal 
geometry. Therefore, any FEM code supporting quadratic order elements supports this singular element.

In the present 2D crack propagation approach, triangular quadratic elements are used, hence, for convenience, triangular quarter-point elements are adopted around the crack tip. For generating the quarter-point elements around the crack tip, a special arrangement of the mesh is needed. Figure 19 shows the rosette around the crack tip, and then quarter-point elements are inserted in the rosette.
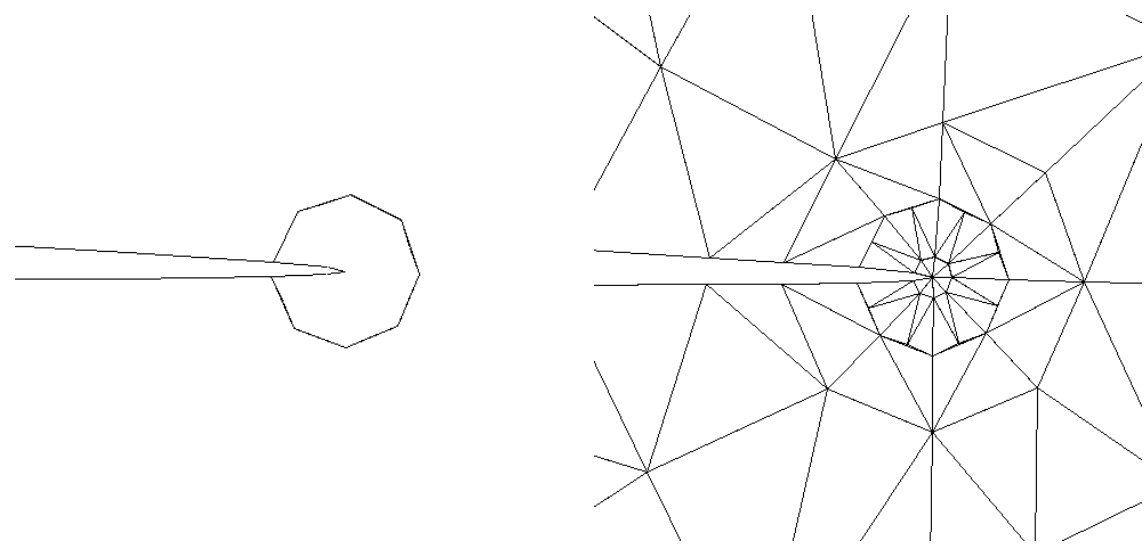

Figure 19. Rosette around crack tip (left) and quarter-point element around crack tip (right)

\subsubsection{Comparison between quarter-point element and normal quadratic element}

In this section, a comparison between the quarter-point element and the normal quadratic element is made. Figure 20 shows the principal stress I distribution of a benchmark case. The plate is fixed at the bottom edge and is subjected to a farfield shear stress $\tau=1$ unit along the top edge. The plate has an initial crack length $a=3.5$ units. The modulus of elasticity and the Poisson ratio are $30 \times 10^{6}$ units and 0.25 , respectively. A plane strain condition is assumed in the analysis. The figure on the left shows the result of quarter-point elements, the figure on the right shows the result of the normal quadratic element. From these results, there is almost no difference in trend of the principal stress distribution. However, when one plots the principal stress I (P1) in 3D form, i.e. take the P1 value as the Zaxis value, a significant difference can be observed. The $\mathrm{P} 1$ distribution in $3 \mathrm{D}$ 
plot is shown in figures 21 and 22 of quarter-point element and normal quadratic element, respectively. One can see that at the crack tip, the principal stress I increases sharply towards the crack tip in figure 21 , which exactly represents the singularity according to theory. However, for the normal quadratic element (Fig. 22), stress concentrates around the crack tip, but no sharp peak is observed.
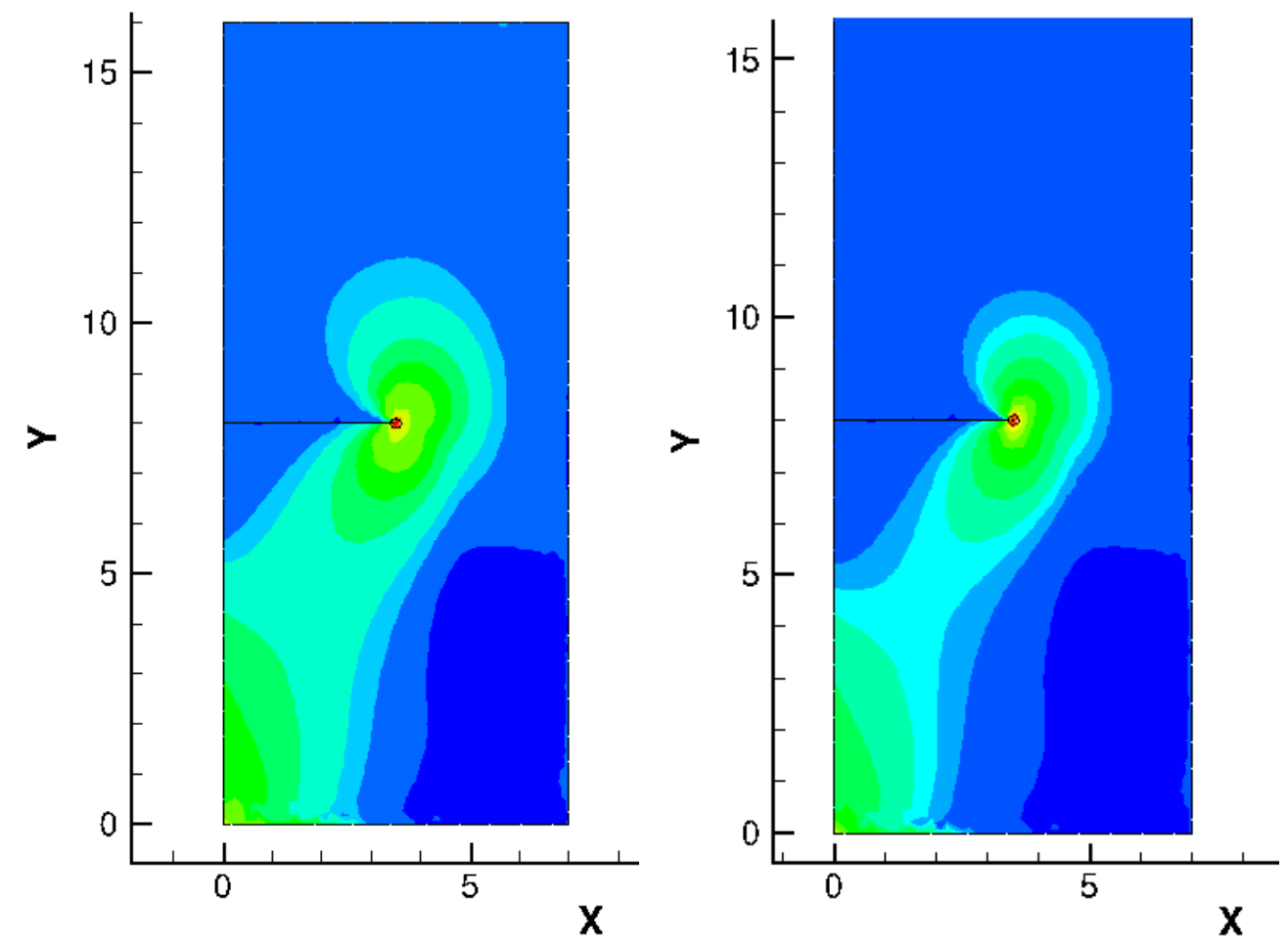

Figure 20. Quarter-point element (left) and normal quadratic element (right) 


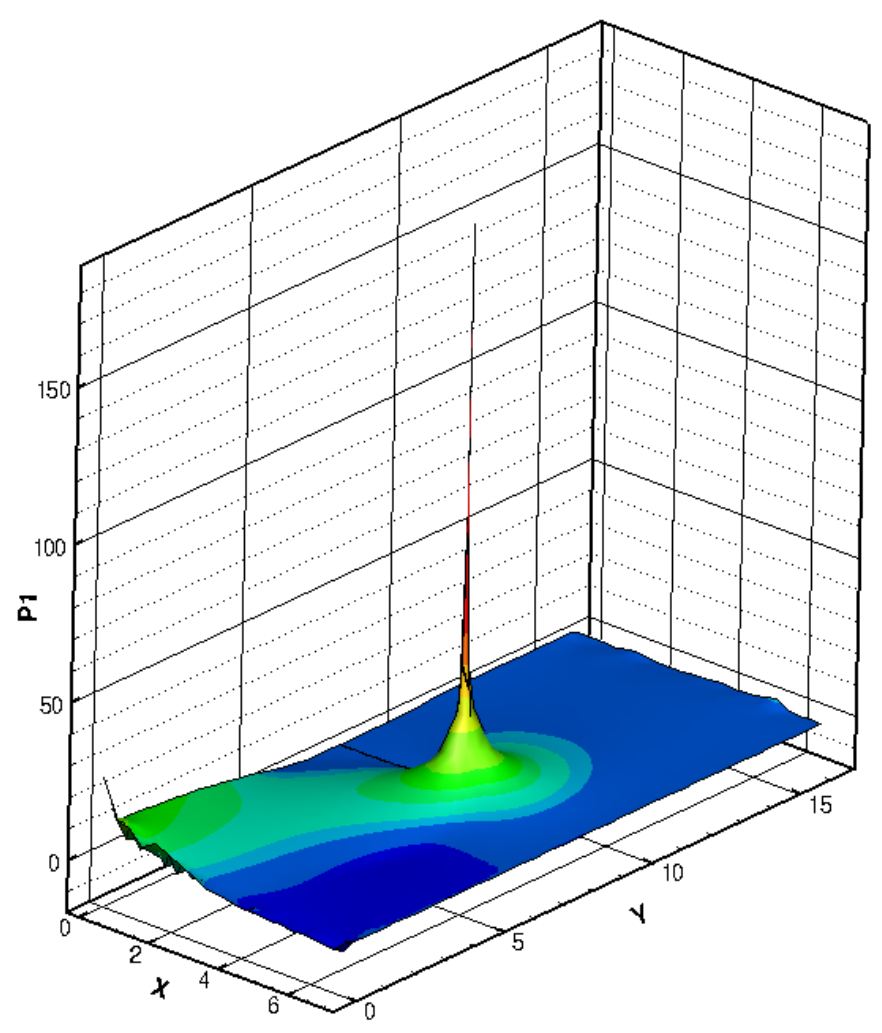

Figure 21. Principal stress I distribution in 3D of quart-point element

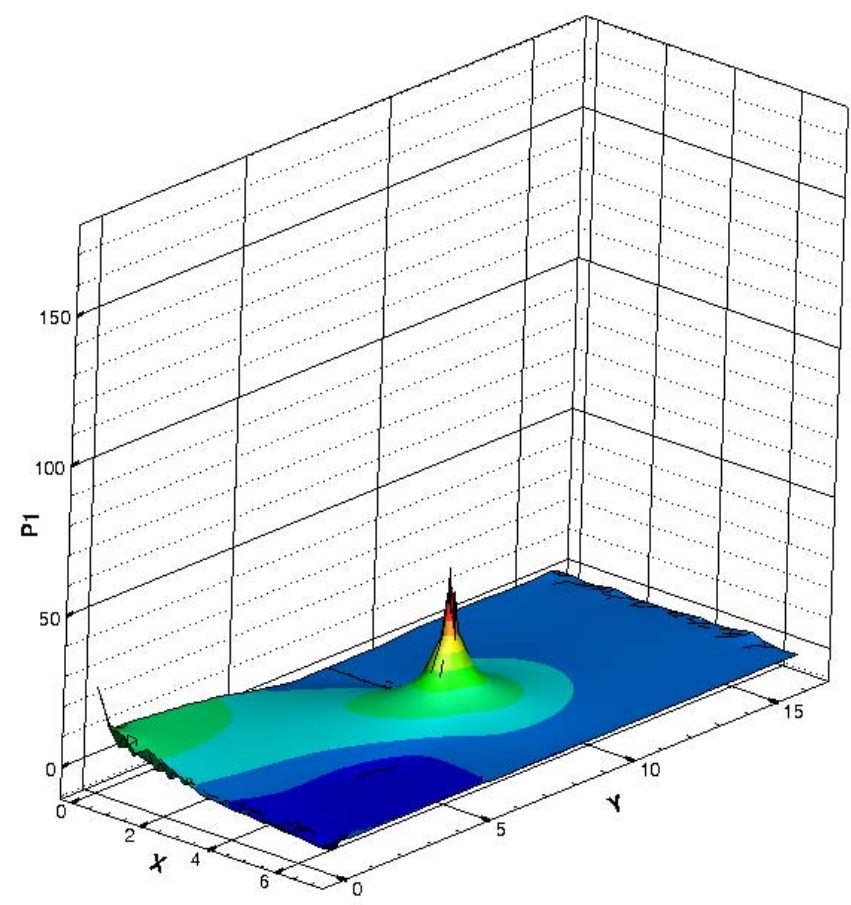

Figure 22. Principal stress I distribution in 3D of normal quadratic element 
Fig. 23 and Fig. 24 give a more detailed view of stress distribution near the crack tip. From the quarter-point element in Fig. 23, it can be seen that stress is highly concentrated at the crack tip. However, for the normal quadratic element in Fig.24, the stress at the vicinity of crack tip is not as concentrated as compared with Fig. 23.

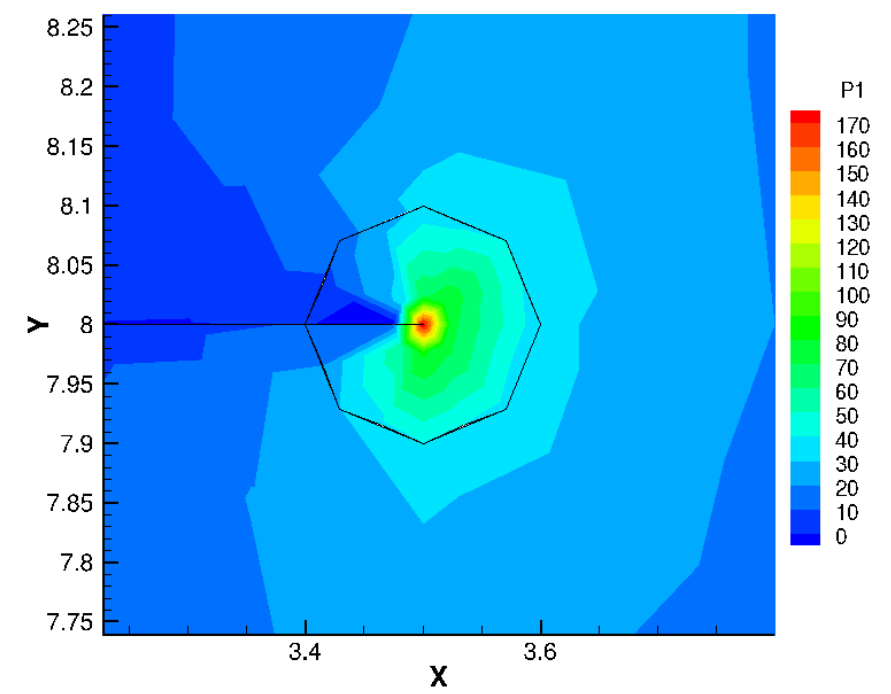

Figure 23. P1 distribution in the vicinity of crack tip for quart-point element

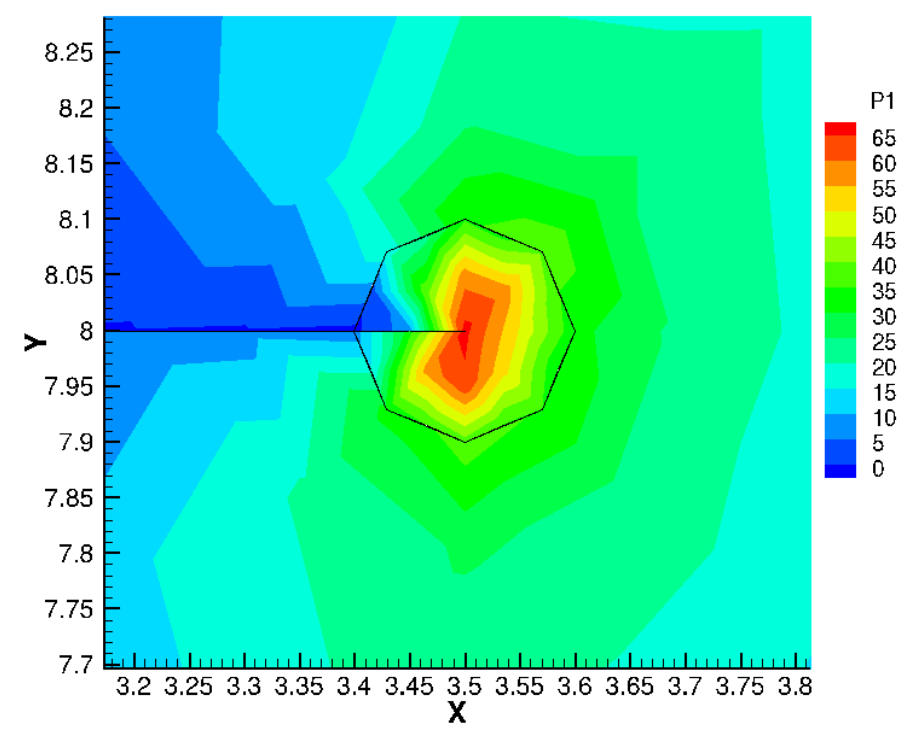

Figure 24. P1 distribution in the vicinity of crack tip for normal quadratic element 


\subsubsection{Crack initiation}

From literature review, the tensile strength of ice is much lower than compressive strength. Hence the region with the highest principal tensile stress is most vulnerable to crack initiation [27]. Based on the tensile strength of ice, whether a crack will occur or not could be determined. In this study, the initial crack is placed in the element having maximum first principal stress. In case the first principal stress is negative throughout the computational domain (i.e. compressive stress only), then no initial crack is placed.

\subsubsection{Evaluation of the stress intensity factor (SIF)}

Stress intensity factor is one of the most important parameters in predicting the direction of crack propagation, and the calculation of precise SIF plays a key part in fracture mechanics.

There are several methods for extracting SIF from local field information. In the present study the displacement correlation method is used, due to its simplicity and high accuracy. The idea of displacement correlation method is simple, that is correlate computed FEM local displacements with their theoretical values, with SIF as scaling parameter.

The form of the theoretical asymptotic displacement field near the crack tip for plain strain in mode I, is

$$
\begin{aligned}
& u=\frac{K_{I}}{\mu}\left[\frac{r}{2 \pi}\right]^{1 / 2} \cos \frac{\theta}{2}\left[1-2 v+\sin ^{2} \frac{\theta}{2}\right] \\
& v=\frac{K_{I}}{\mu}\left[\frac{r}{2 \pi}\right]^{1 / 2} \sin \frac{\theta}{2}\left[2-2 v-\cos ^{2} \frac{\theta}{2}\right]
\end{aligned}
$$




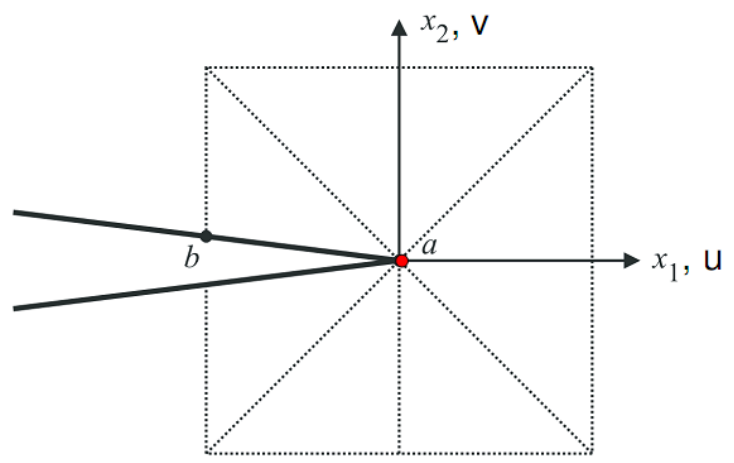

Figure 25. Triangle elements and nodes around the crack tip

From figure 25 , if one sets $\theta=180$ and $r=r_{a b}$, then,

$$
v_{b}-v_{a}=\frac{K_{I}}{\mu}\left[\frac{r_{a-b}}{2 \pi}\right]^{1 / 2}(2-2 v)
$$

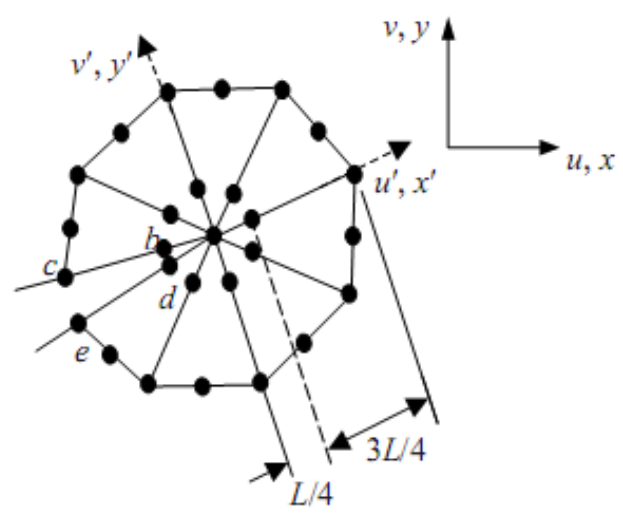

Figure 26. Quarter-point elements and nodes around the crack tip [41] For a quarter-point element, from equation (3.33),

$$
\begin{aligned}
& v_{\text {upper }}=v_{a}+\left(-3 v_{a}+4 v_{b}-v_{c}\right) \sqrt{\frac{r}{l}}+\left(2 v_{a}-4 v_{b}+2 v_{c}\right) \frac{r}{l} \\
& v_{\text {lower }}=v_{a}+\left(-3 v_{a}+4 v_{d}-v_{e}\right) \sqrt{\frac{r}{l}}+\left(2 v_{a}-4 v_{d}+2 v_{e}\right) \frac{r}{l}
\end{aligned}
$$

Then evaluating (3.38) along $\theta=+180^{\circ}, r_{a-b-c}$ and $-180^{\circ}, r_{a-d-e}$, and find the theoretical $v_{\text {upper }}-v_{\text {lower }}$, and equate it to the approximate value in (3.42)

$$
v_{\text {upper }}-v_{\text {lower }}=\left[4\left(v_{b}-v_{d}\right)+v_{e}-v_{c}\right] \sqrt{\frac{r}{l}}+\left[4\left(v_{b}-v_{d}\right)-2\left(v_{e}-v_{c}\right)\right] \frac{r}{l}
$$

Then evaluate $K_{I}$, 


$$
K_{I}=\frac{\mu \sqrt{2 \pi}}{\sqrt{r_{a-b-c}}(2-2 v)}\left[4\left(v_{b}-v_{d}\right)+v_{e}-v_{c}\right]
$$

In the same way, $K_{I I}$ could be evaluated,

$$
K_{I I}=\frac{\mu \sqrt{2 \pi}}{\sqrt{r_{a-b-c}}(2-2 v)}\left[4\left(u_{b}-u_{d}\right)+u_{e}-u_{c}\right]
$$

where $\mu$ is the shear modulus, $v$ is Poisson's ratio, $u, v$ is the local displacement along and normal to crack tip as depicted in figure 26 The same expressions can be used for plane stress assumptions if $v$ is replaced with $v=v /(1+v)$.

\subsubsection{Calculating the direction of crack propagation}

The direction of crack is based on the Maximum Hoop Stress Criterion [12]. The shear stress in cylindrical coordinates:

$$
\sigma_{r \theta}=\frac{K_{I}}{\sqrt{2 \pi r}} \sin \frac{\theta}{2} \cos ^{2} \frac{\theta}{2}+\frac{K_{I I}}{\sqrt{2 \pi r}}\left(\frac{1}{4} \cos \frac{\theta}{2}+\frac{3}{4} \cos \frac{3 \theta}{2}\right)
$$

The value of Hoop Stress is maximum when shear stress in cylindrical coordinates equals to zero. According to the theory, a crack will kink into the direction normal to the maximum hoop stress. So the crack-tip propagates in the direction where $\sigma_{r \theta}$ is zero. Substituting $\sigma_{r \theta}=0$ into Eq. 3.45 we get:

$$
\theta=2 \arctan \frac{1}{4}\left[\frac{K_{I}}{K_{I I}}-\operatorname{sign}\left(K_{I I}\right) \sqrt{\left(\frac{K_{I}}{K_{I I}}\right)^{2}+8}\right]
$$

\subsubsection{Mesh refinement and mesh splitting}

Techniques for mesh refinement around the crack tip can be found in the literature [42,43], but in the present analysis, we adopt a simple approach where we identify a node very close to the crack tip and regenerate a new mesh. Since our mesh generation procedure ensures that the nodes specified in the input file remain unaltered, we automatically get a refined mesh around the crack tip. The numerical results shown in Section 5 demonstrate that this simple approach is sufficient for accurately predicting the crack shape. 
Mesh splitting is achieved by creating new nodes that are geometrically coincident with nodes on the crack's edge. New nodes are then used to form the connectivity of elements on one side of the crack, while the original nodes are used for the elements on the other side. By calculating the cross-product of the crack propagation vector $\vec{a}$ and the vector $\vec{b}$ directed from the crack tip to the centroid of the element, as shown in figure 27 , the side of the element could be determined according to the direction of the cross-product.
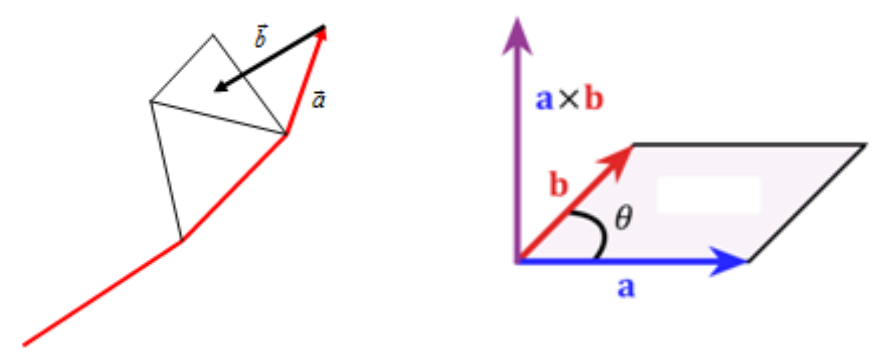

Figure 27. The crack tip vectors (left) and cross-product of $\vec{a}$ and $\vec{b}$ (right)

\subsection{Summary}

This chapter described the framework of ice break-up from wings of aircraft in detail. Ice shape determination, meshing and stress analysis in solid ice are introduced in the first part of the chapter. The $2 \mathrm{D}$ crack propagation package is then described in detail, including the stress field at the crack tip by theory, quarter-point element, evaluation of stress intensity factor (SIF) and determination of crack propagation direction, as well as mesh refinement and splitting. 


\section{Chapter 4 NUMERICAL RESULTS OF 2D ICE BREAK-UP FROM AIRCRAFT WINGS}

Using the framework described in chapter 3 , a benchmark study for validation of the crack propagation package is done in this chapter. Then a series of different ice shapes are simulated to see whether and how ice will break.

\subsection{Benchmark Study}

A well-known geometry used in the evaluation of crack propagation procedure is the single edge cracked plate [42]. Figure 28 shows the problem statement and final mesh of the test case. This plate is fixed at the bottom edge and is subjected to far-field shear stress $\tau=1$ unit along the top edge. The plate has an initial crack length $a=3.5$ units. The modulus of elasticity and the Poisson ratio are $30 \times 10^{6}$ units and 0.25 , respectively. The plane strain condition is assumed in the analysis. Figure 29 shows the comparison of the final crack shape, along with the reference result of Alshoaibi and co-workers [42]. In Alshoaibi's paper, mesh adaptation based on adjoint error estimation around the crack tip is used, while in the present study, only mesh refinement with quarter-point element around the crack tip is adopted. The results are in good agreement. Figure 30 shows the comparison of stress intensity factor I at each step of crack propagation. One can see that the $\mathrm{KI}$ value of the present code is in good agreement with FRANC2D, an open source fracture mechanics code that is highly validated. 

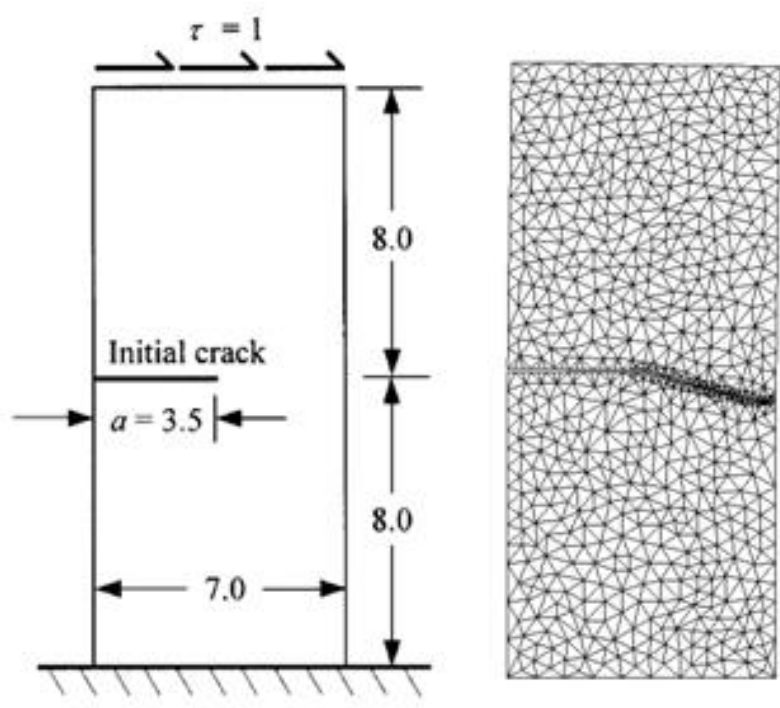

Figure 28. Problem description (left) and final mesh (right) of the single edge cracked plate
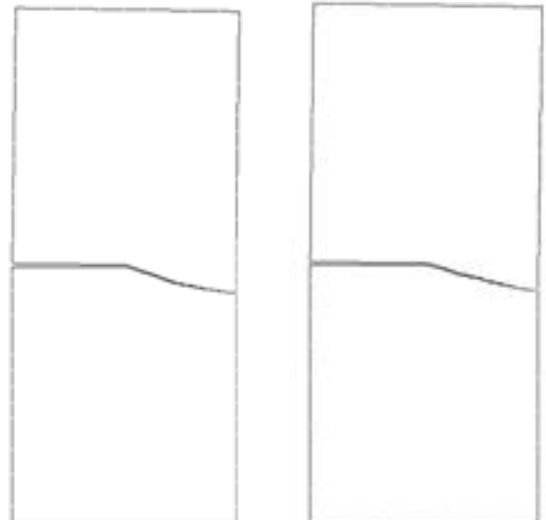

Figure 29. Crack shape for reference result [42] (left) and in-house code (right)

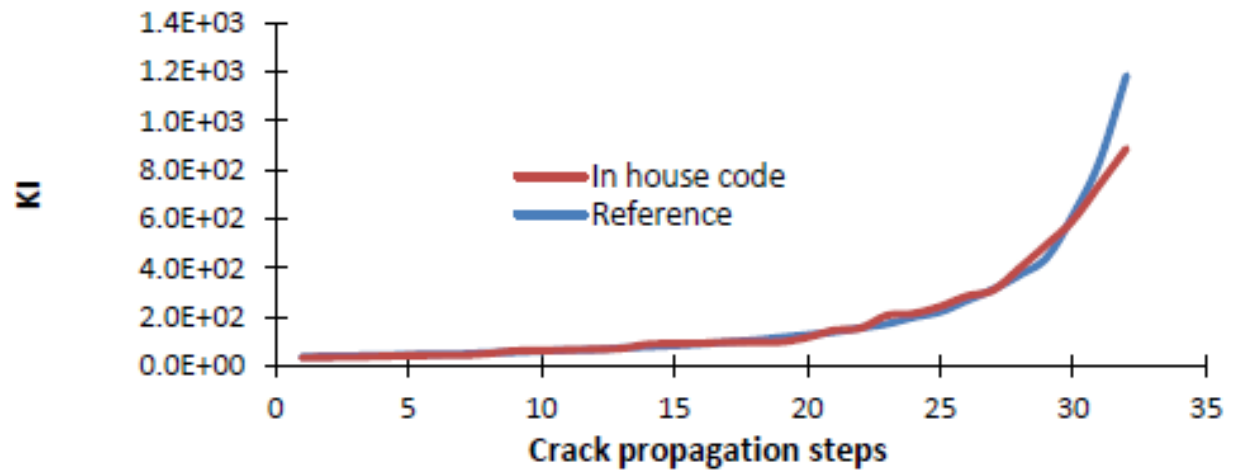

Figure 30. Stress Intensity factor I for reference (Franc2d) result and in-house code 


\subsection{Simulation of Ice Shapes}

The simulation of in-flight icing is performed using FENSAP-ICE [1-2]. The overall solution procedure requires solving the Navier-Stokes equations for flow around the desired shape. Then, employing this flow solution, FENSAP-ICE determines water collection efficiency. Finally, according to the flow and water solutions the equations for ice accretion are solved providing the mass of ice that accretes on the surface. This procedure is repeated for a variety of flow and icing conditions determined by varying parameters like Reynolds number, Mach number, liquid water content (LWC), and droplet median volume diameter (MVD). In the following sub-sections, five different cases are considered, based on the shape of ice resulting from different flow and icing conditions. The resulting ice shapes are then analyzed for break-up by using the procedure of chapter 3 .

\subsubsection{Case I}

In the first test case, we consider an ice shape that appears to be prone to fracture. The ice shape is shown in figure 31 , which also shows the fluid mesh and pressure field experienced by ice. The resulting principal stress 1 and cracked ice are shown in figure 32 and the crack evolution is shown in figure 33. The mesh refinement during the evolution of crack is shown in figure 34 .
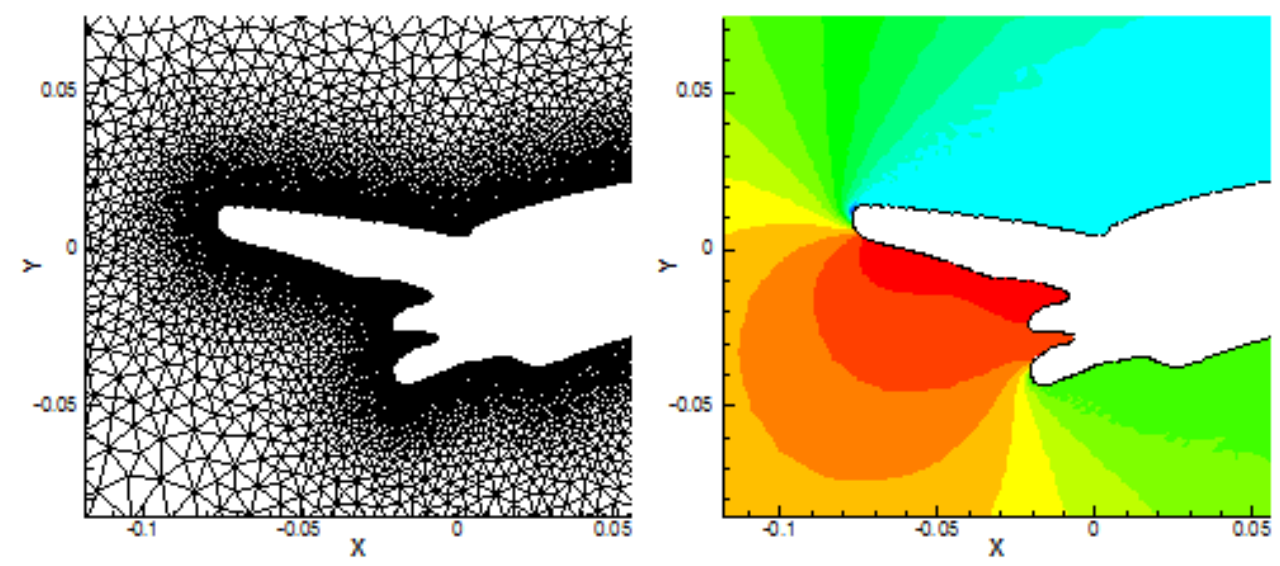

Figure 31. Fluid domain: mesh (left) and pressure field (right) 

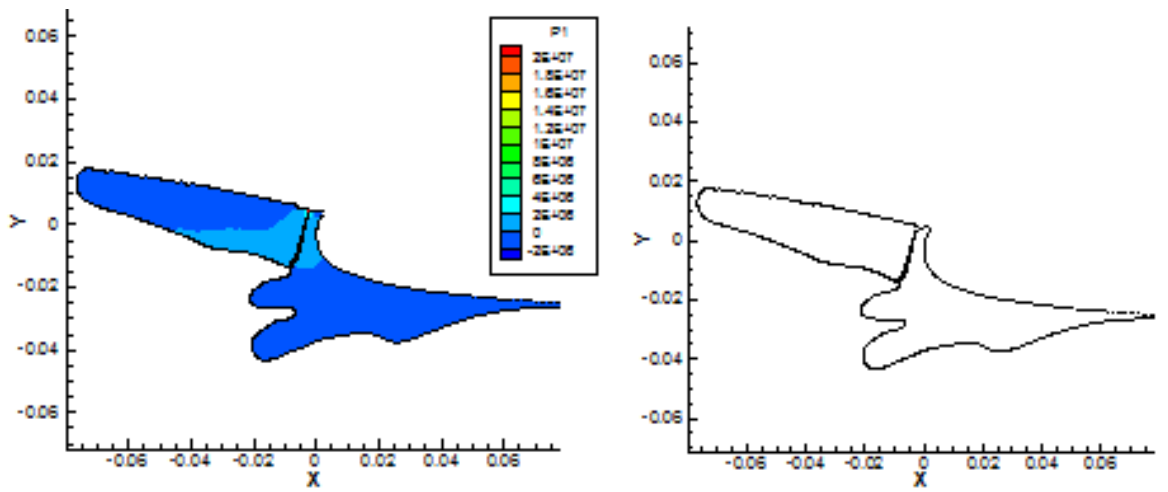

Figure 32. Solid (ice) domain: principal stress 1 (left) and cracked ice (right)

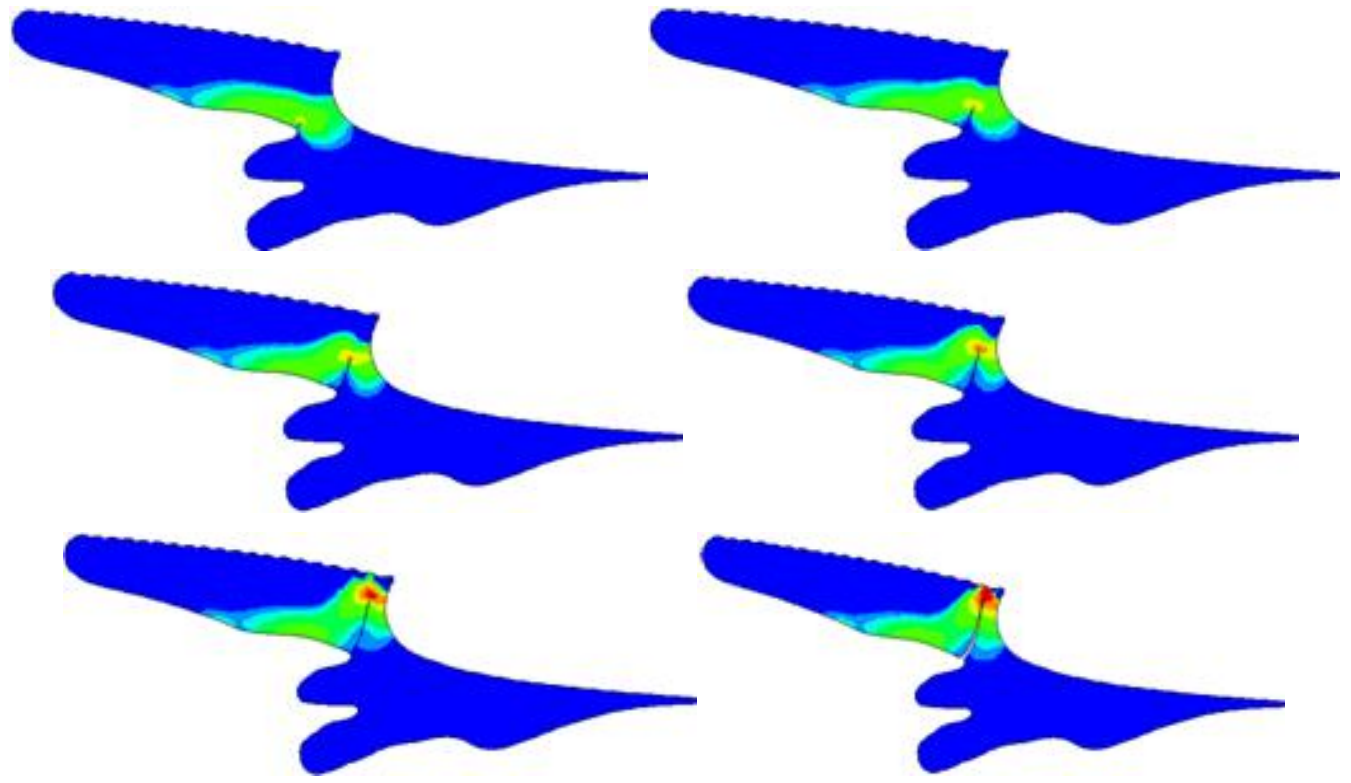

Figure 33. Evolution of crack (from top, right to left) and principal stress 1 distribution
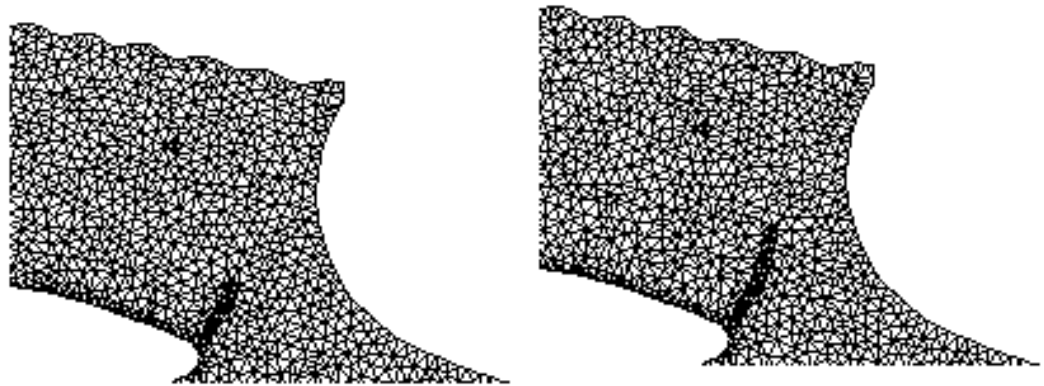

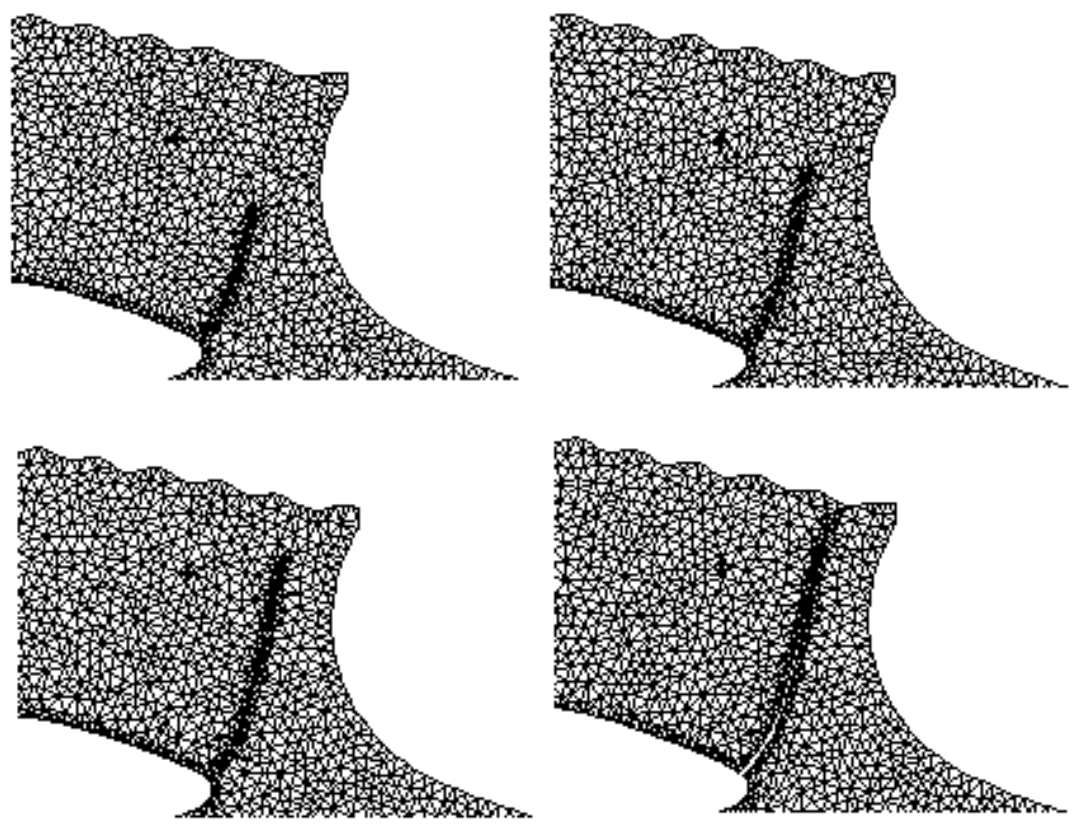

Figure 34. Mesh refinement during the evolution of crack (from top, right to left)

The crack prediction capability presented in this thesis is compared with an open source fracture mechanics code - FRANC2D [44], a state-of-the-art crack propagation software developed at Cornell University, which uses linear elastic fracture mechanics. In spite of similar approaches, there are some differences in the two codes such as: FRANC2D uses quadratic elements [45], whereas we propose in this case linear triangular elements. Figure 35 shows the meshes used for this comparative study. FRANC2D mesh consists of 7,746 quadratic elements, while the in-house code in this case employed only 4,560 linear triangular elements. The number of nodes for FRANC2D and in-house meshes are 16,207 and 2,627 , respectively, a ratio of $6: 1$. This is done to demonstrate that low order elements and relatively coarse meshes are sufficient for this analysis, as long as mesh refinement is done at each step near the crack tip. Figure 36 shows the comparison of principal stress 1 obtained by the two codes. Both the maximum stress and its location are in good agreement. The crack shapes obtained by the two codes are shown in figure 37. Again, a good agreement is observed. Figure 38 shows a comparison of $\mathrm{KI}$ obtained by Franc2d and the present code. 

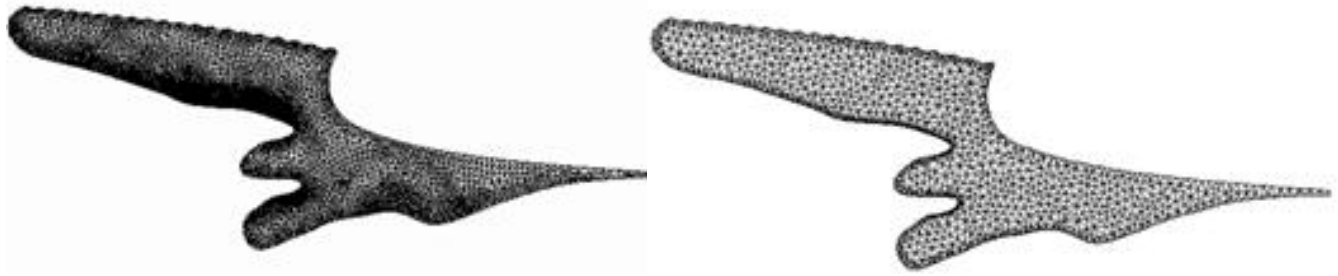

Figure 35. FRANC2D mesh (left) and in-house code mesh (right)

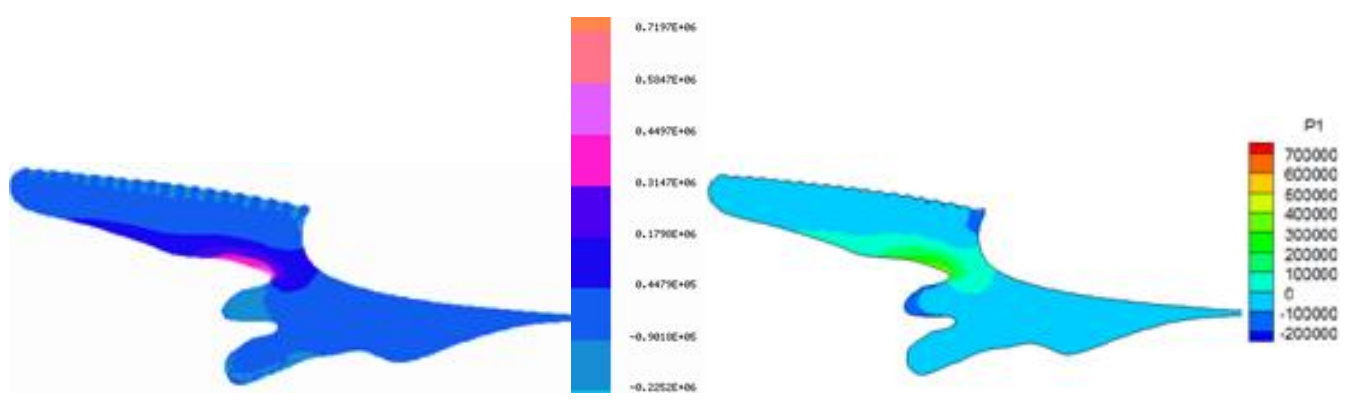

Figure 36. Principal stress 1 distribution for FRANC2D (left) and in-house code (right)

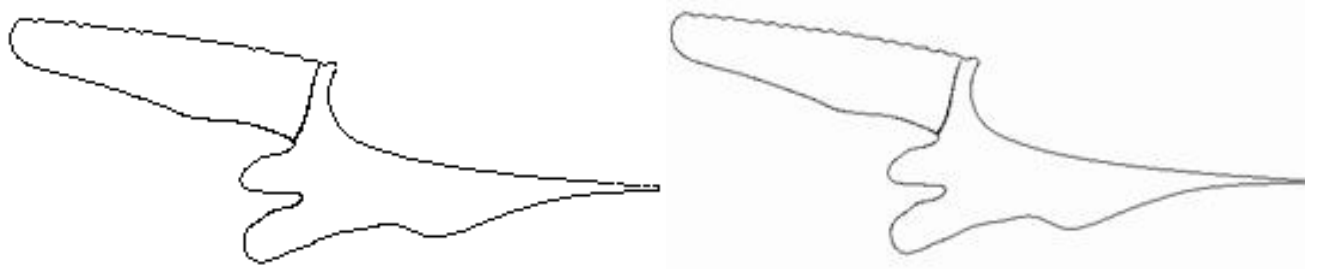

Figure 37. Comparison of crack shape in ice between FRANC2D (left) and in-house code (right)

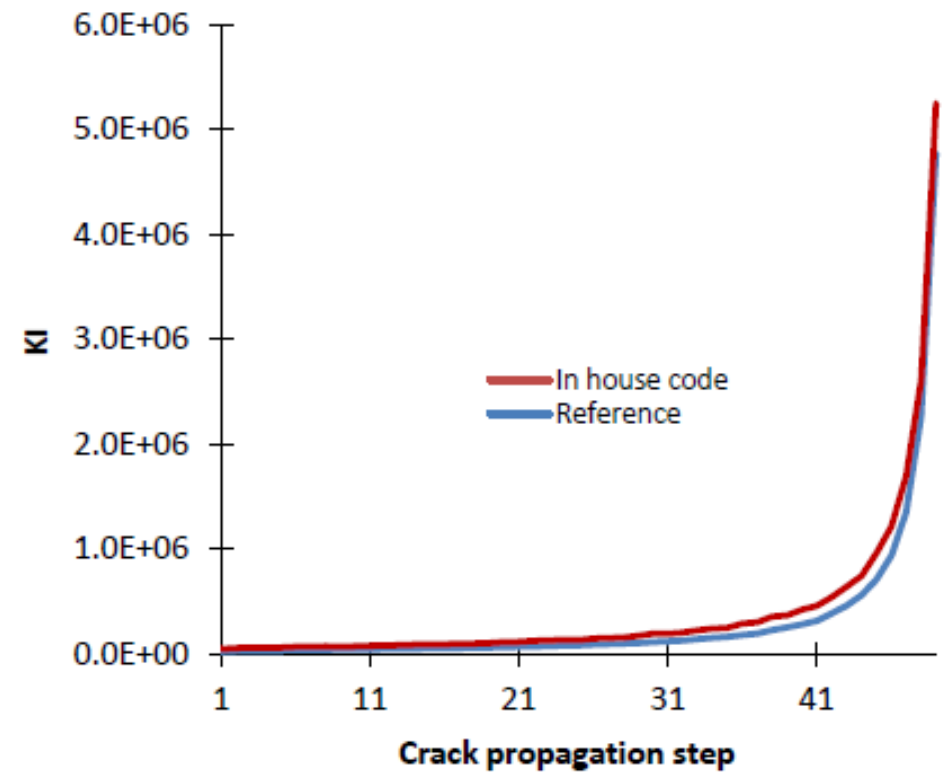


Figure 38. Stress Intensity factor I for reference (Franc2d) result and in-house code

\subsubsection{Case 2}

The accretion of ice on a NACA 0012 airfoil for 231 seconds is considered here. This test case is taken from the NASA CD-ROM [case AE1030336]. The multishot computation is split into 15 steps of 15 seconds of ice accretion each, plus a final step of 6 seconds of ice accretion [46]. The freestream Mach and Reynolds numbers are, respectively, 0.316 and $4.376 \times 10^{6}$. The angle of attack of the airfoil is $4^{\circ}$. The conditions of the air in terms of LWC and MVD are, respectively, 1 $\mathrm{g} / \mathrm{m}^{3}$ and $20 \mu \mathrm{m}$. Figure 39 shows the comparison of principal stress obtained by the two codes. The results are in good agreement and the region of ice under tension can be seen in both simulations. The initial crack was placed in that region but the crack did not propagate.

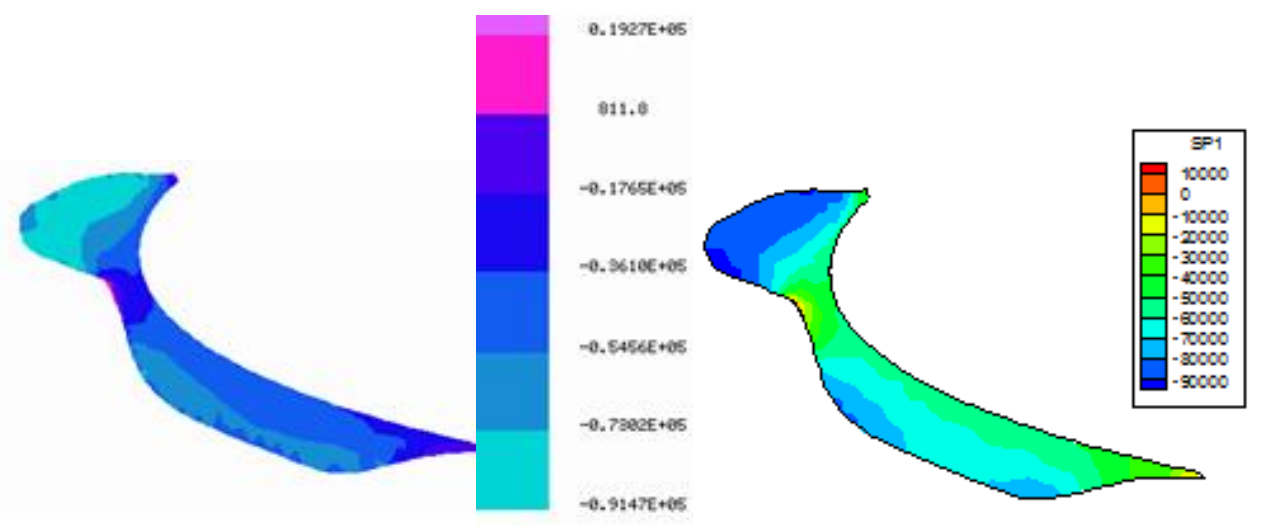

Figure 39. Principal stress 1 distribution for FRANC2D (left) and present code (right)

\subsubsection{Case 3}

This next multi-shot test case is also taken from the NASA CD-ROM [case AE1001836]. The freestream Mach and Reynolds numbers are, respectively, 0.21 and $3.03 \times 10^{6}$. The angle of attack of the airfoil is $4^{\circ}$. The conditions of the air in terms of LWC and droplet MVD are, respectively, $1.0 \mathrm{~g} / \mathrm{m}^{3}$ and $20 \mu \mathrm{m}$. The ice accretion time is 360 seconds and the multi-shot computation is split into 6 equal steps of 60 seconds of ice accretion [47]. Figure 40 shows the principal stress 1 in ice and since the entire ice is under compression, no crack is initiated. 


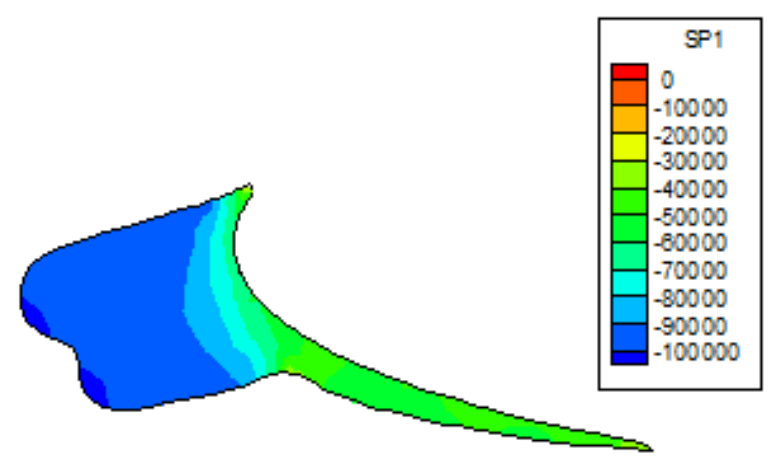

Figure 40. Principal stress 1 distribution obtained by the in-house code

\subsubsection{Case 4}

The next case is also taken from the NASA CD-ROM [case AE1033136. The free stream Mach and Reynolds numbers are, respectively, 0.207 and $2.88 \times 10^{6}$. The angle of attack of the airfoil is $0^{\circ}$. The conditions of the air in terms of LWC and MVD are, respectively, $1.3 \mathrm{~g} / \mathrm{m}^{3}$ and $30 \mu \mathrm{m}$. The total ice accretion time is 336 seconds and the multi-shot computation is split into 10 equal steps of 33.6 seconds of ice accretion [47]. Figure 41 shows the principal stress 1 in ice and since the entire ice is under compression, no crack is initiated.

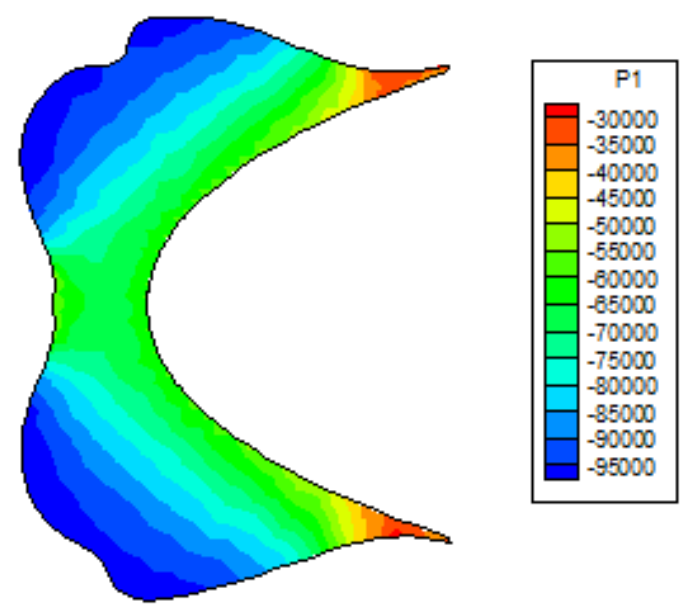

Figure 41. Principal stress 1 distribution obtained by the in-house code

\subsubsection{Case 5}

The business jet main wing airfoil used in this test is based on a GLC-305 airfoil [48]. For ice accretion simulations, the freestream Mach and Reynolds numbers 
are, respectively, 0.275 and $6.3 \times 10^{6}$. The angle of attack of the airfoil is $4^{\circ}$. The conditions of the air in terms of LWC and MVD are, respectively, $0.54 \mathrm{~g} / \mathrm{m}^{3}$ and $20 \mu \mathrm{m}$ and the total ice accretion time is 22.5 minutes. The multi-shot computation is split into 90 equal steps of 15 seconds of ice accretion [47]. Figure 42 shows the principal stress 1 in ice and since the entire ice is under compression, no crack is initiated.

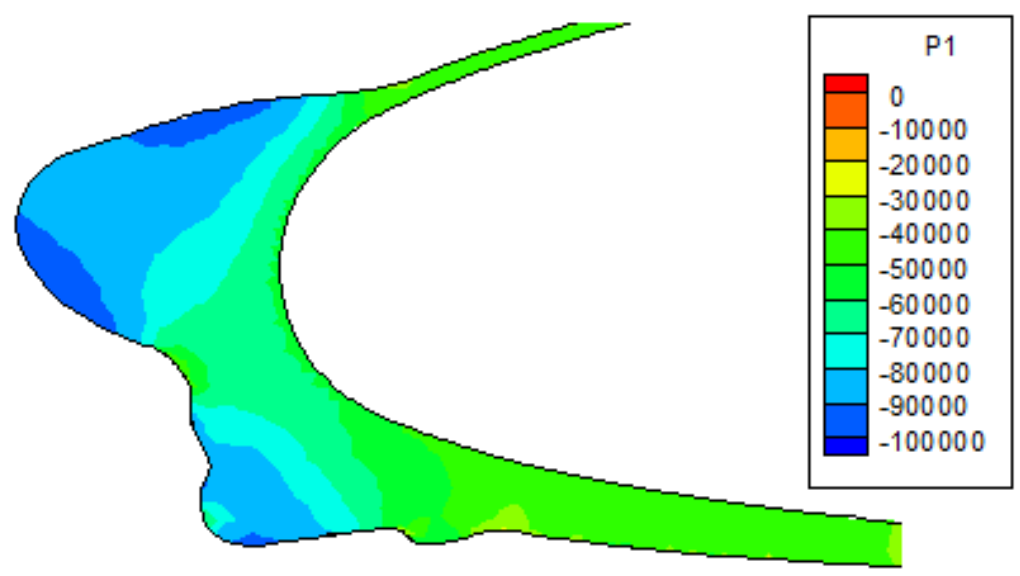

Figure 42. Principal stress 1 distribution obtained by the present code

\subsection{Summary}

In this chapter, several complicated ice shapes are analyzed and comparison is performed with a contemporary fracture mechanics code-Franc2D. From these analysis and simulations, it can be seen that the breaking of ice has a strong dependence on its shape, i.e. under similar aerodynamic loadings, some ice shapes failed while others did not. One of the ice shapes cracked in two parts, while for another shape, a crack initiated but did not propagate. The rest of the ice shapes did not crack, indicating that the ice break-up highly depends on the shape of ice. 


\section{Chapter 5 3D ICE SHEDDING FROM HELICOPTER BLADES}

Traditionally, helicopter operating manuals have addressed the issue of in-flight icing and its effect on helicopter performance with a caution or a warning to the pilot to avoid an icing environment. Such restriction and limitations were acceptable when helicopters were viewed as aircraft operating primarily in visual meteorological conditions. Since early helicopters lacked the equipment and sophisticated systems normally employed for flight in instrument meteorological conditions, there was little justification for expending valuable time and resources on helicopter icing research and development [4]. However, modern helicopters have a greatly expanded concept of operations, in some scenarios, for example, emergency rescue, the icing environment is unavoidable. Hence, it is this expansion of the helicopter's operating envelope that compels a more thorough understanding of the hazards associated with in-flight icing.

Beside the effect on lift, drag, weight and thrust, another key hazard of in-flight icing for helicopters is ice shedding. The shedding of rotor blade ice is welcomed from the view of removing the ice from the blades. Unfortunately, it is as likely to create a problem as it is to relieve one. The most dangerous among them are the severe blade vibration, shedding ice ingestion and ballistic impact.

Ice shedding can create severe vibrations. The severity of the vibration has been documented by test pilots engaged in conducting natural icing studies with helicopters. Their reports identify numerous occasions where in-flight icing tests were aborted due to main rotor blade icing and subsequent asymmetrical shedding which caused vibrations so severe that it became all but impossible to read the instrument panel [4].

Due to a series of hazards caused by ice shedding from rotor blades, it is important to investigate and analyze the process of in-flight ice shedding. 


\subsection{Ice Accretion on Helicopter Blades}

The simulation of in-flight 3D icing is performed using FENSAP-ICE [1-2]. Caradonna hover test case 8 [57] has been used for the flow solution. The rotor has two untwisted and untapered blades which have a rectangular platform, comprised of a NACA 0012 airfoil section with a rotor radius of $1.143 \mathrm{~m}$ and an aspect ratio of 6 . The flow and droplet solutions are computed in rotational reference for the rotor speed of 400 rpm and collective pitch angle of 8 degrees. Ice accretion is also modeled in rotational reference at ambient temperature of $19^{\circ} \mathrm{C}$, liquid water content (LWC) of $1 \mathrm{~g} / \mathrm{m}^{3}$ and droplet mean value diameter (MVD) of 20 microns. The turbulence model is the one-equation Spalart-Allmaras model and the total ice accretion time is 120 seconds. Figure 43 shows the ice accumulation on the blades.

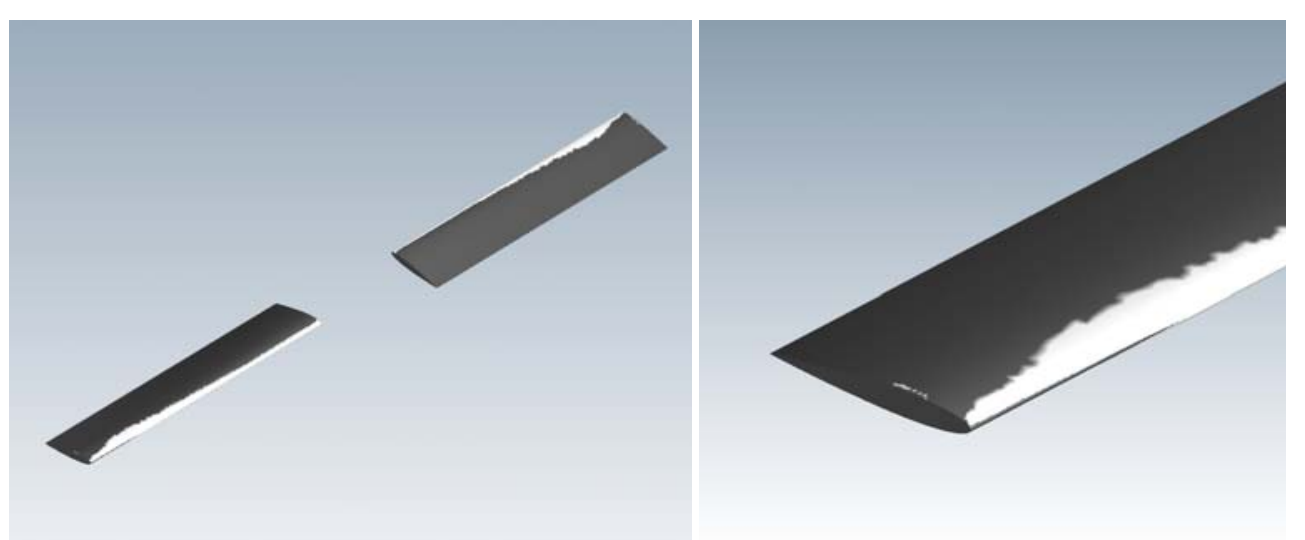

Figure 43. Ice accretion on helicopter blades

\subsection{Identification of Ice Shape and Boundary Conditions}

$3 \mathrm{D}$ ice shape determination requires the input from ice accretion solution. Figure 44 shows the grids on clean and iced blade. Since the mesh motion during the ice accretion is performed by employing ALE-based mesh motion scheme, there is one-to-one correspondence between the nodes in the clean and iced grids. The shape of ice, as shown in Figure 45-left, is determined by comparing the distances of each node on the wall of the clean airfoil to each node on the wall of the iced airfoil. A facet-bounded surface mesh of the 3D ice (Figure 45-right) is 
obtained from the nodes on the clean blade and the iced surface. The surface mesh is also the boundary of the computational domain of the solid (ice) mesh and is thus divided into Dirichlet and Neumann nodes.

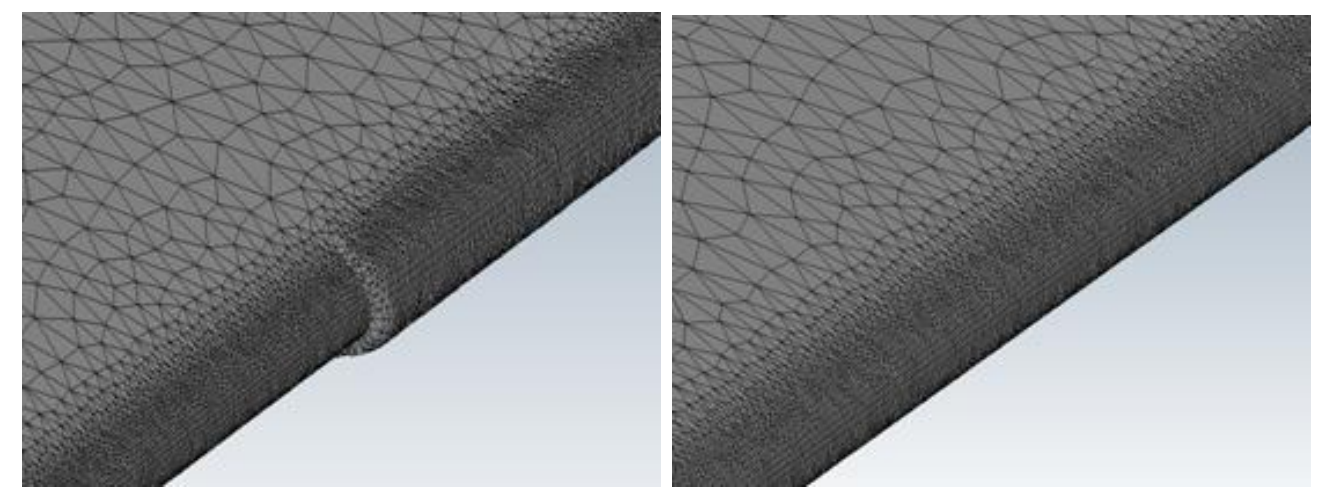

Figure 44. Grid on the clean airfoil (left), grid on the iced airfoil (right)
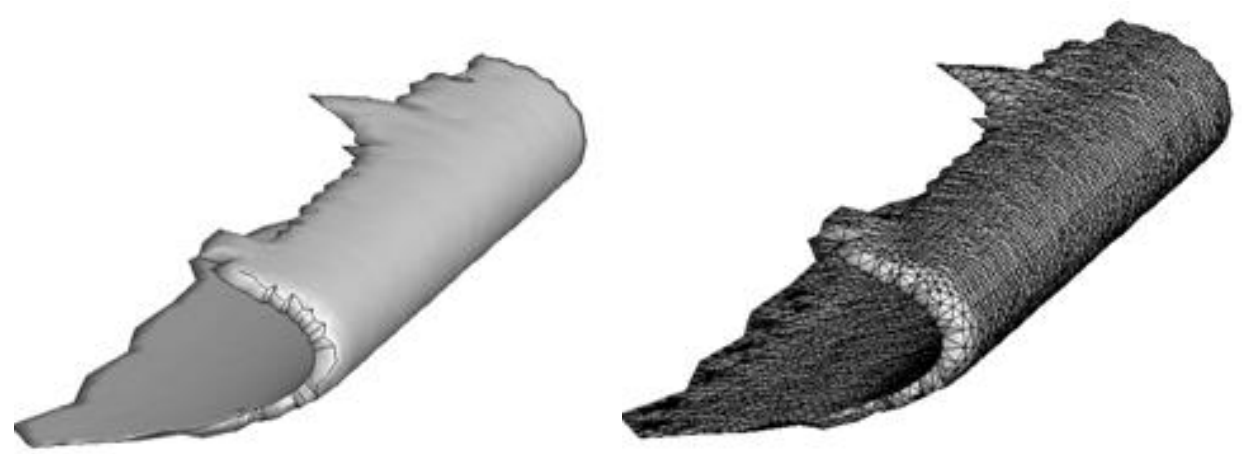

Figure 45. 3D ice shape obtained from blade (left) surface mesh of the ice (right)

\subsection{Meshing}

The meshing in the ice is done by using an open source code named TetGen [49]. The completely facet-bounded surface mesh consisting of the boundary nodes is the input to the code and a mesh of unstructured linear tetrahedral elements is produced based on Delaunay tetrahedralization. 

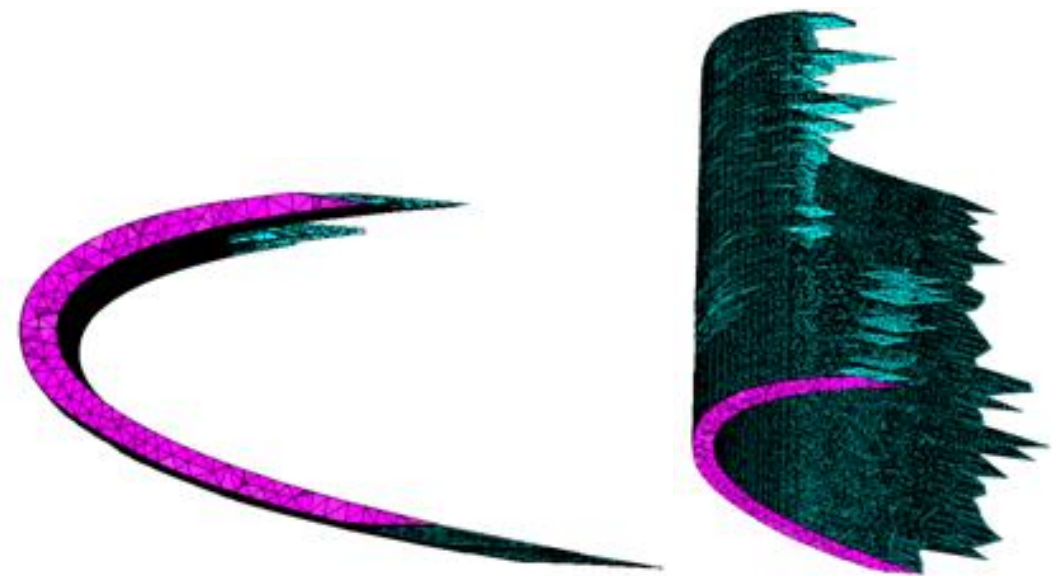

Figure 46. Tetrahedral volume mesh of ice generated by TetGen

\subsection{Stress Analysis}

For the ice on helicopter blades, the net aerodynamic force is considered to be negligible compared to the centrifugal force [51]. Hence centrifugal force is the only driving force for ice shedding in this analysis. The centrifugal force [21] is given by:

$$
\boldsymbol{f}_{c f}=\rho V r \omega^{2}
$$

where $\boldsymbol{f}_{c f}$ is the centrifugal force, $\rho$ is the density of ice, $V$ is ice volume in the element, $r$ is the radius of the element from the root of the blade, and $\omega$ is the rotational speed. In the present study, the density of ice is considered as 920 $\mathrm{kg} / \mathrm{m}^{3}$, the volume is calculated from the tetrahedral element, and $r$ is calculated from the centroid of the element. Total span of the blades is 1.143 meters but in order to save the computational cost, only a section of blade that is 0.3 meter from the tip, is considered. The rotational speed used here is $400 \mathrm{rpm}$, which is typical for helicopter blades. Figure 47 shows the stress distribution inside the ice. 


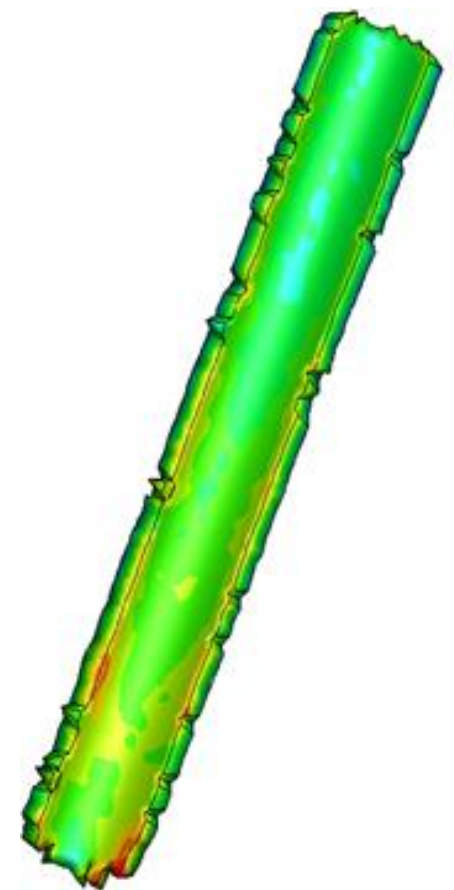

Figure 47. Stress distribution at the ice-airfoil interface shear stress (left) and principal stress (right)

\subsection{Interface Bond Breaking}

From literature review, the cohesive strength (tensile strength) of ice is about 1 to $2 \mathrm{MPa}$ [17], the adhesive strength (shear strength) of ice with Aluminum at $-11^{\circ}$ varies from 0.3 to $1.6 \mathrm{MPa}$ [50]. For polymeric or carbon fiber composite materials, the adhesive strength with ice is much lower than Aluminum [18]. The surface roughness also affects adhesive strength at the interface according to reference [51]. From the earlier experiment on the adhesion properties of ice with different materials [18] and numerical analysis of ice shedding on helicopter blade [21], ice will start to break or yield at the interface between airfoil and ice, and when the principal stress in the ice reaches the critical value of cohesive strength, a tensile crack will start to propagate inside the ice. Figure 48 shows a cut section of principal stress distribution within the ice, and the stress concentration at the interface is clearly visible. 


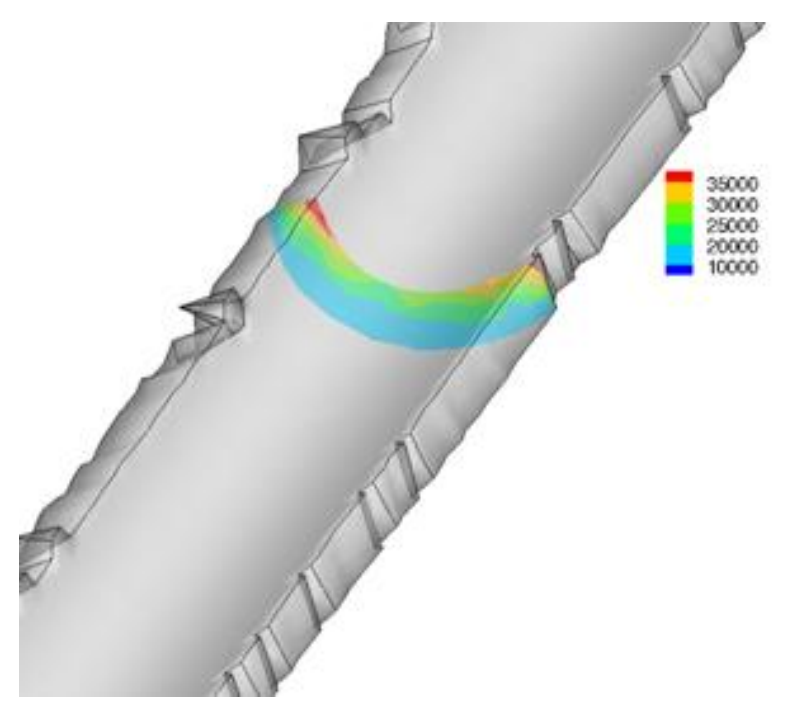

Figure 48. Cut section stress distribution of principal stress 1

In the present study, shear stress, principal stress as well as Von-Mises stresses are checked at each crack propagation step. If either the shear stress or VonMises stresses reaches the critical value, the interface bond between ice and airfoil breaks. Figure 49 shows the interface bond breaking process. In the mean time, the maximum principal stress has to be checked at each step, since once the maximum cohesion stress is reached a crack inside the ice will initiate. Figure 50 shows the maximum principal stress evolution. 

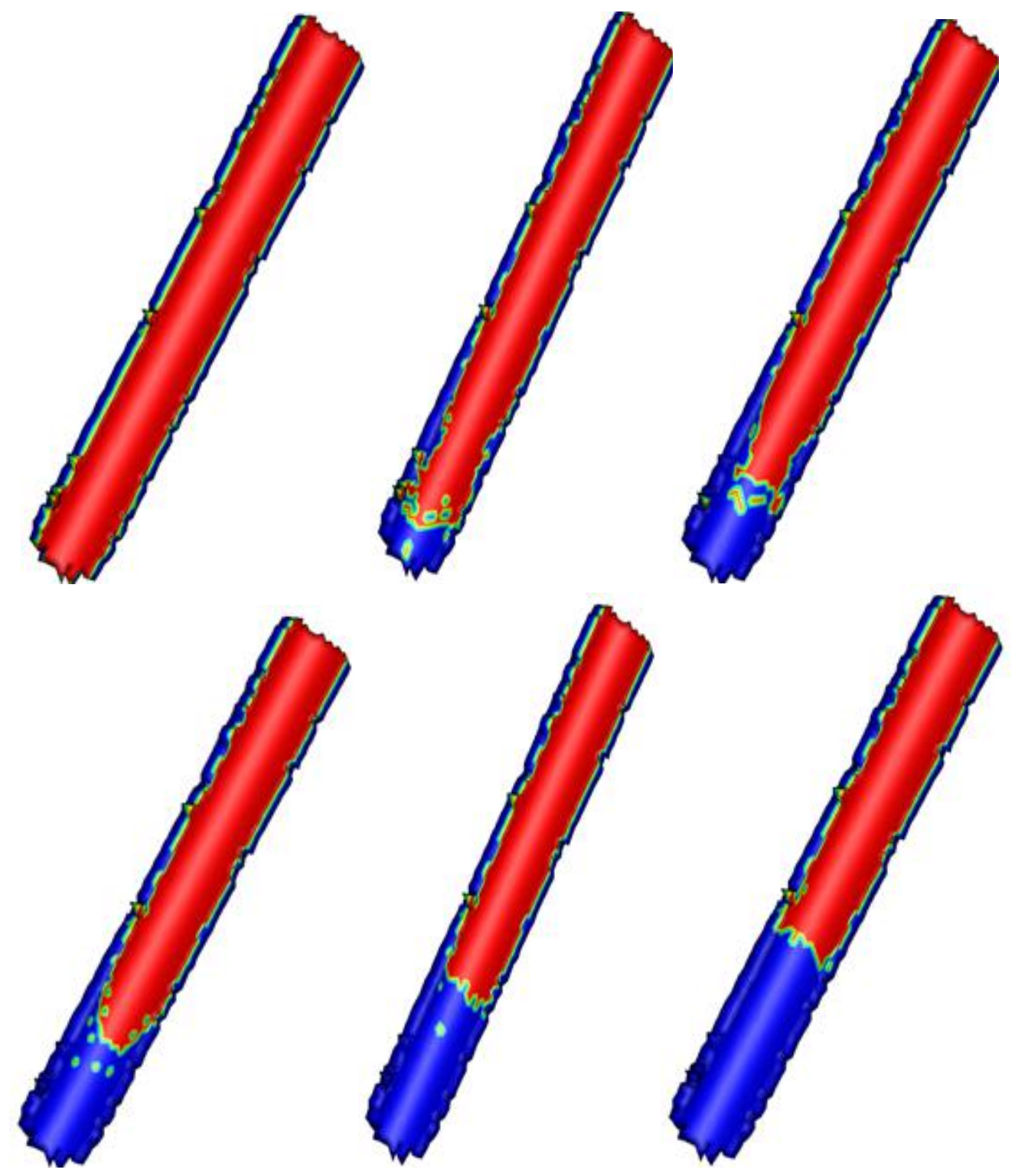

Figure 49. Interface bonding breaking process (red represent the bonding area) 


$$
\text { III }
$$


refinement is adding new nodes to the edge whose first derivative of principal stress over the length of edge has reached a critical value, as shown in (5.2).

$$
\left|\frac{a_{i 1}-a_{i 2}}{\Delta l_{i}}\right| \geq c
$$

Where $a_{i 1}$ and $a_{i 2}$ are the values of interest, like principal stress I or shear stress, on node 1 and node 2 of the edge. $\Delta l_{i}$ is the length of the edge. $c$ is the critical value setting by the user.

Fig. 51 shows the mesh adaptation along with the interface bond breaking process. It can be seen that the mesh refinement successfully captured the process of interface bond breaking process, i.e. the mesh refinement is in the region of bond breaking transition. 

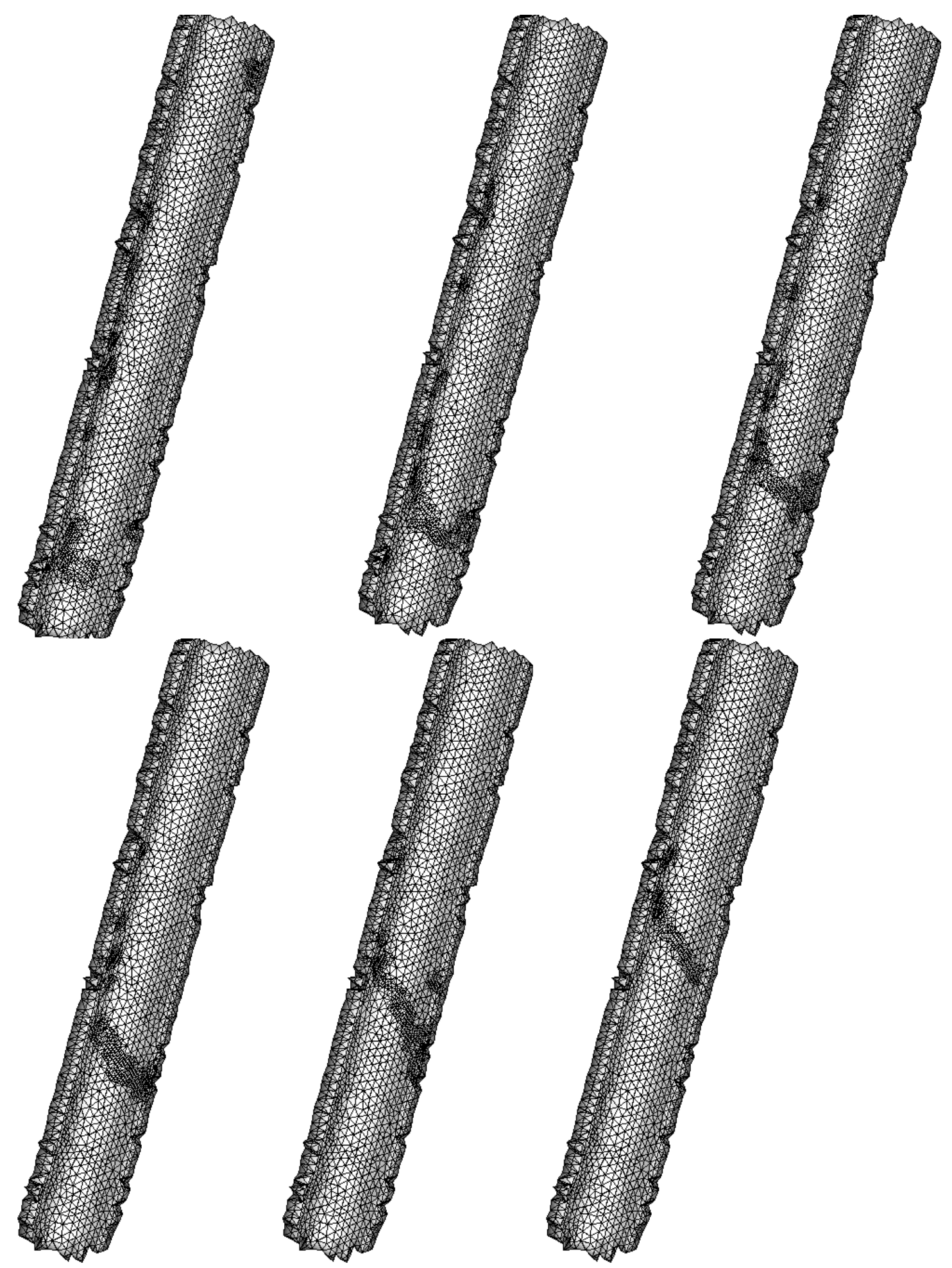

Figure 51. Mesh adaptation in the process of interface bond breaking 


\subsection{D Crack Propagation}

Crack propagation inside the ice is using the present 3D crack propagation method. This method is developed for the evaluation of 3D crack growth processes under general mixed mode loading conditions. Based on the finite element method, the method predicts quasi-static crack growth in 3D components. Through out the simulation of crack propagation, automatic mesh manipulation and refinement are carried out in the vicinity of the crack front nodes. Figure 52 shows the overall structure of the 3D crack propagation method. It is established modularly and it is divided into three parts. During the simulation sequence, these three independent modules are invoked successively.

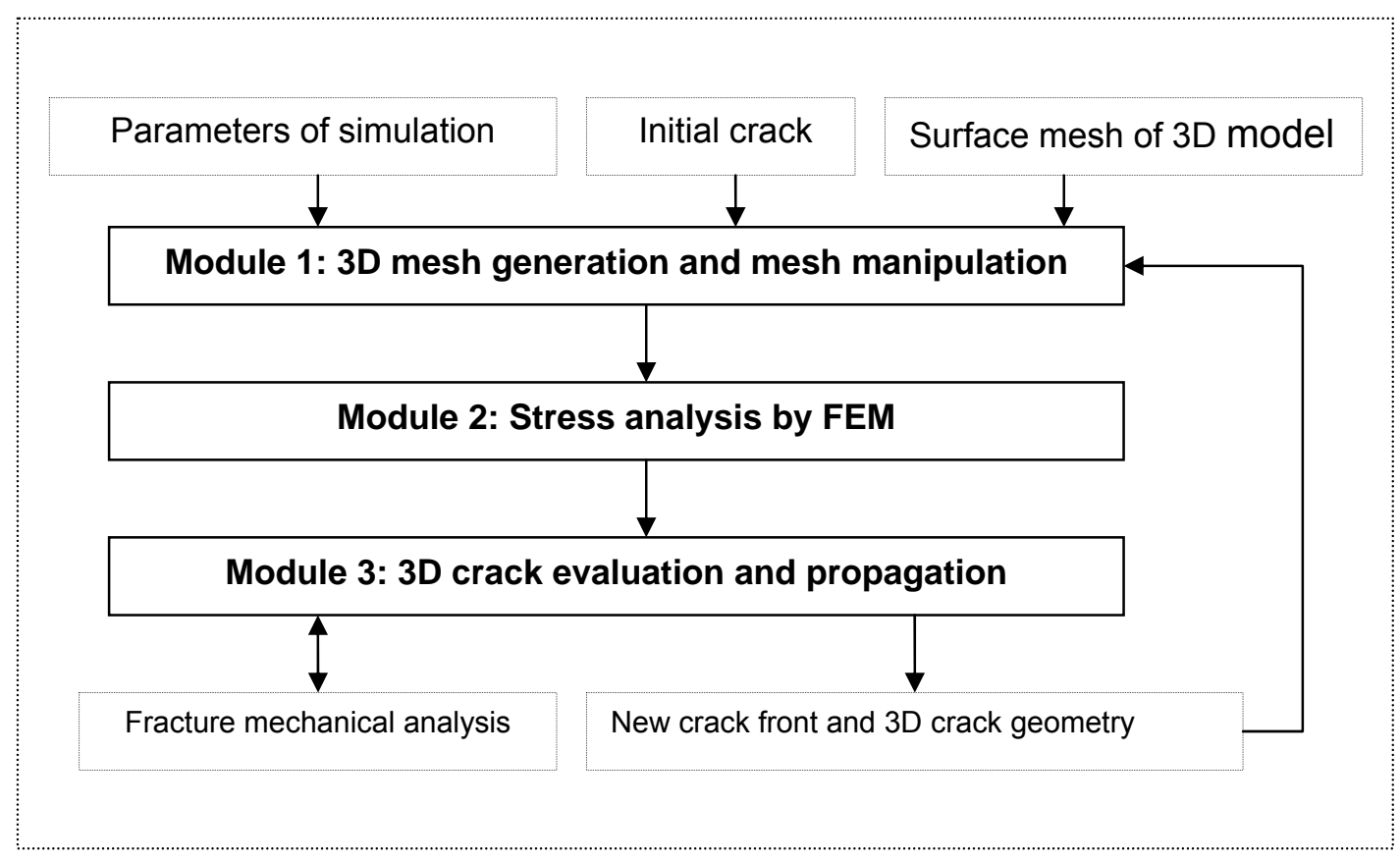

Figure 52. Structure of in-house 3D simulation package

The first module contains all the necessary algorithms for mesh generation and mesh manipulation. It reads data from three input files, i.e. a file containing the parameters of simulation, like maximum crack growth increment and materials properties; a second file containing initial crack information and a file containing surface mesh which describes the geometry of the object. For the file of initial 
crack, after the first crack propagation step, it will be injected with new crack front information. The mesh generation step employs the open source tetrahedral element mesh generator - TetGen, to generate high quality volume mesh. In the crack propagation process, a new crack is inserted into the ice at each step. The insertion of a crack into the mesh of a model needs efficient mesh manipulation, considering the geometric complexity of 3D crack and the demand of high quality mesh in the vicinity of the crack front.

There are two different methods to insert a crack into the model. One approach is to insert a crack face into the meshed model, and then splitting the mesh [52]. This method is straight forward but can lead to a very complex mesh splitting process and lead to a bad quality mesh, requiring a mesh improvement algorithm. In the present package, however, another mesh insertion method is implemented. Instead of inserting a 3D crack face into the model directly, we first create a duplicate surface of the crack face where all of the nodes and connectivity are duplicated except for the crack front nodes and edges as shown in figure 53. Consequently, the duplicated surface and the original crack face are connected at the crack front, which forms a single surface. The next step is to insert this connected surface into the previous surface mesh of the model. Then a completely facet-bonded or waterproof model containing the crack described by surface mesh is obtained, as shown in figure 54 . Using this surface mesh, it is very easy to obtain a volume mesh of the domain with high quality in the vicinity of the crack front. The main advantage of this method is that the mesh splitting process is greatly reduced, as we only need to split a very small part of the surface mesh. Another advantage of the present method is mesh refinement. This can be achieved conveniently by just inserting more nodes at the crack face near the front, as the Constrained Delaunay Tetrahedralization will automatically generate a refined mesh with high quality based on these nodes [53]. 


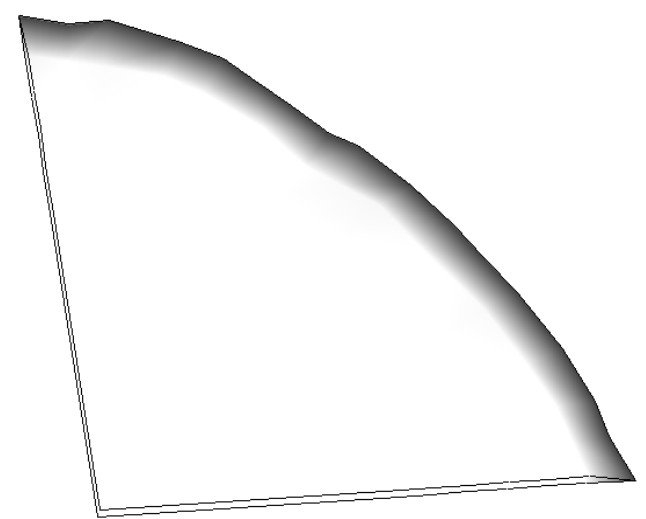

Figure 53. Duplicated crack surface
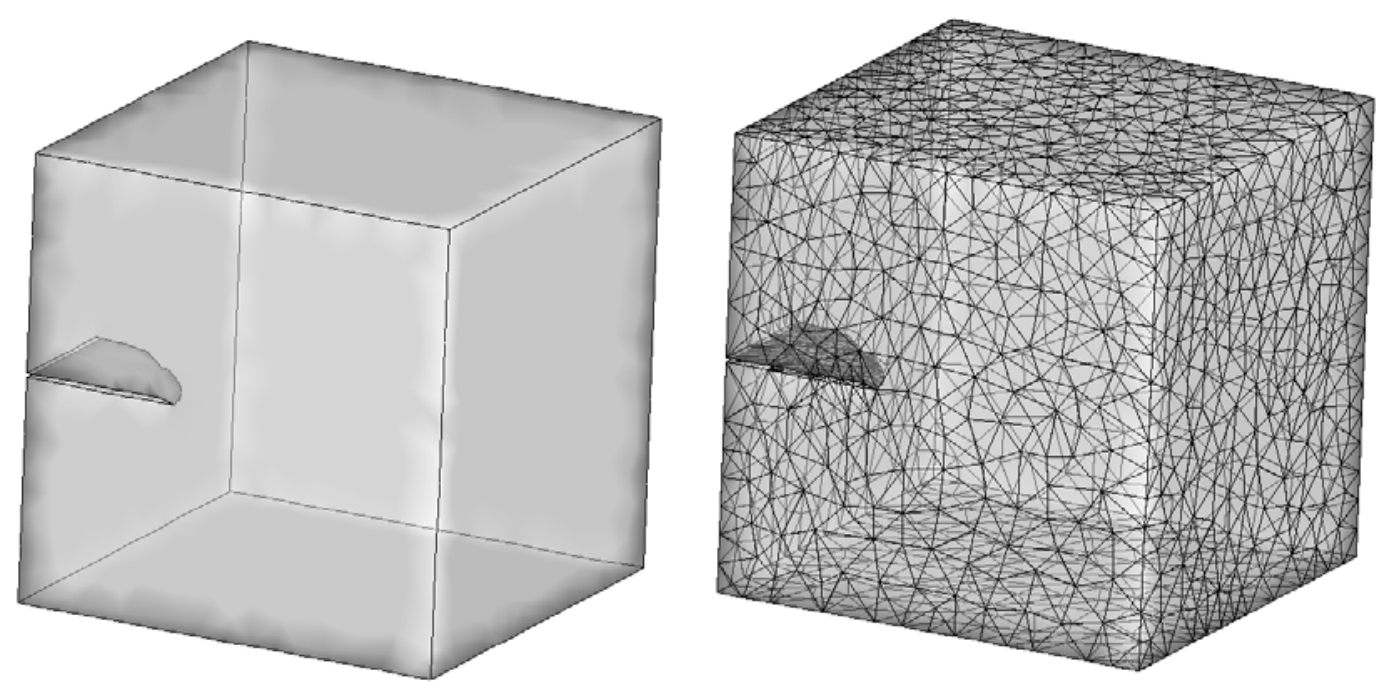

Figure 54. Crack inserted model

The second module is the stress analysis. Employing the FEM and the appropriate boundary conditions, the displacements and stresses can be calculated. The advantage of using FEM for stress analysis is that the crack propagation simulation package can be compatible with several other commercial stress analysis packages, where FEM is widely used.

The third module comprises the algorithms for 3D crack evaluation and propagation, which is the key component of the package, as the calculation of crack growth is the main task of the $3 \mathrm{D}$ crack propagation simulation package. The inputs of this module consist of the stress analysis result, current step crack 
geometry and crack front nodes information. The outputs are a new crack geometry and a new crack front.

\subsubsection{Tracking 3D crack propagation}

There are many criteria for tracking a propagating crack. Considering the simplicity and ease of implementation, the maximum principal stress criterion is adopted. The basic assumption is that the crack propagation direction is perpendicular to the maximum principal stress direction. Hence, the calculation of maximum principal stress and its direction are the prerequisites for predicting crack propagation.

According to the theory of elasticity, the maximum principal stress and its direction are obtained by solving an eigenvalue problem with a given stress tensor. Given $\sigma$ find $\boldsymbol{v}$ and $\lambda$ with such that:

$$
\sigma . v=\lambda v
$$

Where $\sigma$ is the stress tensor obtained from stress analysis, $\boldsymbol{v}$ is the Eigenvector or principal stress direction vector, $\lambda$ is the principal stress value. Solving this Eigenvalue problem is as follows:

1). Check that $\sigma$ is symmetric

2). Calculate characteristic equation: $\operatorname{det}\left(\sigma_{i j} \lambda \delta_{i j}\right)=0$

3). Solving characteristic equation to get the 3 Eigenvalues $\lambda^{(1)}, \lambda^{(2)}, \lambda^{(3)}$

4). For each Eigenvalue find its associated eigenvector, which is the principal stress direction by solving: $\left(\sigma_{i j}-\lambda^{(m)} \delta_{i j}\right) v_{j}^{(m)}=0$, where $\sigma_{i j}$ is the index notation form of stress tensor, $\delta_{i j}$ is the Kronecker delta, $\lambda^{(m)}$ and $v_{j}^{(m)}$ are the Eigenvalue and Eigenvector in index notation form. 


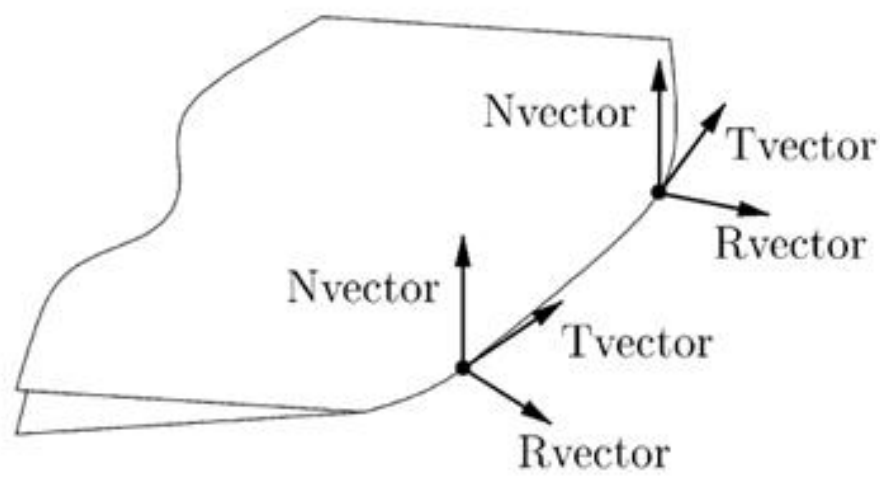

Figure 55. Local coordinate system along the crack front

After obtaining the principal stress and its direction, the crack propagation front is predicted by constructing a local coordinate system at each node on the crack front. Figure 55 shows the local coordinate system along the crack front. The local coordinate system consists of three vectors, i.e. tangential vector, Tvector, normal vector, Nvector, and propagation direction vector, Rvector. Among these three vectors, the normal vector is the direction of maximum principal stress, which could be calculated from the principal stress. The tangential vector is calculated from the crack front geometry, i.e. nodes' coordinates. Then the propagation vector will be calculated from the cross product of tangential vector and the normal vector. Hence, through these local coordinate systems, the crack propagation of each node is obtained.

\subsubsection{Determination of crack growth increments}

For $2 \mathrm{D}$ problems, the increment for crack extension is adjusted in each step according to the stress intensity factor. With the same idea, the 3D crack growth increments are varied both in different steps and in different locations of the same step. In the present crack propagation package, the crack growth process is driven by a user-defined maximum crack growth increment. In the crack face generation process, it is formed by a series of accumulated crack fronts, and then forming the connectivity of the whole surface. Hence extremely small crack extensions (or even "zero extension", if the maximum principal stress is below 
the threshold) would cause enormous numerical problems, as the crack surface mesh would degenerate. Therefore, an algorithm is implemented that adjusts the crack growth increment $\Delta a_{i}$ of all crack front nodes $i$ to a range of $0.33 \cdot \Delta a_{o} \leq \Delta a_{i} \leq \Delta a_{o}$, where $\Delta a_{o}$ is the user defined maximum crack growth increment. This simple approach is motivated by the recognition that some nodes of crack front will always have maximum principal stress below the critical value and others permanently above. In fact, for any given initial crack configuration within a few steps, a steady state with a self-similar crack growth will be reached. Thus this simple approach produces reliable results after a few steps, in the numerical setting [52].

\subsubsection{Crack propagation algorithms validation (Benchmark study)}

Based on the crack propagation algorithms described above, a benchmark study of 3D out-of-plane crack propagation is taken here. In this numerical example, a three points bending test of the cracked specimen shown in Fig. 56 is simulated. The case is interesting because the crack is initially inclined with respect to the load direction, which causes a high kink angle at the beginning of the propagation. The crack is subjected to a mixed mode loading condition and a twisted propagation is obtained. The problem has been solved in [54] and the solution reported there is taken as reference.

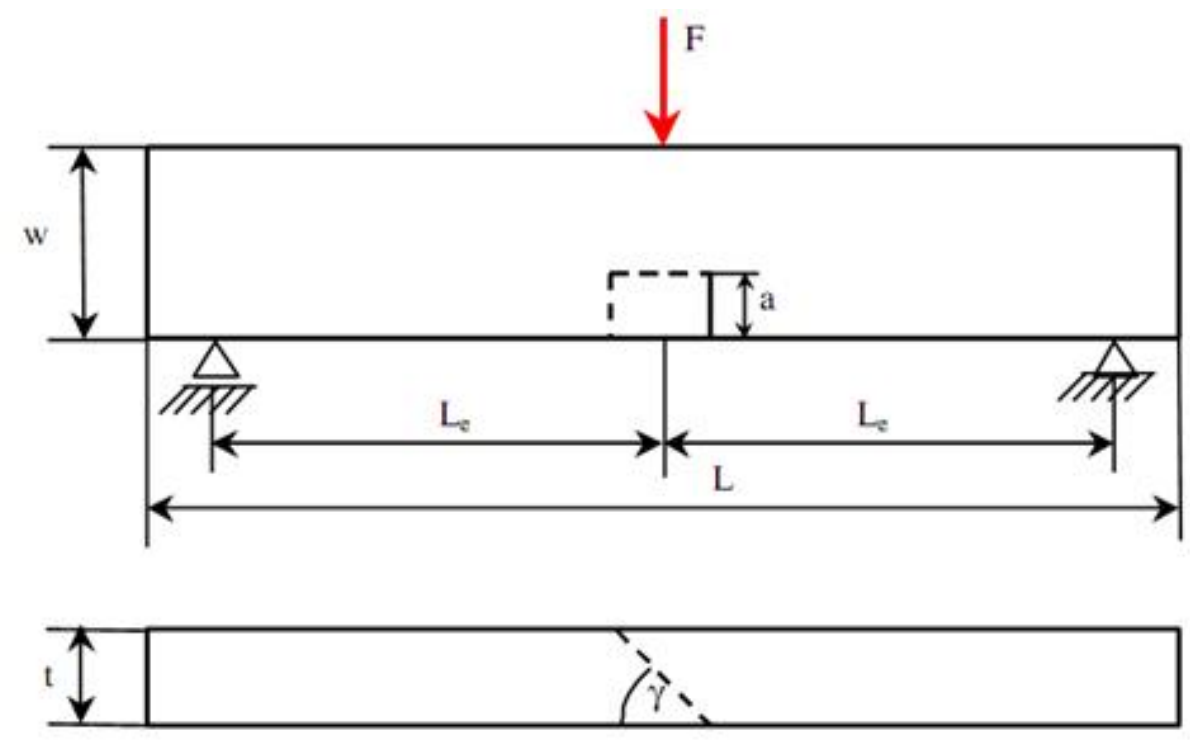


Figure 56. Three-point bending test with the initial crack of an inclined plane $\left(\gamma=45^{\circ}\right)[54]$

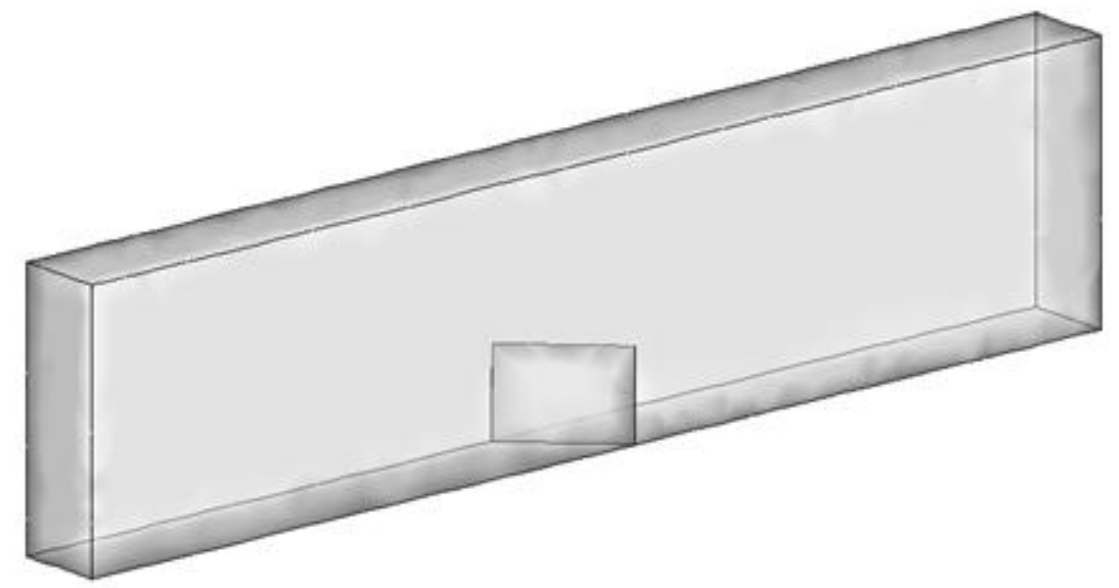

Figure 57. The model of three-point bending test

The specimen length is $130 \mathrm{~mm}$, its thickness is $10 \mathrm{~mm}$ and its width is $30 \mathrm{~mm}$. The materials properties are as follows: Young Modulus: 9.8GPa; Poisson ratio: 0.33. The mesh used in the calculations is composed of tetrahedral linear elements that are refined in the vicinity of the crack, as shown in figure 58

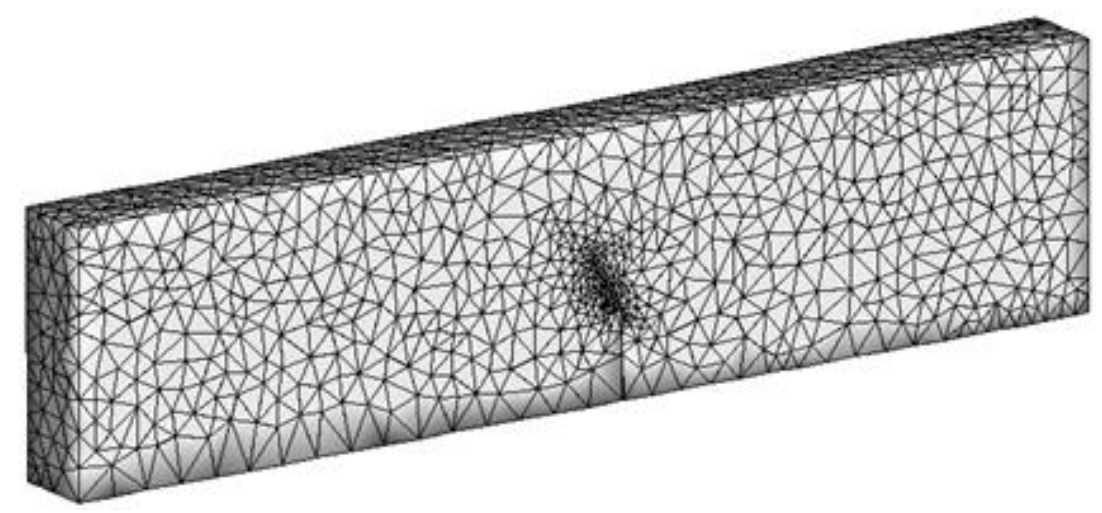

Figure 58. Meshing of the model

The simulation results are shown below, and one can see the good agreement with reference [54]. 


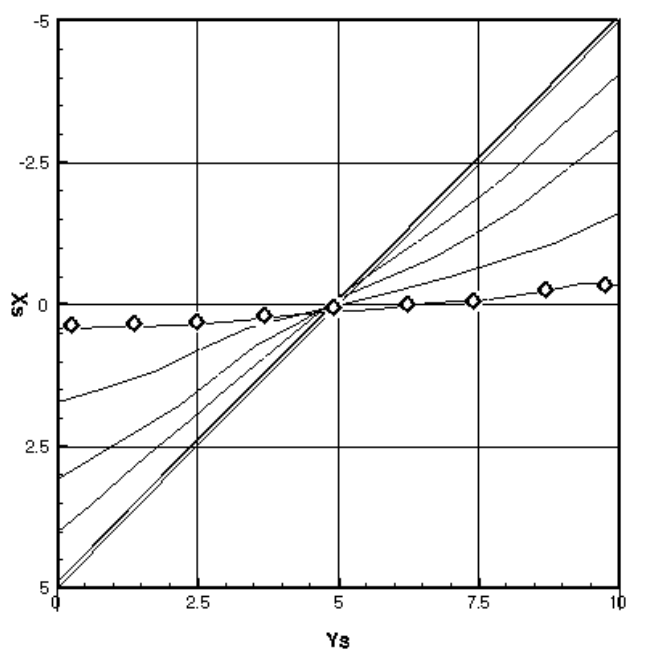

Figure 59. Crack fronts obtained for each propagation step (top view)

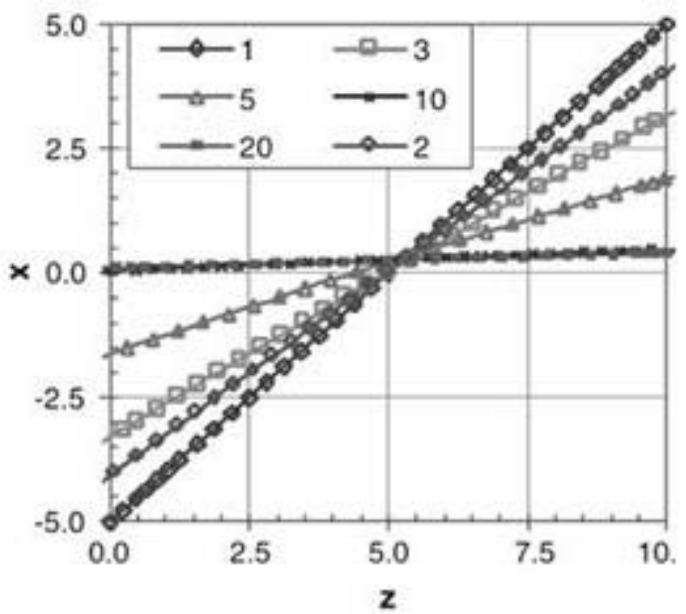

Figure 60. Crack fronts of the solution reported in [54] (top view)

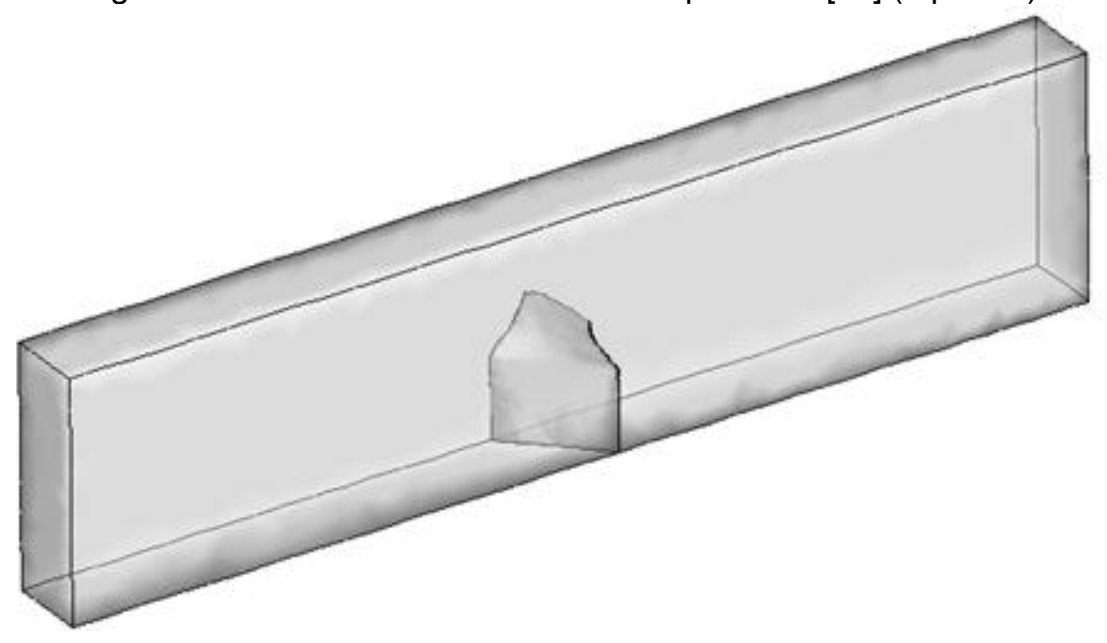


Figure 61. Crack propagation inside the specimen
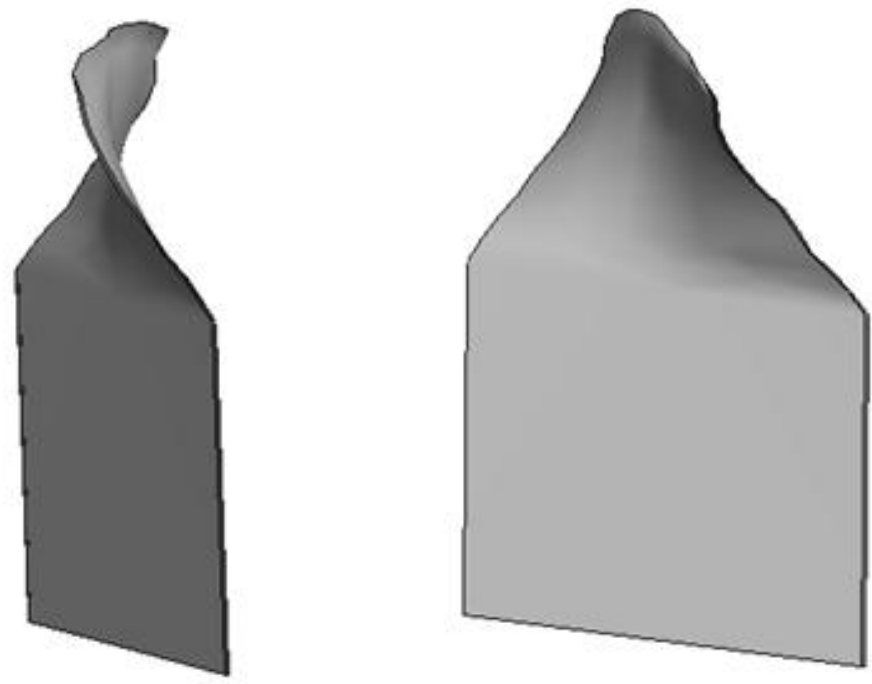

Figure 62. 3D geometry of crack inside the specimen

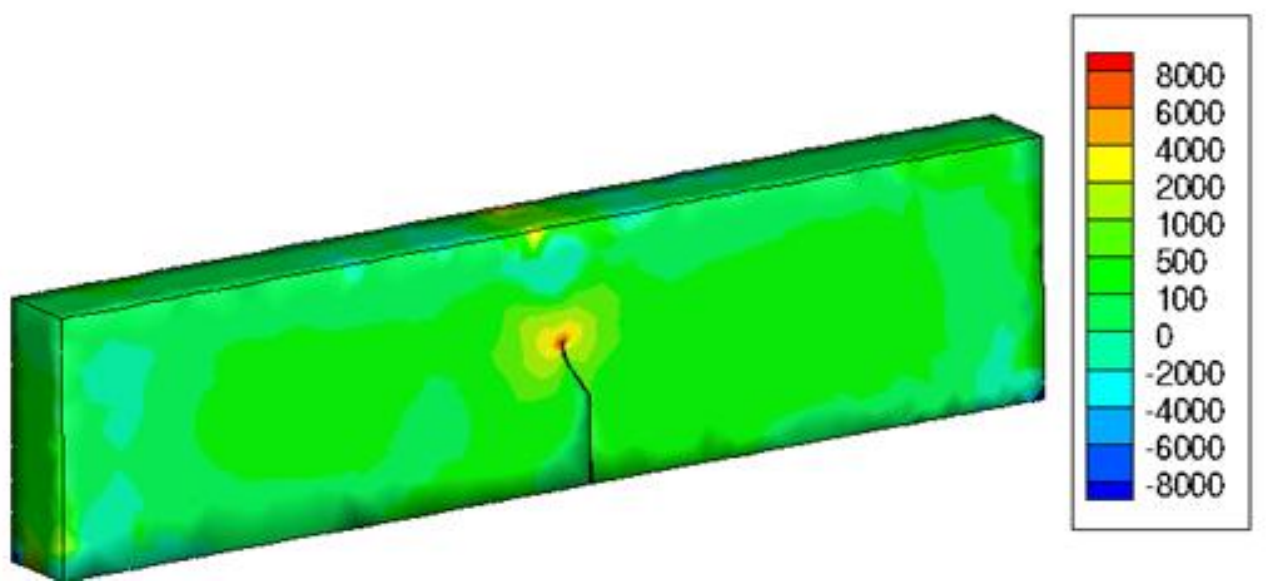

Figure 63. Crack path on the surface and its principal stress distribution

In figure 59, the propagation path obtained by applying the methodology presented in this study is shown. From Fig. 61 and 62, the twisted propagation is clearly visible. The crack path and the maximum principal stress on the surface of the specimen are shown in figure 63 . The crack fronts calculated for each propagation step are shown in Fig. 59. For comparison, the crack fronts reported in [54] are shown in Fig. 60. Qualitatively, the solution obtained is in good agreement with the one of Ref. [54], showing that the methodology presented in this paper correctly simulates the mixed mode propagation of the crack. 


\subsection{Numerical Experiment of Ice Break-up from Helicopter Blade}

\subsubsection{Crack initiation in ice}

During the interface bond breaking process, if the principal stress in the ice reaches the critical value of principal stress I, i.e. the cohesive strength of ice, a crack will start to initiate at the point where the principal stress I reaches the threshold value. From reference [17], the cohesive strength of ice is in the range of 1 to $2 \mathrm{MPa}$. Once the critical value is reached, a tiny 3D crack whose direction is perpendicular to the principal stress $I$ is inserted into the ice. Figure 64 shows the crack initiation process
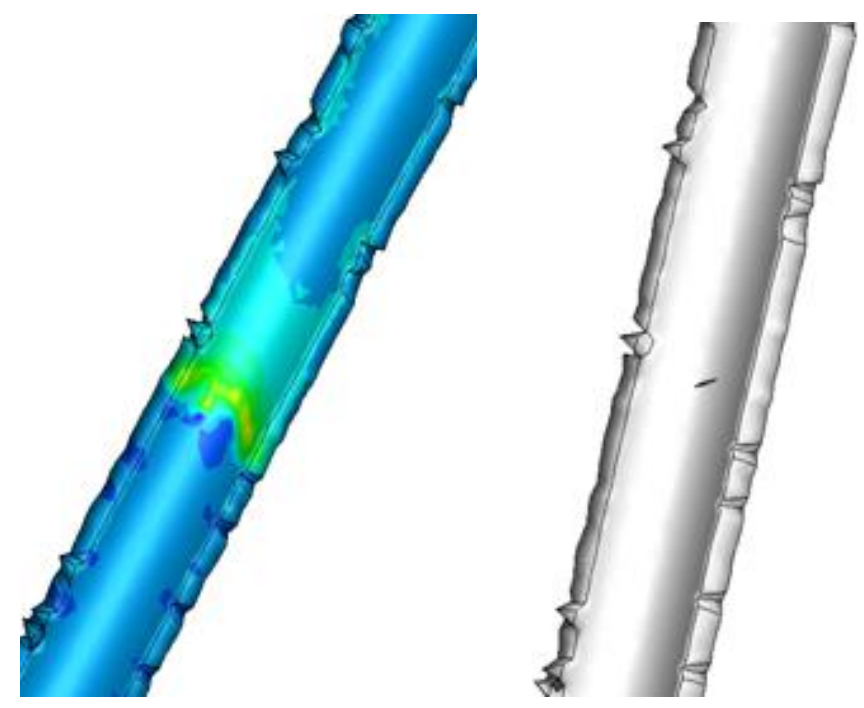

Figure 64. Crack initiation

\subsubsection{Crack propagation in ice}

Once the crack is initiated, employing the 3D crack propagation package developed in the previous section, the crack propagation process in the ice is simulated.

Figure 65 shows the crack evolution process inside the ice. After the crack tip reaches the two sides of the ice, we can clearly get the ice shape that will shed away from the blade. Figure 66 shows the principal stress distribution during the 
crack propagation process. The maximum principal stress is concentrated in the vicinity of the crack surface. Figure 67 shows the 3D crack shapes during the crack propagation process. It can be seen that the shape of the crack is out of one plane and is an arbitrary 3D shape.
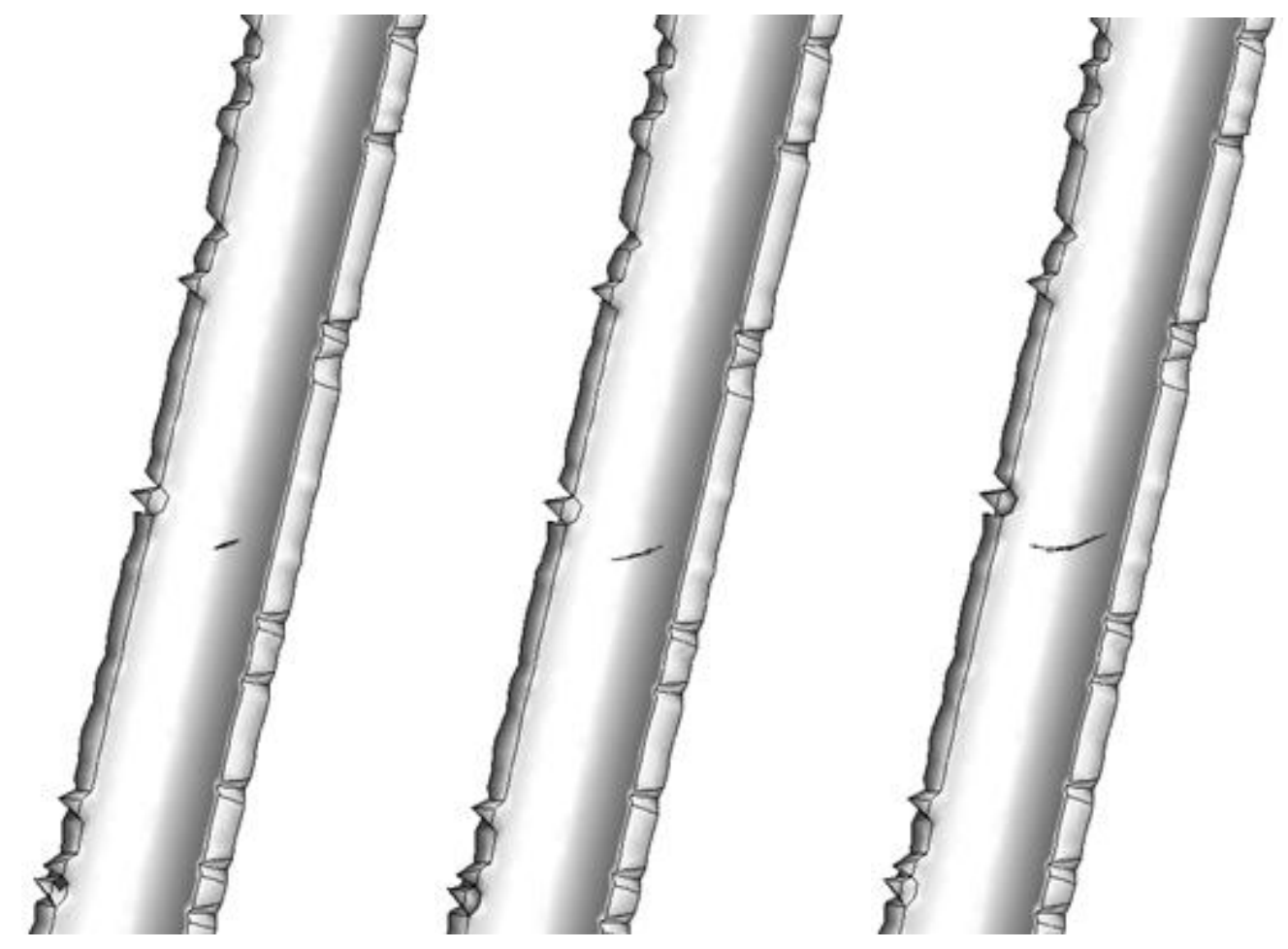

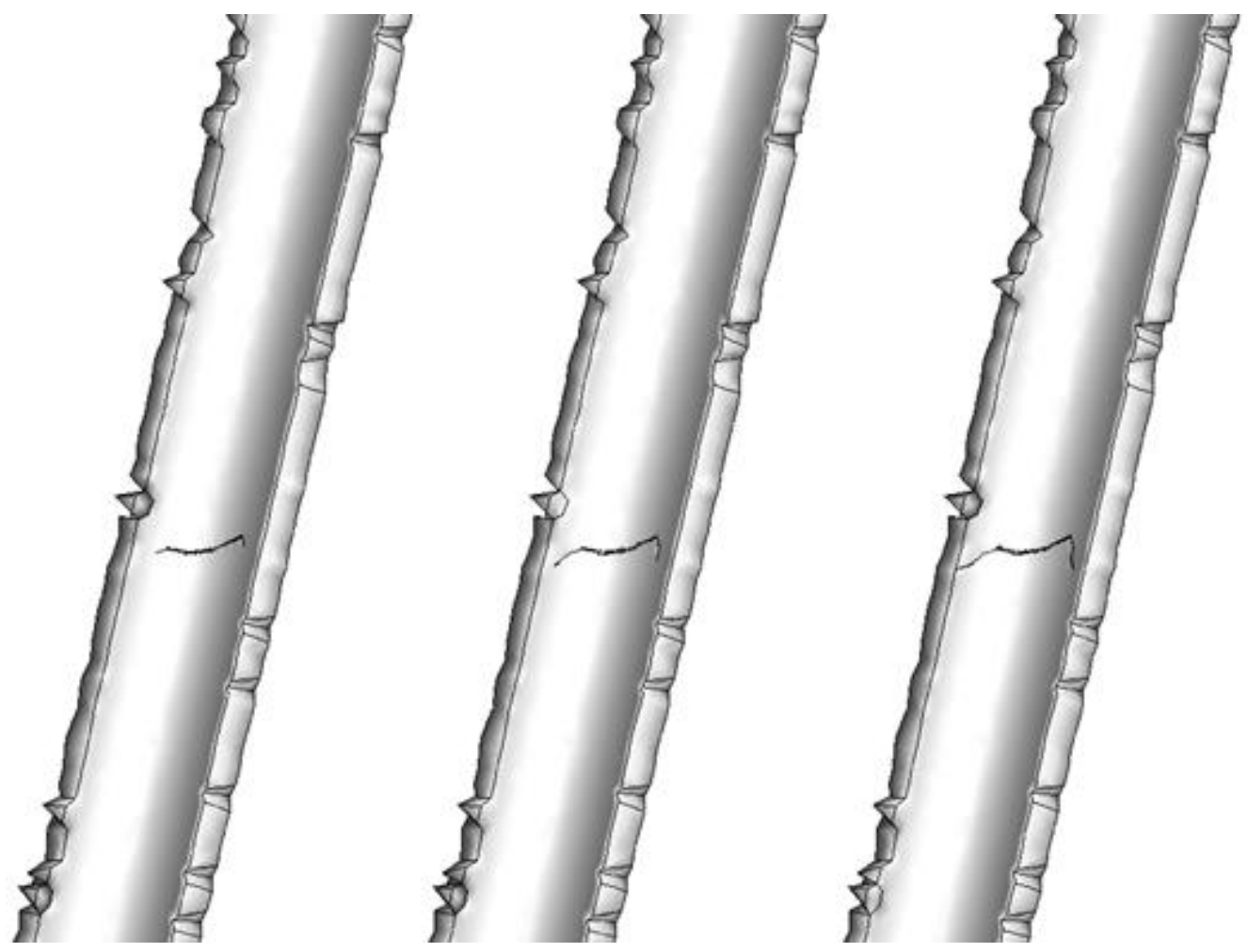

Figure 65. Crack propagation process
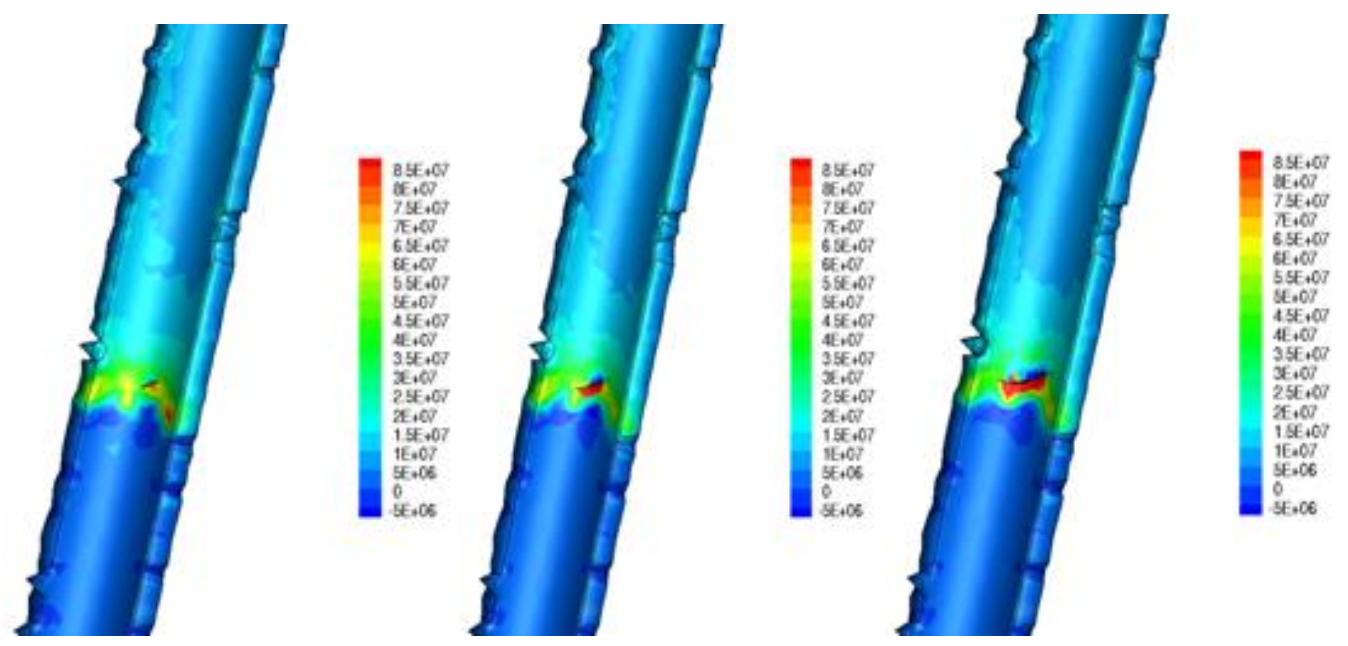

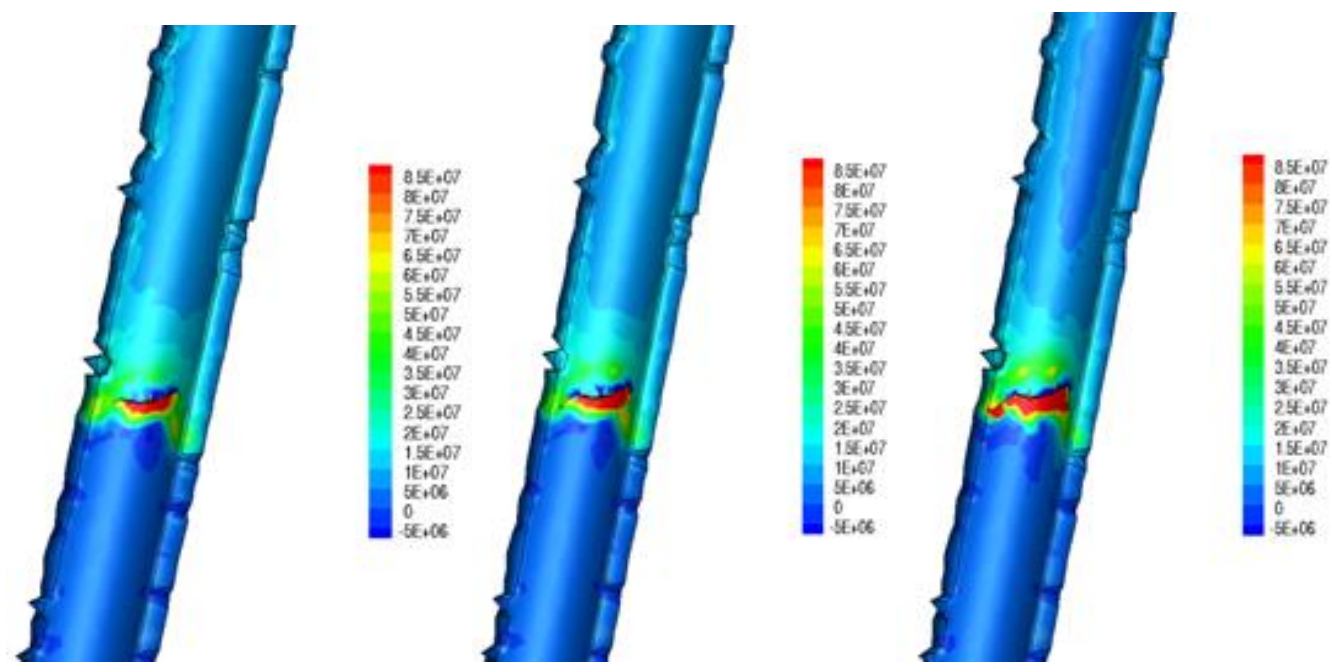

Figure 66. Principal stress 1 during the crack propagation process
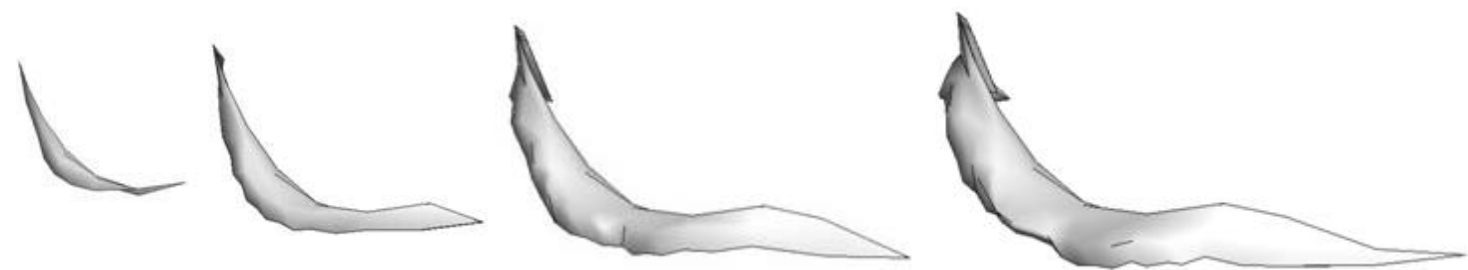

Figure $67.3 \mathrm{D}$ crack shape growth during the crack propagation process

\subsection{Summary}

In this chapter, the development of a complete 3D module for ice break-up and shedding from helicopter blades is described. The module includes ice shape determination, mesh generation and refinement, stress analysis, interface bond breaking, crack initiation and crack propagation. A 3D crack propagation package based on the maximum principal stress is developed, and its comparison with reference results validates the reliability of this method. Finally, using this $3 \mathrm{D}$ crack propagation package, the ice break-up process is fully simulated in 3D. The location of break-up is also predicted. 


\section{Chapter 6 CONCLUSIONS}

Ice break-up and shedding pose a threat to the in-flight safety of airplane and helicopter. In order to predict when and where the ice will break-up and shed away, a 2D ice break-up code for ice on wings of airplane and a 3D ice break-up code for ice accreted on blades of helicopter are developed. Using these 2D and $3 \mathrm{D}$ ice break-up codes, the location and the mechanism of ice break-up are predicted.

Through numerous simulations done in this thesis, a conclusion can be drawn that for ice break-up and shedding from the wing of an airplane, the possibility of break-up highly depends on the shape of ice, i.e. under the same icing condition, some ice shapes will break, while some will not. Generally speaking, ice shapes with sharp horns are prone to break-up, while smooth ice shape may not break for the same loading conditions. For break-up analysis of ice accreted on helicopter blades, the dominant factors are the blade rotational speed and interface strength between ice and airfoil material, which in turn has a strong dependence on the surface temperature of the blade. The rotational speed determines whether the ice will break-up and shed away or not, while the interface bond strength determines how much of the ice will be shedding away.

The main work of this thesis research has been the development of a $2 D$ and $3 D$ ice break-up simulation packages and their integration with the in flight icing code - FENSAP ICE. The key parts of the break-up systems are the 2D and 3D crack propagation modules. In this study, the $2 \mathrm{D}$ crack propagation has employed the maximum circumferential stress method based on the quarter-point element to predict the crack propagation direction, while for 3D crack propagation package, the maximum principal stress criteria has been used. Through comparisons with contemporary crack propagation codes and published numerical results, the validity of these methods is established. 
Future work includes broadening the application areas of the ice break-up system and improving the robustness and accuracy of the crack propagation system. In the present work, the interaction between air-flow and ice is analyzed in a decoupled way, considering the large deformation and displacement at the final break-up stage, a fully-coupled fluid structure interaction could be considered in the future if its utility is proven.

In terms of broadening the applications, the ice break-up simulation package could be used to model ice shedding from wind turbines, as ice shedding is also a threat to wind turbine's life span and safety [56]. Also, the crack propagation simulation package could be used in environmental science, material science, glaciology, and earthquake and rupture analysis.

In addition, the ice break-up simulation system could be integrated in designing anti-icing or de-icing systems for airplanes and helicopters, making air travel safer. 


\section{REFERENCES}

[1] W.G. Habashi, Invited Article, Advances in CFD for in-flight icing simulation, J. Japan. Soc. Fluid. Mech. 28 (2) (2009) 99-118.

[2] H. Beaugendre, F. Morency, W.G. Habashi, Development of a second generation in-flight icing code, ASME Transactions, J. Fluid. Eng. 128 (2006) 378-387.

[3] R. Kuznetsova, S-76D ${ }^{\mathrm{TM}}$ tail rotor ice impact test, 2011-38-0101, SAE 2011 International Conference on Aircraft and Engine Icing and Ground Deicing, Chicago, USA, 2011

[4] Inflight Icing and the Helicopter, Helicopter Safety. 16 (6) (1990) 11-12

[5] X. Zhou, D. Sha, K. Tamma, Y. Miller, A consistent configuration formulation of continuum damage mechanics based Lagrangian hydrodynamic computational framework for 3D high- and hypervelocity impact/damage/penetration analysis, 47th AIAA/ASME/ASCE/AHS/ASC Structures, Structural Dynamics, and Materials Conference, Newport, USA, 2006.

[6] J-M. Deschênes, G.S. Baruzzi, P. Lagacé, W.G. Habashi, FENSAP-ICE: A CFD Monte Carlo approach to shed-ice trajectory and impact, 2011-38-0089, SAE 2011 International Conference on Aircraft and Engine Icing and Ground Deicing, Chicago, USA, 2011

[7] R.J. Scavuzzo, M.L. Chu, V. Ananthaswamy, Influence of aerodynamic forces in ice shedding, J. Aircraft. (0021-8669) 31(3) (1994) 526-530.

[8] E.J. Barbero, J.N. Reddy, The Jacobian derivative method for three-dimensional fracture mechanics, Commun. Appl. Numer. Methods. 6 (7) (1990) 506-518.

[9] D. Nunez, K.S. Surana, A. Romkes, J. N. Reddy, J-Integral for mode I linear elastic fracture mechanics in h, p, k mathematical and computational framework, Int. J. Comput. Methods. Eng. Sci. Mech. 10 (5) (2009) 345-369.

[10] A.A. Griffith, The phenomena of rupture and flow in solids, Philosophical Trans. of the Royal Soci. of London. A 221, (1921) 163-198

[11] S. Chan, I. S. Tuba, W. K. Wilson, On the finite element method in linear fracture mechanics, Eng. Fract. Mech. 2 (1970) 1-17.

[12] W.H. Gerstle, L. Martha, A.R. Ingraffea, Finite and boundary element modeling of crack propagation in Two - and Three - Dimensions, Eng. Comput. 2 (1987) 167183.

[13] M.F. Perutz, A description of the iceberg aircraft carrier and the bearing of the mechanical properties of frozen wood pulp upon some problems of glacier flow. J. of Glaciology. 3 (1948) 95-104 
[14] E.M. Schulson, P.N. Lim, R.W. Lee, A brittle to ductile transition in ice under tension, Phil. Mag. 49 (1984) 353-363

[15] N.K. Sinha, Crack-enhanced creep in polycrystalline material: strain-rate sensitive strength and deformation of ice, J. Materials Sci. 23 (1988) 4415-4428

[16] E.M. Schulson, S.E. Buck, The brittle-to-ductile transition and ductile failure envelopes of orthotropic ice under biaxial compression, Acta Metall. et Mater. 43 (1995) 3661-3668.

[17] R.J. Scavuzzo, M.L. Chu, C.J. Kellackey, Structural analysis and properties of impact ices accreted on aircraft structures. NASA Contractor Report. (1996) CR198473

[18] L.E. Raraty, D. Tabor, The adhesion and strength properties of ice. Proc. R. Soc. Lond. A. 245(1958), 184-201

[19] T. Kálmán, M. Farzaneh, G. McClure, Numerical analysis of the dynamic effects of shock-load-induced ice shedding on overhead ground wires. Comput. Struct. 85 (2007) 375-384.

[20] R.S. Mazzawy, Modeling of ice accretion and shedding in turbofan engines with mixed phase/glaciated (ice crystal) conditions, 2007-01-3288, SAE Aircraft and Engine Icing International Conference, Seville, Spain, 2007.

[21] E.W. Brouwers, J.L. Palacios, E.C. Smith, A.A. Peterson, The experimental investigation of a rotor hover icing model with shedding, AHS 66th Annual Forum and Technology Display, Phoenix, USA, 2010.

[22] B.S. Hardy, R.P. Welle, R.L. Williams, Aerodynamically induced fracture of ice shed from the space shuttle external tank, AIAA 2006-3873, 24th Applied Aerodynamics Conference, San Francisco, USA, 2006.

[23] M. Papadakis, H.W. Yeong, K. Shimoi, Parametric investigation of ice shedding from a business jet aircraft, 2007-01-3359, SAE 2007 International Conference on Aircraft and Engine Icing, Seville, Spain, 2007

[24] R.J. Scavuzzo, M.L. Chu, C. J. Kellackey, Impact ice stresses in rotating airfoils, J. Aircraft. 28(1991), 450-455

[25] J.J. Petrovic, Mechanical properties of ice and snow, J. Mater. Sci. 38 (2003) 1-6.

[26] P.H. Gammon, H. Kiefte, M.J. Clouter, Elastic constants of ice samples by Brillouin spectroscopy, J. Phys. Chem. 87 (1983) 4025-4029.

[27] L.W. Gold, Deformation mechanics in ice, Building Research, 15827 (1963)

[28] P.V. Hobbs. Ice physics. Oxford, Clarendon Press, 1974. xvii, 837 p.

[29] E.M. Schulson, P. Duval, Creep and Fracture of Ice, Cambridge University Press, 2009. 401 p. ISBN-10: 0-521806-20-6.

[30] L.W. Gold, On the elasticity of ice plates, Can. J. Civil. Eng. 15 (1988) 1080-1084.

[31] E. M. Schulson, The brittle compressive fracture of ice, Acta Metal. Mater. 38 (10) (1990) 1963-1967. 
[32] M. Mellor, D.M. Cole, Deformation and failure of ice under constant stress or constant strain-rate, Cold. Reg. Sci. Technol. 5 (1982) 201-219.

[33] S. Mittal, T. Tezduyar, A unified finite element formulation for compressible and incompressible flows using augmented conservation variables, Comput. Methods Appl. Mech. Eng. 161 (1998) 229-243.

[34] T. Cebeci, J.P. Shao, F. Kafyeke, E. Laurendeau. Computational fluid dynamics for engineers: from panel to Navier-Stokes methods with computer programs, Springer, 2005, xiv, 396 p. ISBN 978-3-540-24451-6.

[35] T. Tezduyar, S. Sathe, R. Keedy, K. Stein, Space-time finite element techniques for computation of fluid-structure interactions, Comput. Methods Appl. Mech. Engg. 195 (2006) 2002-2027.

[36] R. Jaiman, X. Jiao, P. Guebelle, E. Loth, Conservative load transfer along curved fluid-solid interface with non-matching meshes, J. Comput. Phys. 218 (2006) 372397.

[37] R.A. Khurram, A. Masud, A multiscale/stabilized formulation of the incompressible Navier-Stokes equations for moving boundary flows and fluidstructure Interaction, Comput. Mech. 38 (2006) 403 - 416.

[38] J.R. Shewchuk, Triangle: Engineering a 2D Quality Mesh Generator and Delaunay Triangulator, in Applied Computational Geometry: Towards Geometric Engineering" (Ming C. Lin and Dinesh Manocha, editors), volume 1148 of Lecture Notes in Computer Science, pages 203-222, Springer-Verlag, Berlin, 1996.

[39] M.R. Ayatollahi, M.J. Pavier, D.J. Smith, Determination of T-stress from finite element analysis for mode I and mixed mode I/II loading, Int. J. Fract. 91 (1998), 283-298

[40] A.R. Ingraffea, P. A. Wawrzynek, Finite Element Methods for linear elastic fracture mechanics, section 2, P6, Elsevier Science, Oxford, England, 2003

[41] T.G. Mamatha, A. Patnaik, S. Biswas, B.K. Satanathy, A.K. Redhewall, Thermomechanical and crack position on stress intensity factor in particle-reinforced Zincaluminium alloy composites, Comp. Mat. Sci. 55 (2012) 100-112

[42] M. Alshoaibi, A.K. Ariffin, M.N. Almaghrabi, Development of efficient finite element software of crack propagation simulation using adaptive mesh strategy, Am. J. Appl. Sci. 6 (4) (2009) 661-666.

[43] L. Remaki, W.G. Habashi, A Hermite-Based mesh adaptation for CFD functional output, J. AIAA. 47(8) (2009) 1965-1976.

[44] FRANC2D, Cornell Fracture Group, Cornell University , http://www.cfg.cornell.edu/software/franc2d_casca.htm

[45] L. Banks-Sills, O. Einav, On singular, nine-noded, distorted, isoparametric elements in linear elastic fracture mechanics, Comput. Struct. 25(3) (1987) 445-449.

[46] M. Fossati, R.A. Khurram, W. G. Habashi, An arbitrary Lagrangian-Eulerian mesh movement scheme for long-term in-flight ice accretion, Int. J. Numer. Meth. Fl. (2011) DOI: 10.1002/fld.2588. 
[47] M. Fossati, R.A. Khurram, W.G. Habashi, Robust moving meshes for the prediction of aerodynamic degradation during in-flight icing, 2011-38-0022, SAE 2011 International Conference on Aircraft and Engine Icing and Ground Deicing, Chicago, USA, 2011.

[48] H.E. Andy, A.P. Broeren, J.G. Zoeckler, S. Lee, A wind tunnel study of icing effects on a business jet airfoil, AIAA paper 2003-0727, AIAA 41st Aerospace Science Meeting and Exhibit, Reno, USA, 2003.

[49] S. Hang, An algorithm for three-dimensional constrained Delaunay Tetrahedralizations, International Conference on Engineering Computational Technology, Lisbon, Portugal, September 2004.

[50] K. Itagaki, The implication of surface energy in ice adhesion. J. Adhesion. 16 (1983), 41-48

[51] M. Zou, S. Beckford, R. Wei, C. Ellis, G. Hatton, M.A. Miller, Effects of surface roughness and energy on ice adhesion strength, Appl. Surf. Sci. 257 (2011), 37863792

[52] M. Schollmann, M. Fulland, H.A. Richard, Development of a new software for adaptive crack growth simulations in 3D structures, Eng. Fract. Mech. 70 (2003) 249-268

[53] S. Zhang, O. El Kerdi, R. A. Khurram, and W.G. Habashi, "FEM analysis of inflight ice break-up," Finite. Elem. Anal. Des. Vol. 57, 2012, pp. 55-66.

[54] R. Citarella, F.-G. Buchholz, Comparison of crack growth simulation by DBEM and FEM for SEN-specimens undergoing torsion or bending loading, Eng. Fract. Mech. 75 (2008), 489-509

[55] Y. Wei, R. M. Adamson, J. P. Dempsey, Ice/metal interfaces: fracture energy and fractography, J. Mater. Sci. 31 (1996) 943-947.

[56] A.G. Kraj, E.L. Bibeau, Measurement method and results of ice adhesion force on the curved surface of a wind turbine blade, Renew. Energ. 35 (2010) 741-746.

[57] F.X. Caradonna, C. Tung, "Experimental and analytical studies of a model helicopter rotor in hover," NASA TM-81232, 1981. 